\title{
WestVirginiaUniversity
}

THE RESEARCH REPOSITORY @ WVU

Graduate Theses, Dissertations, and Problem Reports

2014

\section{Stability of the Shoulder Complex during Manual Exertions}

\author{
Kasey Cutlip \\ West Virginia University
}

Follow this and additional works at: https://researchrepository.wvu.edu/etd

\section{Recommended Citation}

Cutlip, Kasey, "Stability of the Shoulder Complex during Manual Exertions" (2014). Graduate Theses, Dissertations, and Problem Reports. 668.

https://researchrepository.wvu.edu/etd/668

This Thesis is protected by copyright and/or related rights. It has been brought to you by the The Research Repository @ WVU with permission from the rights-holder(s). You are free to use this Thesis in any way that is permitted by the copyright and related rights legislation that applies to your use. For other uses you must obtain permission from the rights-holder(s) directly, unless additional rights are indicated by a Creative Commons license in the record and/ or on the work itself. This Thesis has been accepted for inclusion in WVU Graduate Theses, Dissertations, and Problem Reports collection by an authorized administrator of The Research Repository @ WVU. For more information, please contact researchrepository@mail.wvu.edu. 


\title{
Stability of the Shoulder Complex during Manual Exertions \\ Kasey Cutlip
}

\begin{abstract}
Thesis submitted to the Benjamin M. Statler College of
Engineering and Mineral Resources at

West Virginia University

in partial fulfillment of the requirements for the degree of

Master of Science

in

Industrial Engineering
\end{abstract}

Ashish D. Nimbarte, Ph.D., Chair

Majid Jaridi, Ph.D.

Xiaopeng Ning, Ph.D.

Department of Industrial and Management Systems Engineering

Morgantown, West Virginia

August 2014

Keywords: shoulder, stability, concavity compression, musculoskeletal disorders

Copyright 2014 Kasey Cutlip 


\section{Abstract \\ Stability of the Shoulder Complex during Manual Exertions}

\section{Kasey Cutlip}

Shoulder musculoskeletal disorders (MSDs) are a major cause of morbidity and pain in the modern working population. Epidemiological literature suggests that forceful arm exertions pose an increased risk for shoulder MSD development. Although several previous studies have reported a significant stress-strain relationship for the shoulder complex during physically demanding exertions, a clear assessment method to evaluate the risk of injury to the shoulder complex currently does not exist. The objective of this study was to develop and validate a new shoulder strain index to evaluate strain placed on the shoulder during work-related forceful arm exertions. Specifically, the concept of the concavity compression mechanism of the glenohumeral joint was used to develop the proposed strain index. Nine strain indices were developed using different biomechanical measurements that characterize the concavity compression mechanism. The highest correlation $(\mathrm{r}=0.70)$ between the strain index scores and ratings of perceived exertion was observed for a strain index which comprised of three normalized components: (1) angular deviation between the resultant force vectors (external load and shoulder muscles) in the frontal plane, (2) resultant reaction force acting on the glenohumeral joint due to the shoulder muscles, and (3) contact pressure between the humeral head and glenoid produced as a result of external force. The scores for this strain index were found to be significantly affected by the direction and level of force exertion and indicated that the force exertions performed in the mediolateral direction are more strenuous than the other directions. The proposed stress index could potentially have application in the occupational setting for the assessment of forceful arm exertions that may increase the risk of shoulder MSDs. 


\section{Acknowledgements}

I would like to express my sincerest gratitude to my advisor, Dr. Ashish Nimbarte for providing me the opportunity to further my education and whose continued support, guidance, and encouragement throughout my studies have been truly appreciated and have allowed me to reach this milestone.

I would also like to thank the members of my committee, Dr. Majid Jaridi and Dr. Xiaopeng Ning, for their invaluable advice and support.

I also wish to thank my colleagues in the Ergonomics laboratory for their assistance, advice, and friendship, which I will always be grateful for.

Finally, I wish to thank my parents and my friends for their constant support and encouragement throughout the years and in my many endeavors. 


\section{Table of Contents}

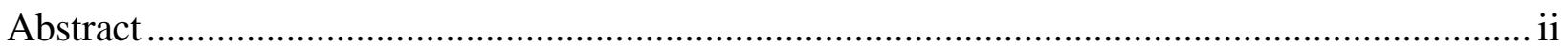

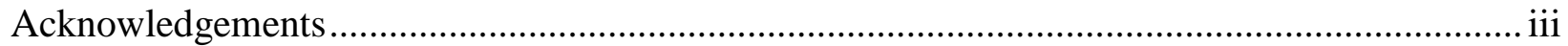

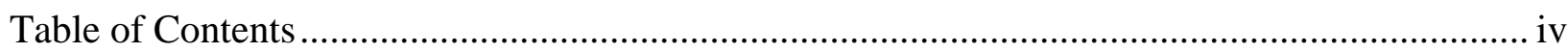

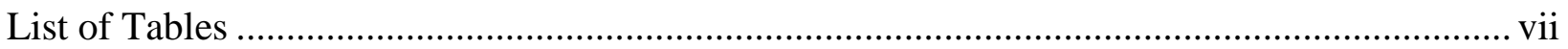

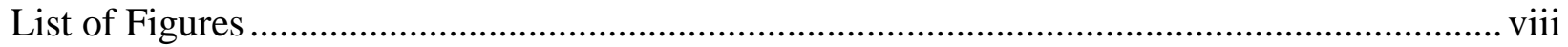

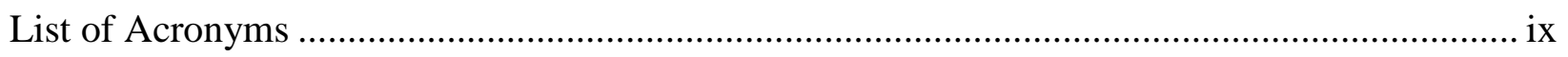

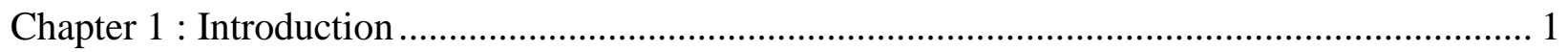

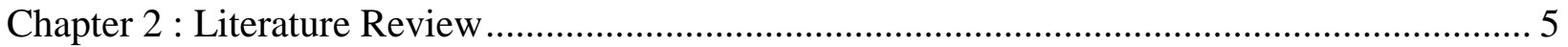

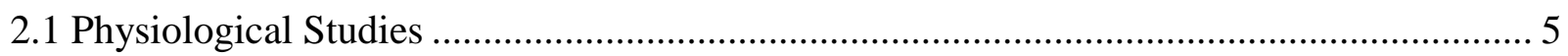

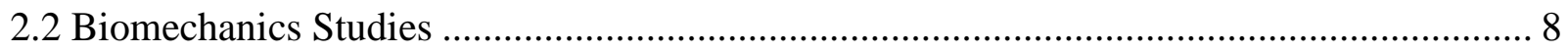

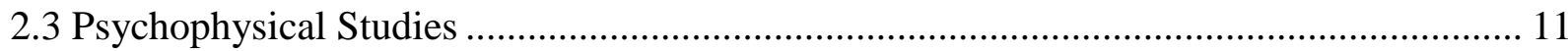

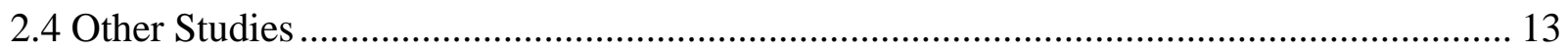

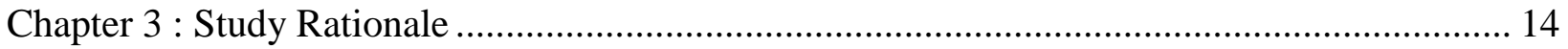

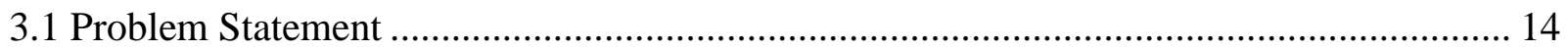

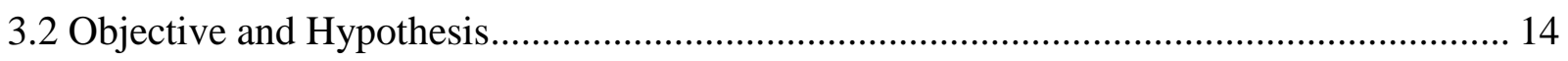

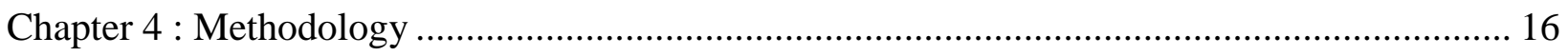

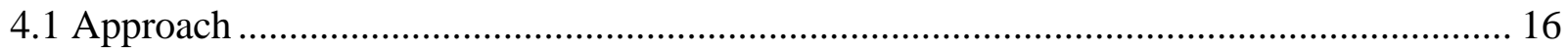

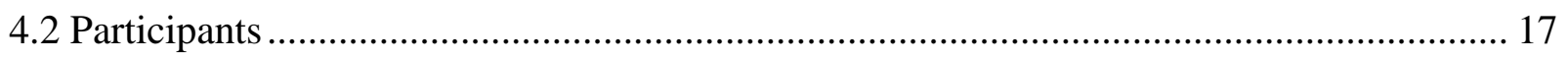

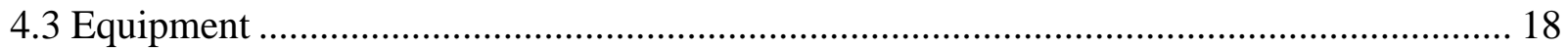

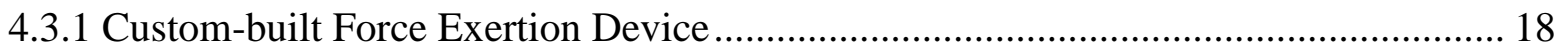

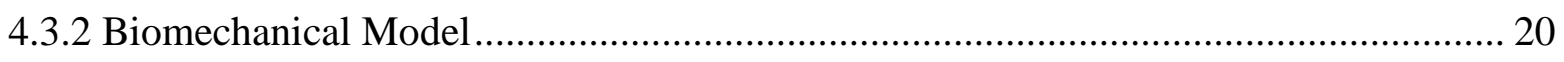

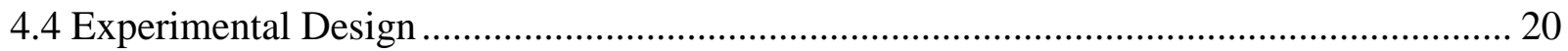

4.5 Experimental Data Collection Procedure …………………………............................ 21

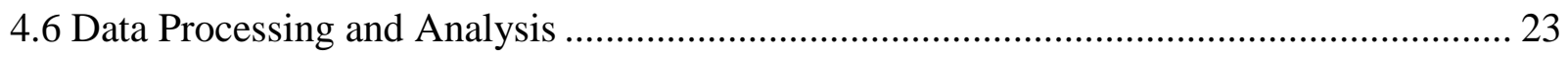

4.6.1 Anybody Biomechanical Model .............................................................................. 23

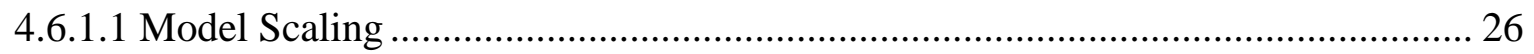

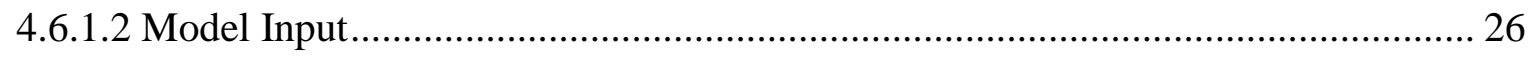

4.6.1.3 Model Output .................................................................................................. 27

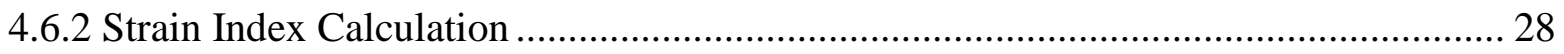




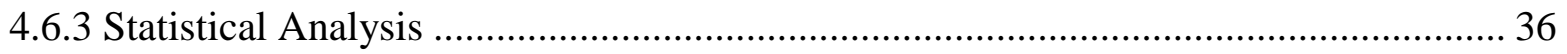

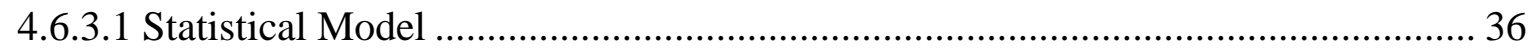

4.6.3.2 Power Analysis and Sample Size Determination.................................................... 38

4.6.3.3 Missing Values.................................................................................................... 40

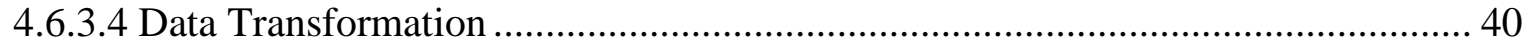

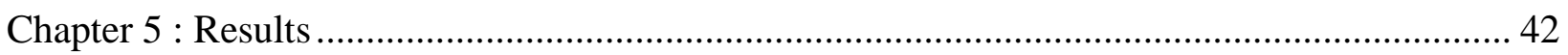

5.1 Resultant Force Orientation Cases …………………………………………………..... 42

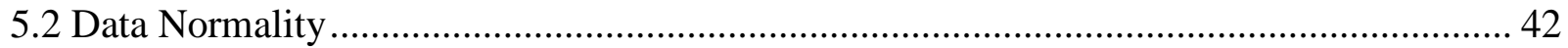

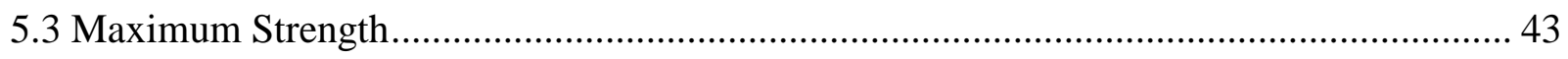

5.4 Strain Indices and Perceived Exertion Rating ................................................................... 45

5.5 Strain Index and the Effect of Direction, Force Level, and Gender.................................... 46

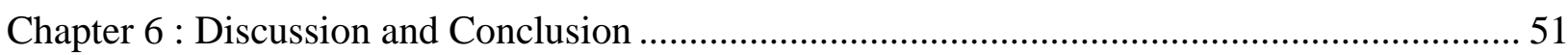

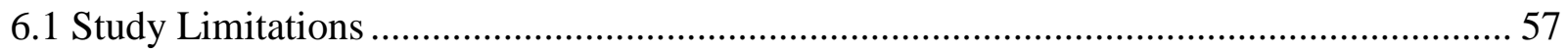

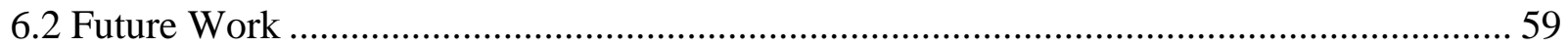

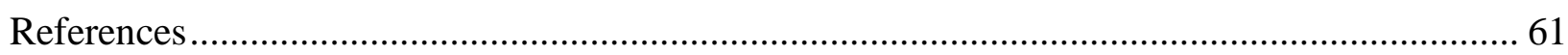

Appendix A: Physical Activity Readiness Questionnaire (PAR-Q) ......................................... A-1

Appendix B: West Virginia University Institutional Review Board and Participant Consent Form

Appendix C: Participant Demographic Data ……………................................................ C-1

Appendix C-1: Participant mean (SD) anthropometric and characteristic data ...................... C-2

Appendix D: Power Calculations for Determining the Number of Participants ......................... D-1

Appendix D-1: Sample size calculations ..................................................................... D-2

Appendix E: Glenohumeral Joint Resultant Force Orientation Cases...........................................

Appendix E-1: Resultant force orientation case examples.......................................................

Appendix F: Data Normality of Strain Index 9 and Perceived Exertion Ratings .........................F-1

Appendix F-1: Normality plot of strain index 9 (SI 9) ……..............................................

Appendix F-2: Normality plot of perceived exertion ratings (PER) .......................................F-2

Appendix F-3: Johnson transformation of strain index 9 …………………………….......F-3

Appendix F-4: Johnson transformation of perceived exertion ratings .....................................F-3

Appendix F-5: Equality of variance for strain index 9 vs. gender, direction, and force level .F-4 Appendix G: ANOVA Output for Strain Index 9 …………................................................ 


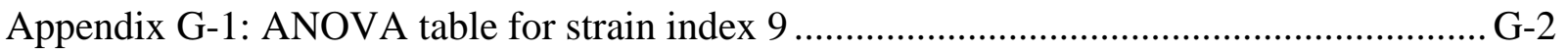

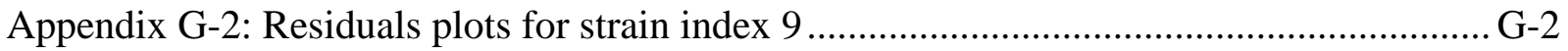

Appendix G-3: Minitab output: Tukey comparisons for direction ..................................... G-3

Appendix G-4: Minitab output: Tukey comparisons for force level .................................... G-4

Appendix H: Data for Strain Indices 1 through 9 and Perceived Exertion Ratings ..................H-1

Appendix I: Data for Strain Index 9 (Raw, Transformed, and Back-Transformed)....................I-1

Appendix J: Participant Strength Data........................................................................... J-1

Appendix J-1: Average maximum strength $(\mathrm{N})$ by direction of exertion ............................ J-2 


\section{List of Tables}

Table 4.1: Mean (SD) participant demographic data....................................................... 18

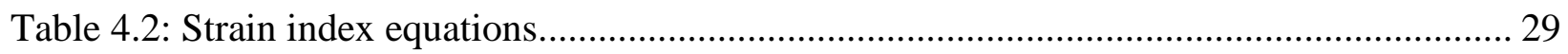

Table 4.3: Reaction forces at the glenohumeral joint obtained for a forceful arm exertion of $40 \mathrm{~N}$ performed in the superior direction $(+\mathrm{Y})$ and maximum resultant force values observed for the

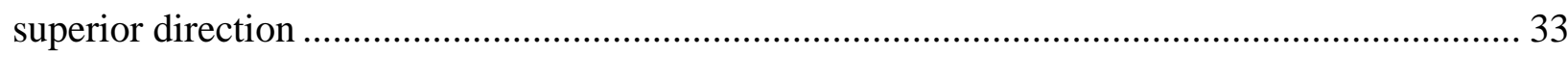

Table 4.4: Example problem strain index values ......................................................... 35

Table 4.5: Power values for different number of participants. ............................................. 39

Table 4.6: Johnson transform families and corresponding functions ................................. 41

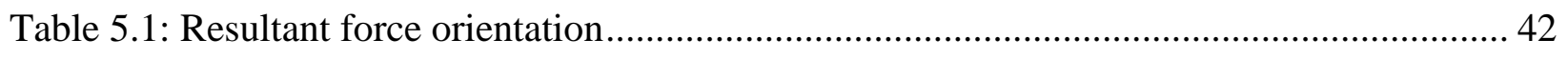

Table 5.2: Johnson transformation for strain index and perceived exertion rating data .............. 43

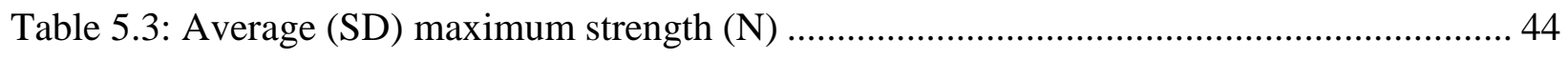

Table 5.4: Correlation strength between strain index values and perceived exertion ratings...... 45

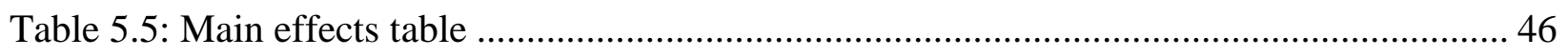




\section{List of Figures}

Figure 1.1: The shoulder complex is comprised of the sternoclavicular, acromioclavicular, and glenohumeral joints

Figure 1.2: (a) Position of the humeral head with respect to the glenoid cavity; (b) Concavity

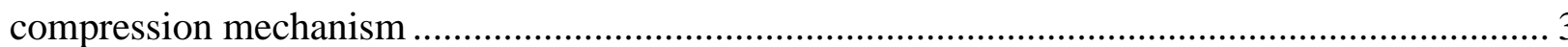

Figure 4.1: Biomechanical model showing the resultant force vectors from the two model configurations. Blue: without shoulder muscles; Red: with shoulder muscles.

Figure 4.2: Force exertion device: (a) chair with attached four-point harness facing bar-handle assembly and computer monitor, (b) F/T sensor mounted with a handle and attached to bar, and (c) force level feedback screen 19

Figure 4.3: Borg's CR-10 scale 22

Figure 4.4: Inverse dynamic analytical process implemented by the AnyBody modeling system

Figure 4.5: Basic structure of AnyBody model 25

Figure 4.6: Graphical representation AnyBody biomechanical model under the: (a) withoutmuscle condition, and (b) with-muscle condition.

Figure 4.7: Calculation of the three dimensional (a) and two dimensional (b) angular deviations between the resultant force under the without-muscle condition (blue) and the with-muscle condition (red).

Figure 5.1: Mean maximum strength by the direction of force exertion. ................................ 44

Figure 5.2: Correlation between strain index scores and perceived exertion. .......................... 46

Figure 5.3: Mean strain index scores vs. direction of force exertion...................................... 47

Figure 5.4: Mean strain index scores vs. force exertion level. .............................................. 49

Figure 5.5: Interaction effect between direction of force exertion and force exertion level. ...... 50

Figure 6.1: General orientation of the shoulder muscle resultant force vector in the (a) sagittal, (b) frontal, and (c) transverse plane 


\section{List of Acronyms}

$\begin{array}{ll}\text { ANOVA } & \text { Analysis of Variance } \\ \text { AP } & \text { Anterior-Posterior } \\ \text { DIS } & \text { Centimeter } \\ \text { EMG } & \text { Distraction } \\ \text { GH } & \text { Electromyography } \\ \text { IS } & \text { Glenohumeral joint } \\ \text { Kg } & \text { Inferior-Superior } \\ \text { ML } & \text { Kilogram } \\ \text { MSBL } & \text { Medial-Lateral } \\ \text { MSD } & \text { Mean Square of Blocks } \\ \text { MSE } & \text { Musculoskeletal Disorders } \\ \text { PE } & \text { Mean Square Error } \\ \text { PAR-Q } & \text { Physical Activity Readiness Questionnaire } \\ \text { PE } & \text { Standard Deviation } \\ \text { Sewtons }\end{array}$




\section{Chapter 1: Introduction}

Musculoskeletal disorders (MSDs) place a substantial burden on both the employer and worker in terms of healthcare costs, human suffering, and the resulting socioeconomic impact. In particular, MSDs of the shoulder are a major cause of morbidity and pain in the modern working population. Shoulder pain is a common musculoskeletal problem with an estimated prevalence rate between 16-26\% in the primary care setting (House and Mooradian, 2010). In 2011, shoulder disorders were the second most prevalent type of MSD but were the most severe requiring 21 median days away from work compared to 11 days for all other MSDs combined (Bureau of Labor Statistics, 2012). In addition to lost workdays, shoulder MSDs also generate expensive medical costs. For compensation claims data spanning from 1997 to 2005, the average total direct cost of a work-related shoulder disorder was $\$ 16,092$ per claim in the state of Washington (Silverstein and Adams, 2007). In addition to the immediate and highly visible direct costs, these disorders also cause not so evident indirect costs such as reduced health, impaired task ability, and decreased productivity (Lotters et al., 2005; Ostor et al., 2005).

Multiple epidemiological investigations have proposed several work-related exposures that are associated with shoulder disorders. These exposures include, but are not limited to awkward and prolonged sustained postures of the upper extremities, and repetitive and forceful arm exertions (da Costa and Vieira, 2010; Larsson et al., 2007; Putz-Anderson et al., 1997; Walker-Bone and Cooper, 2005). Occupations such as nursing, material handling, janitorial work, transportation, and manufacturing have been found to have workers who suffer from shoulder MSDs as they are frequently exposed to these risk factors; in particular, exposure to forceful arm exertions in pushing and pulling directions (Bureau of Labor Statistics, 2012; Dunning et al., 2010; Putz-Anderson et al., 1997). A significant dose-response relation between 
pushing and pulling exertions and shoulder complaints was also reported in a previous study (Hoozemans et al., 2002).

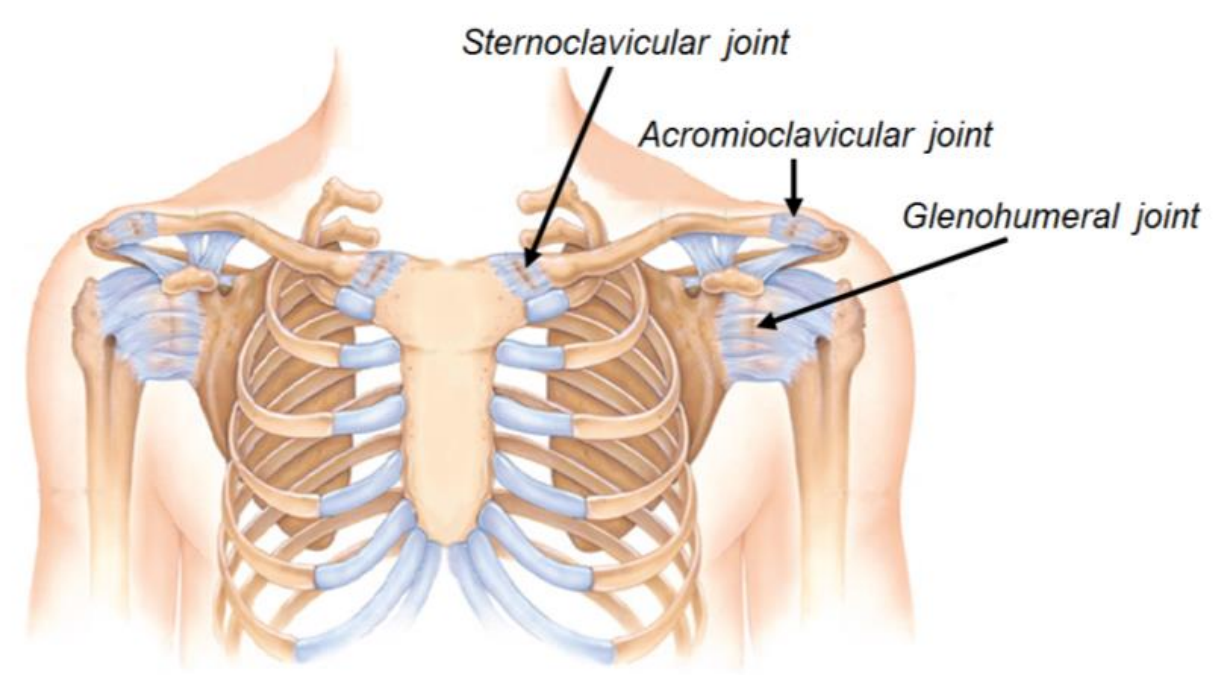

Figure 1.1: The shoulder complex is comprised of the sternoclavicular, acromioclavicular, and glenohumeral joints. Figure is modified based on image by Lydia Kibiuk, National Institutes of Health

The shoulder complex is the most mobile part of the human body with a range of motion covering nearly $65 \%$ of a sphere (Engin and Chen, 1986). The shoulder complex is comprised of three anatomical joints: the sternoclavicular, acromioclavicular, and glenohumeral joints (Figure 1.1). These joints, along with several other components such as muscles, tendons, and ligaments, gives the shoulder its strength and mobility (Culham and Peat, 1993). The high level of mobility of the shoulder complex allows a person to adopt a wide variety of postures and facilitates the application of forces of varying magnitude in nearly any direction. However, in exchange for its high flexibility and force exertion capabilities, the shoulder sacrifices its inherent stability (Veeger and van der Helm, 2007). The main shoulder joint, the glenohumeral joint, provides much of the shoulder's mobility functioning as a ball-and-socket type joint. The ball-like 
protrusion of the humerus of the upper arm fits together with the concave glenoid cavity of the scapula. The glenohumeral joint is characteristically unstable in that the humeral head is not fully encapsulated by the glenoid with only around $30 \%$ of the humeral head in contact with the glenoid in various shoulder postures (McCluskey and Getz, 2000). Because of this, the glenohumeral joint is typically stabilized by the forces produced by the shoulder muscles that press the humeral head into the glenoid cavity through a mechanism called "concavity compression" (Figure 1.2) and is destabilized by translational forces that push the humeral head away from the glenoid (Konrad et al., 2006).

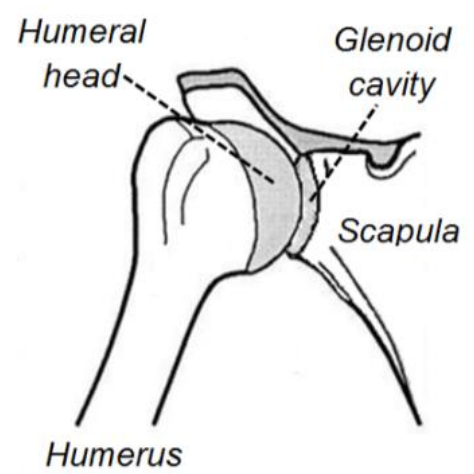

(a)

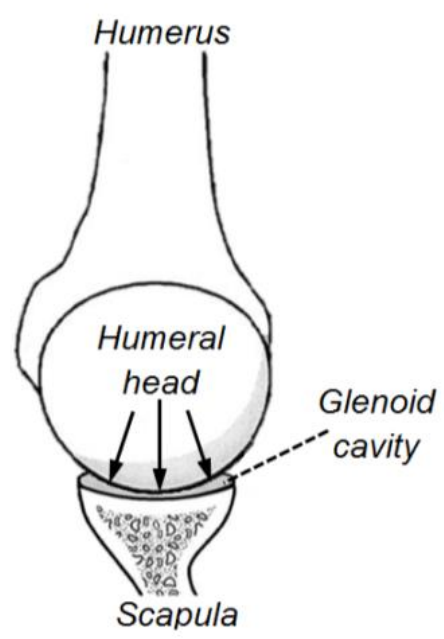

(b)

Figure 1.2: (a) Position of the humeral head with respect to the glenoid cavity; (b) Concavity compression mechanism

Forceful exertions that are commonly performed in the workplace can alter the compressive and translational forces acting on the glenohumeral joint. Such exertions, especially pushing and pulling, can potentially destabilize the glenohumeral joint with high translational forces and may place the shoulder at an increased risk for injury. Currently no method exists to evaluate strain experienced by the shoulder complex during forceful arm exertions that generate 
different levels of concavity compression. We propose to develop and validate a new shoulder strain index based on shoulder stabilization achieved through concavity compression between the humeral head and glenoid cavity. This is a significant contribution because the development of this strain index is expected to provide a new method to assess the physical risk factors associated with work-related shoulder MSDs. Precise identification of the workplace physical risk factors will enable us to devise intervention strategies to curtail the incidence of shoulder MSDs and improve workers' health. 


\section{Chapter 2: Literature Review}

Previous studies investigating the stress-strain relationship for the shoulder complex during physically demanding tasks have utilized several different methodologies. These methodologies can be broadly categorized into three main groups: physiological, biomechanical, and psychophysical, with each method having its own set of advantages and drawbacks. Below, a brief review of these studies is presented.

\subsection{Physiological Studies}

The goal of the physiological approach is to determine whether a task falls within acceptable limits based on the body's response. One common method used to gauge physiological response is muscle fatigue, which is the point where the muscle can no longer maintain the required contraction (De Luca, 1997). Electromyography (EMG) has been widely used to evaluate muscle fatigue as a measure of shoulder loading in a number of studies (Anton et al., 2001; Chopp et al., 2010; McDonald et al., 2012; Nimbarte et al., 2012a; Nimbarte et al., 2012b; Strasser and Muller, 1999). This direct approach measures the electrical activity produced by the muscles upon their contraction. Surface EMG in particular is commonly used to measure the activity of superficial muscles where bipolar electrodes are affixed to the skin's surface over the muscle of interest (Criswell, 2010). One aspect of surface EMG is that its amplitude is typically qualitatively related to the amount of torque (or force) measured about a joint (De Luca, 1997). The advantage of surface electromyography is that it's an easy, non-invasive way to quantify the activity of a muscle which can be related to the force production of the muscle of interest. It also shows the muscle recruitment pattern over the course of a task, allowing peak 
activation of a particular muscle or set of muscles to be identified (Criswell, 2010; De Luca, 1997).

Evaluating the strain placed on the shoulder musculature can be useful to indicate stressful exertions that may cause increased muscle fatigue and joint loading and therefore pose an increased risk of MSD. In a study by Strasser and Muller (1999), subjects were asked to transfer loads from several remote starting points on a table located along several angles to the frontal body plane to a target location near the subjects' body. The area on the table containing the axial directions from $90^{\circ}$ to $160^{\circ}$ counterclockwise from the right side of the frontal body plane was found to place the greatest amount of strain on the muscles studied with $150^{\circ}$ being the most unfavorable and $30^{\circ}$ found to be the most optimal (Strasser and Muller, 1999). McDonald et al., (2012) measured the strain of several muscles of the shoulder-arm system during push/pull exertions at locations along $\mathrm{X}, \mathrm{Y}$, and $\mathrm{Z}$ axes corresponding to the frontal, sagittal, and transverse planes respectively. They found that for pulling exertions along the Yaxis, total muscle activity for the 14 muscles measured decreased as the hand location moved forward. For the $\mathrm{X}$-axis, muscle activity was parabolic with higher activity occurring at the extreme left and right positions tested. For the Z-axis, activity increased with an increase in the vertical position. For pushing exertions, the $\mathrm{X}$ positions showed a similar parabolic pattern as in the pulling exertions. For the Z-axis, only the highest vertical hand location was significantly different than any of the other hand locations. The Y-axis paralleled the pulling results, but to a less pronounced extent (McDonald et al., 2012).

Working in awkward postures, such as overhead work, is also known to stress the shoulder musculature which can result in fatigue, discomfort, and shoulder disorders such as subacromial impingement syndrome (SIS). In one such overhead task studied by Chopp et al., 
(2010), seated subjects were asked to exert a specified force level on a force transducer located above their heads while pulling backwards, pushing forwards, downwards, sideways, and upwards in four hand position locations while EMG was measured for the biceps, triceps, anterior, middle, and posterior deltoid, upper and lower trapezius, latissimus dorsi, infraspinatus, and pectoralis major. The hand locations during the push/pull exertions corresponded to $-15^{\circ}, 0^{\circ}$, $15^{\circ}$, and $30^{\circ}$ angles created from the vertical and a line drawn from the subjects' pelvis to the middle of the force transducer. Positive angle values indicated a clockwise rotation towards the anterior direction while a negative value indicated a more posterior hand location with $0^{\circ}$ lying directly above the subjects' head. Pulling backwards at angles of $-15^{\circ}$ and $0^{\circ}$ showed the highest total muscular demand out of all angle and force direction combinations while within each angle, backwards pulling and sideways pushing produced higher muscle activity than other directions (Chopp et al., 2010). The anterior deltoid, middle deltoid, biceps, lower trapezius and infraspinatus had higher activation during the more difficult work configurations. Their results suggested that, if possible, positioning overhead work as close to the worker as possible will result in lower upper extremity muscle demand. Another study conducted by Anton et al., (2001) to investigate the effect of overhead drilling positions on shoulder joint moment and electromyography yielded a similar conclusion. The authors found that moving the task closer to the worker decreased anterior deltoid and biceps activity and shoulder moment.

Surface EMG can be very useful in examining the activation patterns of different muscles which in turn can help estimate the loading of the musculoskeletal system. However, it is not without its own set of constraints and limitations. The neuromuscular system is very complex with numerous muscles contributing towards the act of movement and force exertion. The ability to monitor only a few muscles sites at a time with surface EMG equipment can hinder 
understanding of the cooperation between muscles of the musculoskeletal system. Equipment with more channels available for measurement gives better coverage and provides more meaningful information. Another factor is that although surface electrodes are largely not invasive on the skin's surface, they are not totally unobtrusive and can potentially encumber movement. In addition, correct electrode placement to minimize interference by other muscles is of great importance. Electrodes need to be able to isolate the signal of the muscle(s) of interest without picking up signal interference caused by other nearby muscles (Criswell, 2010; De Luca, 1997). Lastly, surface EMG is effective for measuring shallow, superficially located muscles but less so for more deeply located muscles or those covered by other muscles which would require intramuscular electrode probes placed under the skin (Kumar and Mital, 1996).

\subsection{Biomechanics Studies}

Biomechanics can be described as "the study of the movement of living things using the science of mechanics" (Hatze, 1974) to investigate forces and how those forces create movement. This methodology focuses on the loads and stresses placed on the musculoskeletal system and is beneficial in determining the exposure to physical risk factors that can cause MSDs (Marras and Radwin, 2005). A primary area where biomechanics can be applied is in occupational injury prevention where the goal is to investigate work tasks and the loading they place on the body. This information can be used to prevent overuse injuries by ensuring that such tasks do not exceed the capacity of the musculoskeletal system (Knudson, 2007). One such example is the recommended $3400 \mathrm{~N} \mathrm{L5/S1} \mathrm{compression} \mathrm{limit} \mathrm{set} \mathrm{forth} \mathrm{by} \mathrm{the} \mathrm{National} \mathrm{Institute}$ for Occupational Safety and Health (NIOSH) for low back safety (NIOSH, 1981). This limit classifies any task that places compressive loading on the L5/S1 joint exceeding $3400 \mathrm{~N}$ as one 
that poses increased risk for MSD development. Biomechanical modeling has several advantages in that it allows investigation of aspects that may otherwise be difficult to examine, circumvents physiological difficulties such as accurate sensor placement or tissue fatigue buildup, and can be run numerous times without fear of subject discomfort (Favre et al., 2009).

As part of the shoulder complex's characteristic instability, translational forces in the inferior-superior or anterior-posterior directions destabilize the glenohumeral joint while compressive forces in the distraction direction help stabilize it. Physical exertions with a higher ratio between the translational and compressive forces may destabilize the joint and therefore pose an increased risk of MSD (Lippitt et al., 1993). Because of this, it is useful to evaluate the loading present on the shoulder joints in order to calculate this ratio and determine whether a particular exertion poses an increased risk for joint instability and ultimately risk for MSDs.

Several previous studies have investigated the biomechanical loading of the shoulder taking into consideration the joint reaction forces present at the glenohumeral joint. Hoozemans et al., (2004) evaluated the mechanical load on the low back and shoulders during cart pushing and pulling using one or two hands, three different cart weights, and two handle heights. They found that the exerted force and handle height both had a considerable effect on the mechanical loading of the shoulder. During the initial phase of moving the cart, a large increase in the compressive force at the glenohumeral joint while pushing and pulling at hip height was observed with an increase in cart weight. This was also seen for the sustained motion phase, although to a smaller extent. Their recommendation was that cart weight should remain as low as possible and to push or pull at shoulder height with the general idea that the net shoulder moment is kept lower by keeping the shoulder joint close to the line of action of the exerted force (Hoozemans et al., 2004). The study however did not evaluate the translational forces acting at 
the glenohumeral joint with the consideration that the compressive force on the glenohumeral joint is a suitable measure. The compressive forces are largely exerted by the rotator cuff muscles that compensate for the translational forces acting on the glenohumeral joint. Nimbarte et al., (2013) also evaluated the effects of a dynamic cart pushing task on the biomechanical loading of the shoulder and low back. In this study, subjects performed dynamic cart pushing tasks on a walkway of varying gradient $\left(0^{\circ}, 5^{\circ}\right.$, and $\left.10^{\circ}\right)$ using three different cart weights $(20$, 30, and $40 \mathrm{~kg}$ ). Peak reaction forces at the acromioclavicular and glenohumeral joints were found to be comparable to one another and were higher than the peak forces at the sternoclavicular joint. Variation on the cart weight was found to significantly affect the reaction forces at the shoulder complex joints. The peak reaction forces for all three shoulder joints increased with an increase in cart weight suggesting that higher exertion forces required to push the cart resulted in a higher joint loading. For the glenohumeral joint, reaction forces in the distraction (mediallateral) direction were found to be substantially higher than the reaction forces in the anteriorposterior and inferior-superior directions. The reaction forces in the distraction direction stabilize the glenohumeral joint by improving the concavity compression. A significant increase in the distraction forces was observed with the increase in the cart weight and walkway gradient, indicating increased muscular demand of the shoulder stabilizers to improve the concavity compression. Another study by de Looze et al., (2000) investigated the changes in force direction of pushing and pulling as result of changes in handle height and force level. They found that as the force exertion rises, the physical load parameters also rise. An increase in the push/pull force exertion level was reflected in an increased net shoulder torque. The variations in force exertion and physical load observed were due to variations in force direction. They suggested that besides 
force magnitude, force direction with respect to the body posture should also be measured in order for accurate assessment of the physical load.

Some limitations to the use of biomechanical modeling lie with validating the model results. Biomechanical loading criteria are typically based upon maximum acceptable forces and moments, but need to be verified with physiological data such as those done in vitro (Dempsey, 1998). Specifically for the shoulder, some models may be limited by a simplified representation of the glenohumeral joint, allowing for no translational movement. Further still, accounting for the physical contact between muscles and bones or other soft tissues and tissue deformations can further impair accurate muscle representation (Favre et al., 2009).

\subsection{Psychophysical Studies}

Psychophysical methods, such as subjective ratings, have often been used in the past to estimate things such as discomfort, fatigue, and exertion in order to determine tasks that are "acceptable" to the worker. Such ratings are important complements to behavioral and physiological measurements of physical performance and work capacity (Borg, 1982).

One of the most widely used psychophysical rating scales is one based on the research of Gunnar Borg and is commonly referred to as "Borg's CR-10 scale" (Borg, 1990). The Borg CR10 scale provides ratio scaling and exertion level estimations where the categorical expressions of a person's perceived exertion, ranging from "nothing at all" to "extremely strong", are linked to a quantitative 0 to 10 number scale. This permits ratio comparisons to be done between different levels of intensity as well as determination of the intensity level. Such subjective ratings are often used to determine joint loading due to their ease of use and the frequent lack of loading limit guidelines based on objective measures (Nussbaum and Lang, 2005). However, subjective 
joint loading methodology can be somewhat uninformative when the measures have not been validated through comparison with accurate objective measures. Despite this concern, a number of previous studies have found that subjective ratings positively correlate to objective measures (Dickerson et al., 2006; Hall and Dickerson, 2010; Kee and Lee, 2012; Nussbaum and Lang, 2005). Recently, Garg et al. (2006) studied subjects' rating of perceived exertion, fatigue, and pain related to the shoulder during a simulated automotive assembly job. A high repeatability and accuracy of perceived exertion scores was reported in estimating loading of the shoulder complex during the manual material handling tasks. They reported an increase in perceived exertion ratings with an increase in the load weight and hand tool weight. Based on a series of similar studies Garg and colleagues concluded that a mean rating of 3.5 or less on the Borg CR10 scale is a suggested acceptable level of perceived stresses to the shoulder girdle. (Garg, 1983, 1989; Garg and Badger, 1986; Garg and Banaag, 1988; Garg et al., 2002; Garg and Saxena, 1982). Dickerson and colleagues found that the perception of muscular effort in the shoulder was found to be positively correlated to the physical measures of loading used (e.g. shoulder torque, muscle force model predictions, EMG) (Dickerson et al., 2006, 2007). In a cyclic push task by Keir and Brown (2012), RPEs of male and female subjects increased with push frequency and push weight. The activity of the posterior deltoid and triceps also increased with these factors. This shows that increased RPE values were matched physiologically with increased muscle activity. Nussbaum and Lang (2005) exposed subjects to loads, representing fixed fractions of their maximum acceptable load, in different static standing postures and found a linear relationship between the relative joint demands and perceived exertion for the shoulder and the other joints studied. Together, these studies demonstrate that a subjective rating methodology can be used as an accurate measure for quantifying joint loading. 


\subsection{Other Studies}

In addition to the studies mentioned above, other studies have investigated the shoulder complex using slightly different methodologies. One such study by Chow \& Dickerson (2009) investigated shoulder push strengths and stated that the push force exertion ability of the shoulder complex is direction specific with the greatest strength occurring in the vertical pushing downwards and weakest in the horizontal pushing forwards. They found that strength in the vertical direction was about 3 times greater than in the horizontal and lateral directions and that shoulder push force strength decreased in the order of vertical, lateral, and then horizontal. 


\section{Chapter 3: Study Rationale}

\subsection{Problem Statement}

Shoulder MSDs are a prevalent and major cause of morbidity and pain in the modern working population. The impact shoulder MSDs have on medical costs, human suffering, and socioeconomic outcomes is significant and therefore warrant investigation into exposure assessment and prevention methods in order to reduce their occurrence. Past epidemiological studies have identified several risk factors that are associated with shoulder disorders and include awkward and prolonged sustained postures of the upper extremities and repetitive and forceful exertions. In particular, pushing and pulling type exertions have been found to display a doseresponse type relationship with shoulder complaints. Although a number of previous studies have reported a significant stress-strain relationship for the shoulder complex during physically demanding exertions using either physiological, biomechanical, or psychophysical methods, a clear assessment method or criteria to evaluate the risk of injury to the shoulder complex during forceful arm exertions currently does not exist. Therefore, a critical need exists for the development of new risk assessment methods that can precisely evaluate the strain experienced by the shoulder complex during forceful arm exertions.

\subsection{Objective and Hypothesis}

The objective in this research was to develop and validate a new shoulder strain index based on the concept of the concavity compression mechanism. During forceful arm exertions, the shoulder stabilizer muscles compress or pull the upper arm (head of the humerus) into the shoulder socket (glenoid) by counteracting the forces generated by external loading. In this process the resultant vector of the summed muscle forces always attempts to center the humeral 
head in the glenoid. This is known as the concavity compression mechanism which stabilizes the glenohumeral joint. Several biomechanical measurements including direction and magnitude of resultant reaction forces characterize the concavity compression mechanism. The central hypothesis in this study was that the strain experienced by the shoulder complex during forceful exertions can be expressed in terms of biomechanical measurements that characterize the concavity compression mechanism. The hypothesis was tested by performing a correlation analysis between the strain indices (quantified by using different combinations of the biomechanical measurements) scores and ratings of perceived exertion.

The strain index that showed strong relationship with the ratings of perceived exertion was further evaluated to quantify the effect of direction and level of force exertion by testing the following null hypotheses:

$\mathrm{H}_{01}$ : There is no effect of direction of force exertion on the mean strain index scores

$\mathrm{H}_{02}$ : There is no effect of force exertion level on the mean strain index scores

$\mathrm{H}_{03}$ : There is no effect of gender on the mean strain index scores

$\mathrm{H}_{04:}$ There is no interaction effect of direction of force exertion and force exertion level on the mean strain index scores

$\mathrm{H}_{05}$ : There is no interaction effect of direction of force exertion and gender on the mean strain index scores

$\mathrm{H}_{06:}$ There is no interaction effect of force exertion level and gender on the mean strain index scores

$\mathrm{H}_{07}$ : There is no interaction effect of direction of force exertion, force exertion level, and gender on the mean strain index scores 


\section{Chapter 4: Methodology}

\subsection{Approach}

In order to develop a strain index, the biomechanical measurements related to concavity compression mechanism were estimated using the data recorded during a laboratory-based experiment. Human participants performed forceful push/pull arm exertions in six orthogonal directions using three different force levels. The experimental data was modeled using a wellestablished and previously tested biomechanical model of the shoulder complex (Nimbarte et al., 2013) to quantify the reaction forces placed on the glenohumeral joint caused by the exertion. Ratings of perceived exertion were used to quantify the workload placed on the shoulder as a subjective method and to later aid in validation.

The biomechanical modeling analysis was performed under two different model conditions; one with muscles and the other without muscles. The resultant of the reaction forces obtained under the without-muscle configuration takes into account only the forces that are caused by external loading and is always opposite to the direction of the external force application. On the other hand, the resultant of the reaction forces under the with-muscle configuration must instead be redirected towards the shoulder by the shoulder muscles in order to improve the joint's stability by enhancing the concavity compression. Thus, the change in the angular deviation and magnitude between the resultant force vectors of these two conditions provides a direct assessment of the strain experienced by the shoulder complex during forceful arm exertions (Figure 4.1). Several strain indices, which indicate the amount of strain experienced by the shoulder during the exertions, were developed based on different combinations of the angular vector deviations and magnitudes of the resultant forces between the without-muscle and with-muscle model configurations. The indices were then validated using 
participant ratings of perceived exertion recorded during the forceful arm exertions. Previous studies have found that subjective ratings have a high accuracy in estimating loading of the shoulder complex (Dickerson, Martin, \& Chaffin, 2006; Garg, Hegmann, \& Kapellusch, 2006; Nussbaum \& Lang, 2005) and can be a reasonable method in validating the proposed strain indices in their ability to estimate the strain placed on the shoulder.

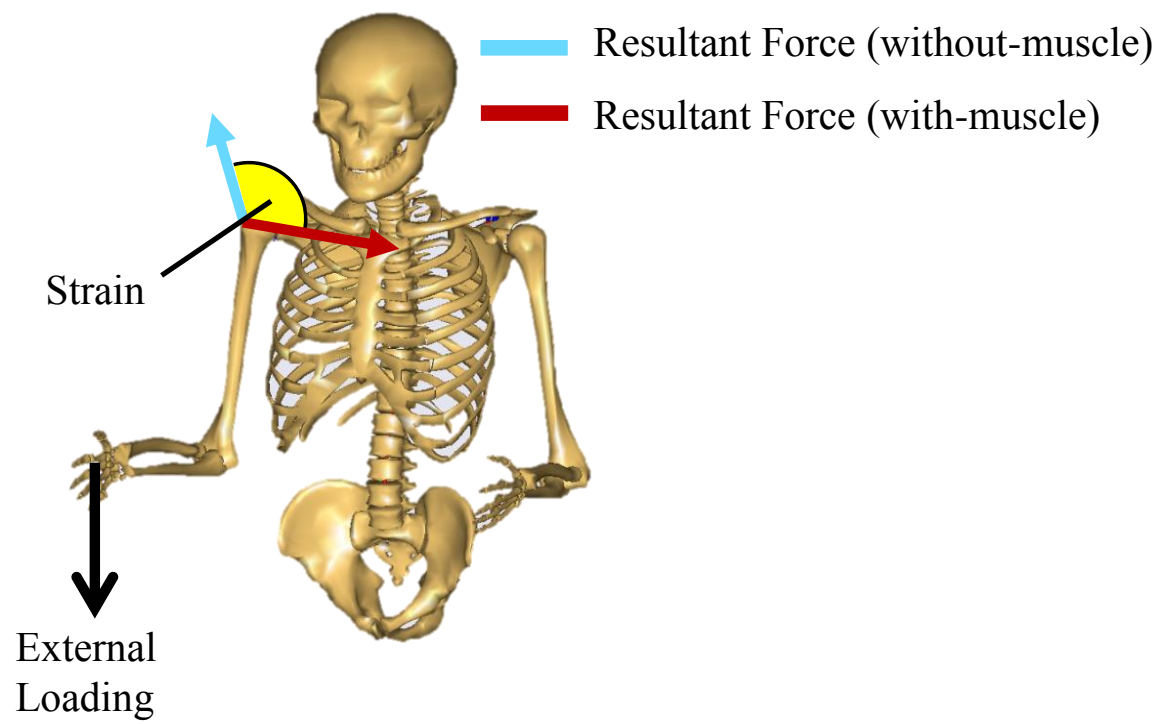

Figure 4.1: Biomechanical model showing the resultant force vectors from the two model configurations. Blue: without shoulder muscles; Red: with shoulder muscles. The yellow highlighted area represents the amount of strain experienced by the shoulder caused by a forceful arm exertion

\subsection{Participants}

Fifteen healthy, right-hand dominant participants (eight male and seven female) between the ages of 18 and 40 were recruited for the research. A summary of participant characteristics such as height, weight, and age is shown in Table 4.1. Data for individual participants can be found in Appendix C. 
Table 4.1: Mean (SD) participant demographic data

\begin{tabular}{|c|c|c|c|c|}
\hline $\begin{array}{c}\text { Gender } \\
(\mathrm{M} / \mathrm{F})\end{array}$ & Height $(\mathrm{cm})$ & Weight $(\mathrm{kg})$ & Age $(\mathrm{yrs})$ & $\#$ \\
\hline $\mathrm{M}$ & $174.8(6.0)$ & $73.8(5.8)$ & $26.1(2.7)$ & 8 \\
\hline F & $166.9(9.3)$ & $71.1(27.1)$ & $28.0(5.4)$ & 7 \\
\hline All & $171.1(8.4)$ & $72.5(18.2)$ & $27.0(4.2)$ & 15 \\
\hline
\end{tabular}

Sample size estimation for determining the number of required participants is discussed in Section 4.6.3.2. Participants were excluded from the research if they suffered from any type of musculoskeletal, degenerative, or neurological disorder or if they had a history of shoulder pain or any current pain. The Physical Activity Readiness Questionnaire (PAR-Q, Canadian Society for Exercise Physiology) (Appendix A) was used to screen participants for cardiac and other health problems (e.g., dizziness, chest pain, and heart trouble). Participants who met the inclusion criteria were asked to read and sign a consent form approved by the West Virginia University Institutional Review Board (Appendix B).

\subsection{Equipment}

\subsubsection{Custom-built Force Exertion Device}

This device consists of a wooden chair attached to a column and base assembly that is fitted with a bar-handle peripheral assembly (Figure 4.2). The chair is equipped with a four-point harness to secure participants in a standard sitting posture in order to prevent any upper body movement that would otherwise interfere with the data collection (Figure 4.2(a)). The column and base assembly sits directly in front of the chair and serves as an attachment point to the barhandle assembly. The bar-handle assembly consists of a small horizontal metal bar mounted to the sturdy, immobile base portion of the column and base assembly. A D-handle is attached to 
this metal bar and is able to be adjusted along the bar's length. The D-handle attachment consists of a small steel plate mounted onto the handle that is screwed onto the face of a Force/Torque (F/T) sensor (Figure 4.2(b)). In addition to the bar-handle assembly, the column and base assembly also has an attached computer monitor that faces the seated participant. This monitor is used to display a real-time force exertion level graph that provides bio-feedback to the participants in order to help them maintain a target force exertion during the experiment (Figure 4.2(c)). Force data from the F/T sensor was acquired using a TeleMyo 2400R G2 receiver at a frequency of $1000 \mathrm{~Hz}$ (Noraxon USA Inc., Scottsdale, AZ). The MyoResearch XP analysis software (Noraxon USA Inc., Scottsdale, AZ) was used to display a real-time force exertion level graph to the participants.

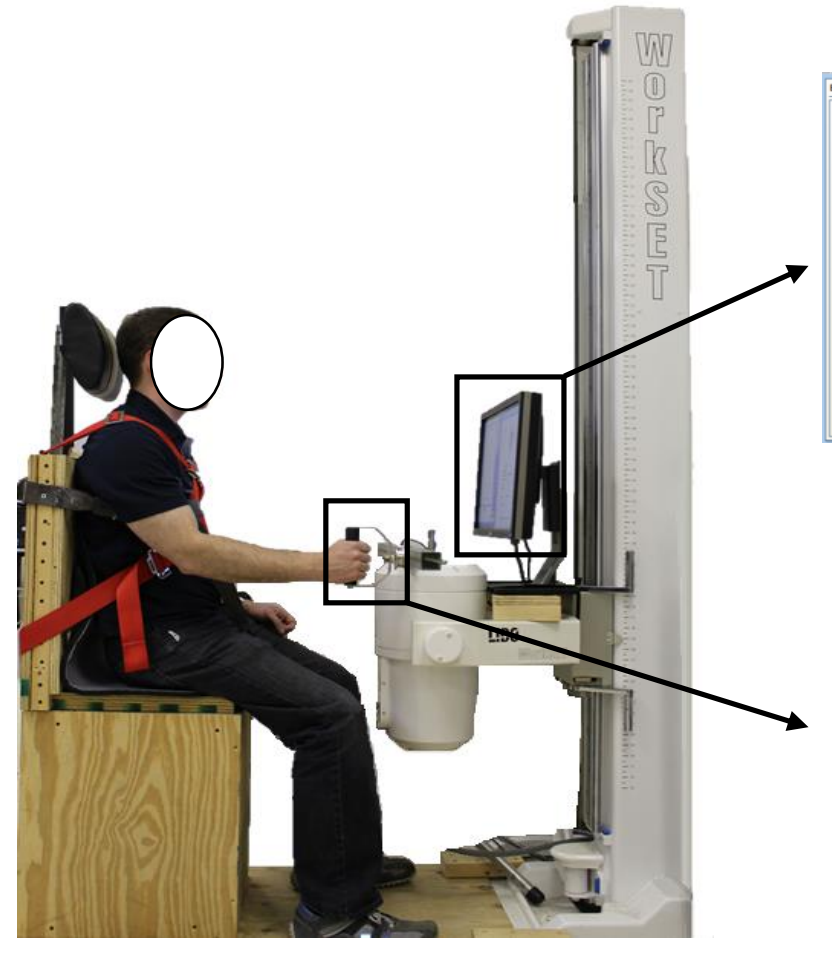

(a)

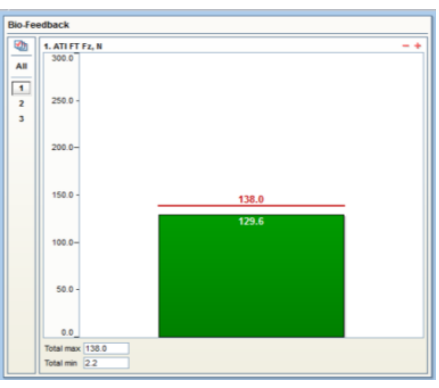

(c)

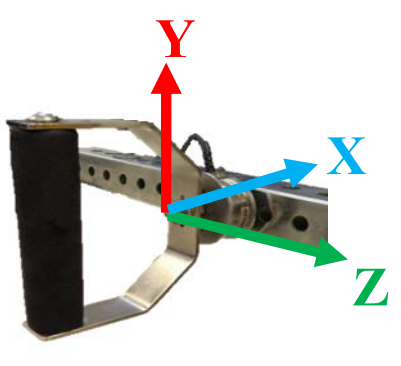

(b)

Figure 4.2: Force exertion device: (a) chair with attached four-point harness facing bar-handle assembly and computer monitor, (b) F/T sensor mounted with a handle and attached to bar, and (c) force level feedback screen 


\subsubsection{Biomechanical Model}

The resultant reaction forces acting at the glenohumeral joint during the forceful arm exertions were estimated using the AnyBody Modeling System ${ }^{\mathrm{TM}}$ (version 5.0, AnyBody Technology, Aalborg, Denmark). This is a full-body biomechanical modeling system where models are formulated using AnyBody's AnyScript modeling language which is similar in syntax to the $\mathrm{C}++$ computer language. It is an object-oriented language developed specifically to define and model bones, joints, and muscle-tendon units based on real physiological properties. Joints in the AnyBody modeling system can be driven by experimentally obtained kinematic and kinetic data. Muscle and joint forces are computed using inverse dynamics analysis. AnyBody musculoskeletal models have been used previously to estimate musculoskeletal shoulder loading during cart pushing and pulling (Nimbarte et al., 2013) and wheelchair propulsion (Dubowsky et al., 2008) tasks.

\subsection{Experimental Design}

A three-factor replicated block design was used in this research. Factor 1, direction of force exertion, was treated at six levels: 1) anterior $(+X), 2)$ superior $(+Y), 3)$ lateral $(+Z), 4)$ posterior (-X), 5) inferior (-Y), and 6) medial (-Z). Factor 2, force exertion level, was treated at three levels: 1) $20 \mathrm{~N}$, 2) $40 \mathrm{~N}$, and 3) $60 \mathrm{~N}$. Factor 3, gender, was treated at two levels: 1) male and 2) female. The force exertion levels used were obtained based on the findings of our preliminary study where the average maximum force that individuals were able to exert in $+X$, $+\mathrm{Y}$ and $+\mathrm{Z}$ directions were 75 (21) N, 111 (32) N, and 220 (54) N, respectively (Cutlip et al., 2013). The force exertion values for the current research are below the maximum strengths observed in the pilot study in order to ensure that participants were able to exert the required 
levels and to reduce the risk of potential discomfort or injury. The selected force exertion levels also approximately represent low, medium, and high exertion demands. Each force exertion trial was approximately 20 seconds long in duration: The first 5 seconds were used for force build up, followed by 10 seconds of constant force exertion, and the last 5 seconds used to return to zero force exertion. Three repetitions were collected for each experimental condition and were later averaged for the statistical analysis. In total, 54 experimental trials $(6$ directions $\times 3$ force exertion levels $\times 3$ repetitions) were collected from each individual participant and the trial order was completely randomized. A rest period of 45 to 60 seconds was provided between the experimental trials to mitigate fatigue. The approximate data collection time for an individual participant was around 2 to 2.5 hours ( 20-25 minutes of forceful arm exertion, $\sim 50-65$ minutes of rest period, $\sim 50-60$ minutes of preparation time).

\subsection{Experimental Data Collection Procedure}

Upon arriving at the laboratory, participants were provided with a tour of the experimental set-up. After equipment, data collection procedures, and specifics of the experimental tasks were explained to the participants, their signatures consenting to participation in the study were obtained on a consent form approved by the local Institutional Review Board (Appendix B). A set of anthropometric and characteristic measures such as height, weight, and age was then recorded for each participant for later use in the biomechanical analysis. Participants were then seated and secured into the wooden chair of the force exertion device using the four-point harness. The position of the D-handle was adjusted such that the participant could grasp it using a $80^{\circ}-90^{\circ}$ flexed elbow joint and a $5^{\circ}-10^{\circ}$ flexed shoulder joint. Next, they were instructed on how to perform the forceful arm exertion tasks and allowed time to practice in 
order to familiarize themselves with the nature of the exertion. After they were comfortable in performing the exertions required, the maximum force exertion ability in the six previously mentioned directions was measured for each participant. The main rationale for recording the maximum force exertion ability was to make sure that participants had sufficient strength to conduct the forceful arm exertions. Following the above preparatory steps, participants then performed forceful arm exertions along the six directions at the three force levels mentioned previously. Immediately following the completion of each exertion, the participant was asked to numerically rate their perceived exertion using Borg's CR-10 scale (Figure 4.3). The Borg CR10 scale contains two columns, one for subjective categories ranging from "nothing at all" to "extremely strong" and the other for numerical ratios ranging on a scale of 0 to 10 that are associated with the different categories. Participants were given instruction on how to interpret the scale prior to actual data collection with a rating of zero corresponding to the participant feeling no noticeable effort required for the exertion and 10 corresponding to the exertion requiring the participant's full effort.

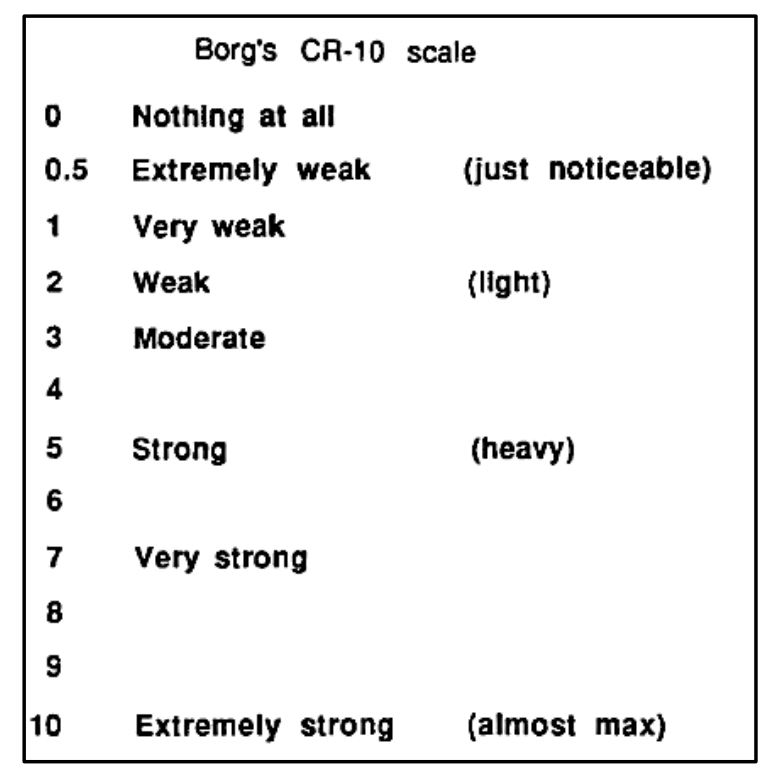

Figure 4.3: Borg's CR-10 scale 


\subsection{Data Processing and Analysis}

\subsubsection{Anybody Biomechanical Model}

A biomechanical model was used to quantify the loading placed on the shoulder complex caused by the forceful arm exertions. This model is part of the public-domain model repository provided by AnyBody Technology as part of their AnyBody Modeling System ${ }^{\mathrm{TM}}$. The model used in this study consists of 118 muscle fascicles on each side of the body (left and right) and defines the three main shoulder complex joints: the glenohumeral joint, the acromioclavicular joint, and the sternoclavicular joint. The muscle forces required to generate motion or sustain body posture are computed using inverse-dynamic methods by solving a multi-body dynamics problem where the unknown internal forces are computed using known external motion and forces (Damsgaard et al., 2006). The muscle recruitment in the inverse dynamics process is solved using a min/max optimization procedure within which the objective function is to minimize the maximal normalized muscle force subject to equilibrium constraints and lower bounds on force (i.e., all forces must be in the "pull" direction) (Rasmussen et al., 2001). The inverse dynamics analytical process utilized by AnyBody is illustrated in Figure 4.4.

Figure 4.5 shows a basic outline of the main model structure showing how different applications, settings, and models make up the biomechanical model. 
INPUT:

Kinematics data, external load data, individual anthropometrics data

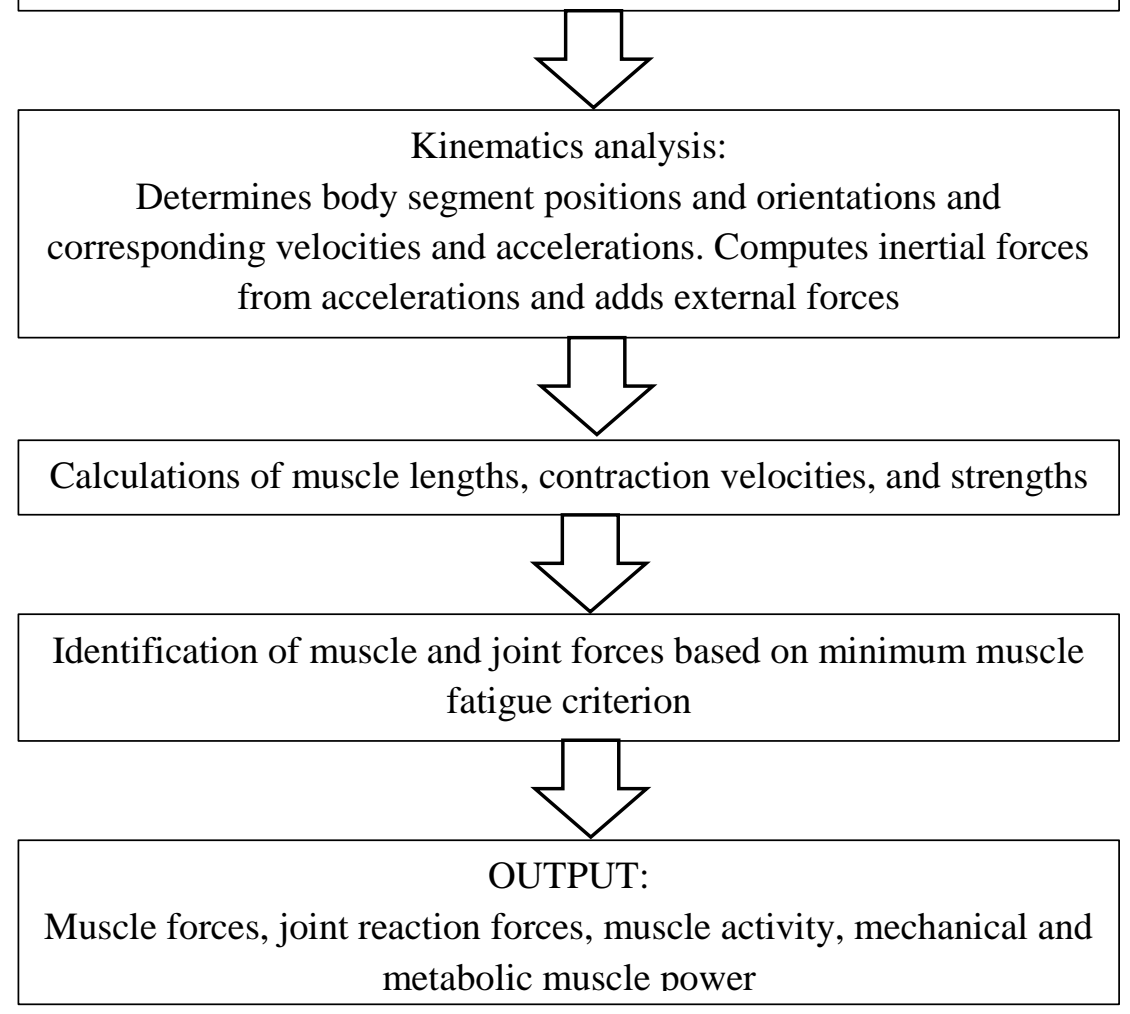

Figure 4.4: Inverse dynamic analytical process implemented by the AnyBody modeling system 


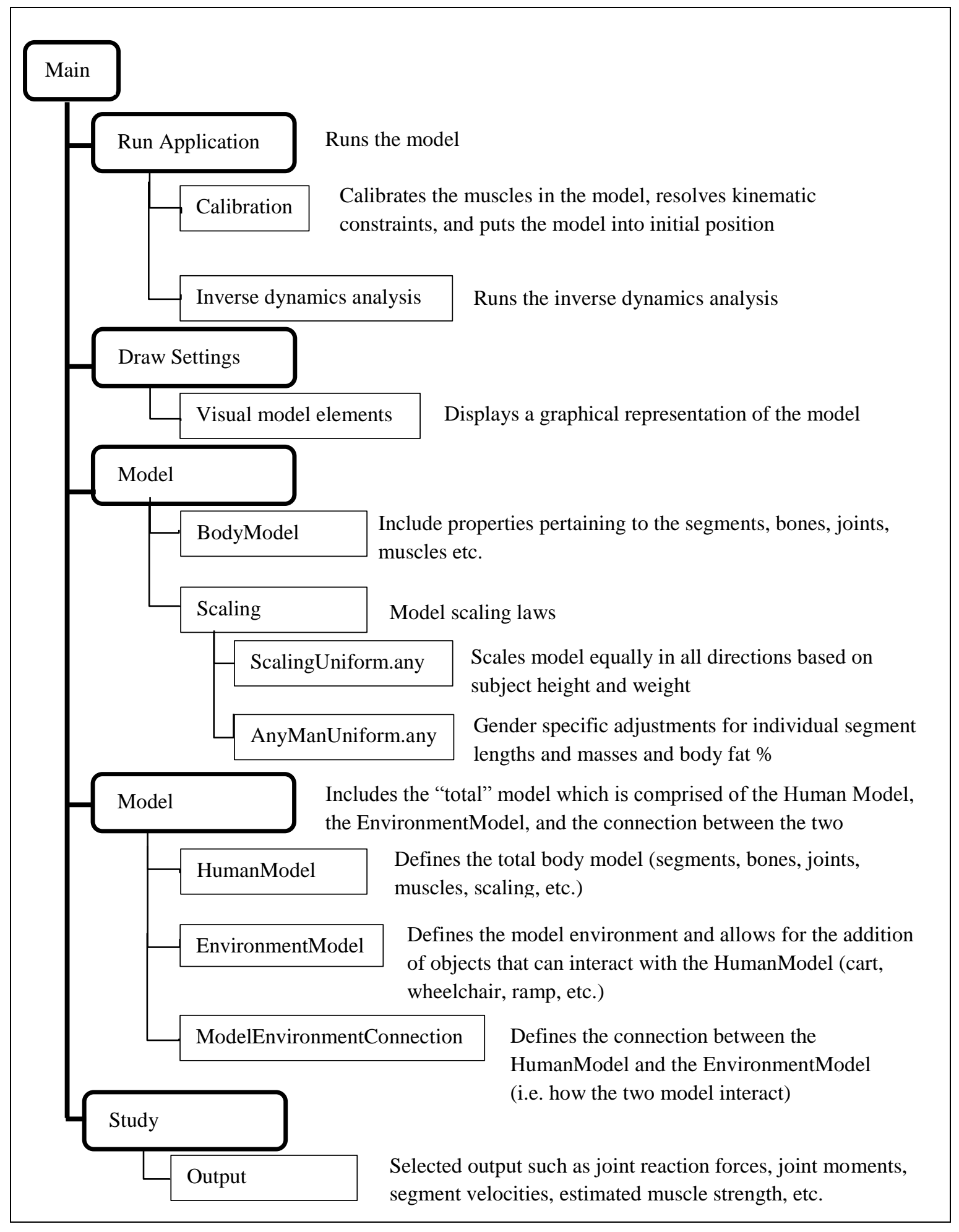

Figure 4.5: Basic structure of AnyBody model 


\subsubsection{Model Scaling}

The model was scaled for each participant based on their individual anthropometric and characteristic data such as height, weight, and gender. The files ScalingUniform.any and AnyManUniform.any within the model (Figure 4.5) were used to make the appropriate participant specific changes to the model. The ScalingUniform.any file takes the individual participant total body mass and height data, defined by the user in the AnyManUniform.any file, and uses these two properties to proportionally scale the model's segments in all three directions. This allows the model to be able to simulate the unique anthropometric characteristics of each participant, for example whether they are tall and lean or short and stout. Additionally, gender specific changes were made to the model such as changes to the model's defined segment lengths and masses and changes to the model's body fat composition in the AnyManUniform.any file. Without changing the default model values for segment length and mass as well as body fat percentage, which are based on male anthropometry measures, the model would not be able to differentiate between male and female participants and would simply use the default male values for both. Using data available from (Chaffin et al., 2006), individual model segments such as the upper arm, forearm, hand, etc. were adjusted for segment length and segment mass for both males and females which allowed the model to properly scale the individual segments depending on the gender of the participant. For body fat percentage, equations by (Frankenfield et al., 2001) were used to define the model's body fat percentage for both males and females.

\subsubsection{Model Input}

The input to the biomechanical model included the force exertion data measured by the F/T sensor and participant posture data. Data is read into the model where it then runs the appropriate scaling and calibration calculations and resolves the model constraints. 


\subsubsection{Model Output}

The outcomes of the biomechanical analysis included the reaction forces acting on the right glenohumeral joint of the shoulder complex in the following anatomical directions: distraction (medial-lateral $(\mathrm{Z})$ ), inferior-superior $(\mathrm{Y})$, and anterior-posterior $(\mathrm{X})$. The reaction forces acting at the glenohumeral joint were obtained by running the model under two different model conditions: without-muscles and with-muscles (Figure 4.6). The mean of the joint reaction forces during the constant force exertion period was used in the computation of the shoulder strain index as explained in section 4.6.2.

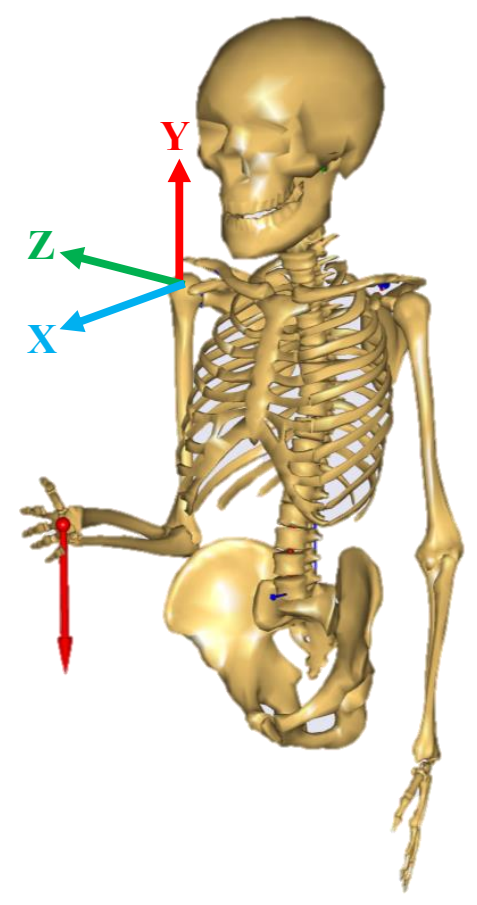

(a)

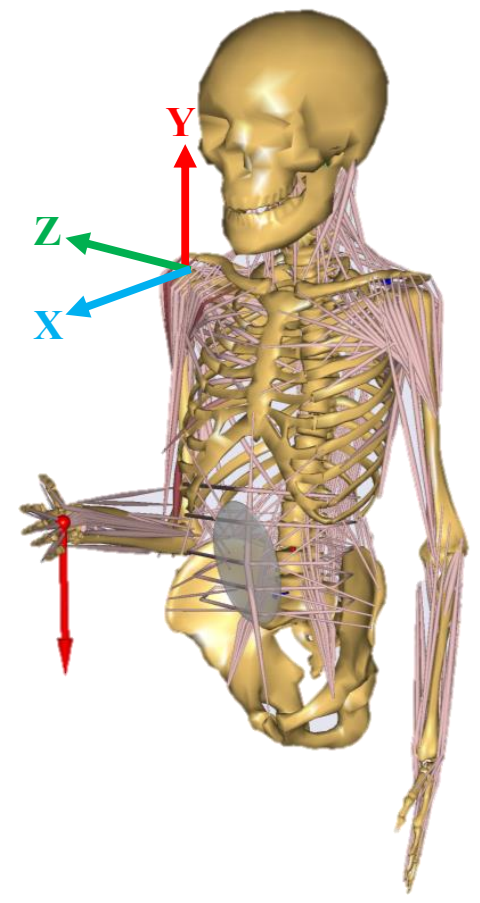

(b)

Figure 4.6: Graphical representation AnyBody biomechanical model under the: (a) without-muscle condition, and (b) with-muscle condition 


\subsubsection{Strain Index Calculation}

The concavity compression mechanism promotes glenohumeral joint stability by redirecting the resultant reaction force in towards the shoulder allowing for increased contact between the humeral head and the glenoid cavity. The proposed stain indices, which indicate the level of strain placed on the shoulder caused by a forceful exertion, were developed using different combinations of the resultant force vector deviations (Figure 4.7) and the magnitude of the resultant force vectors acting at the glenohumeral joint obtained from the two model conditions (Table 4.2).

As previously mentioned, the resultant of the reaction forces obtained under the withoutmuscle model condition takes into account only the forces caused by the external loading. On the other hand, the resultant of the reaction forces under the with-muscle condition includes the forces produced by the shoulder muscles in addition to the forces caused by the external loading. The additional forces supplied by the shoulder muscles work to redirect the resultant force towards the shoulder in order to improve the joint's stability by enhancing the concavity compression. The change in the angular deviation and magnitude of the resultant force vector obtained under these two conditions measures the level of strain experienced by the shoulder complex during the forceful arm exertion. A larger difference between the two vectors will result in a higher strain index, indicating that the shoulder muscles are working harder to compress the upper arm into the shoulder socket compared to an exertion resulting in a smaller angular deviation. 


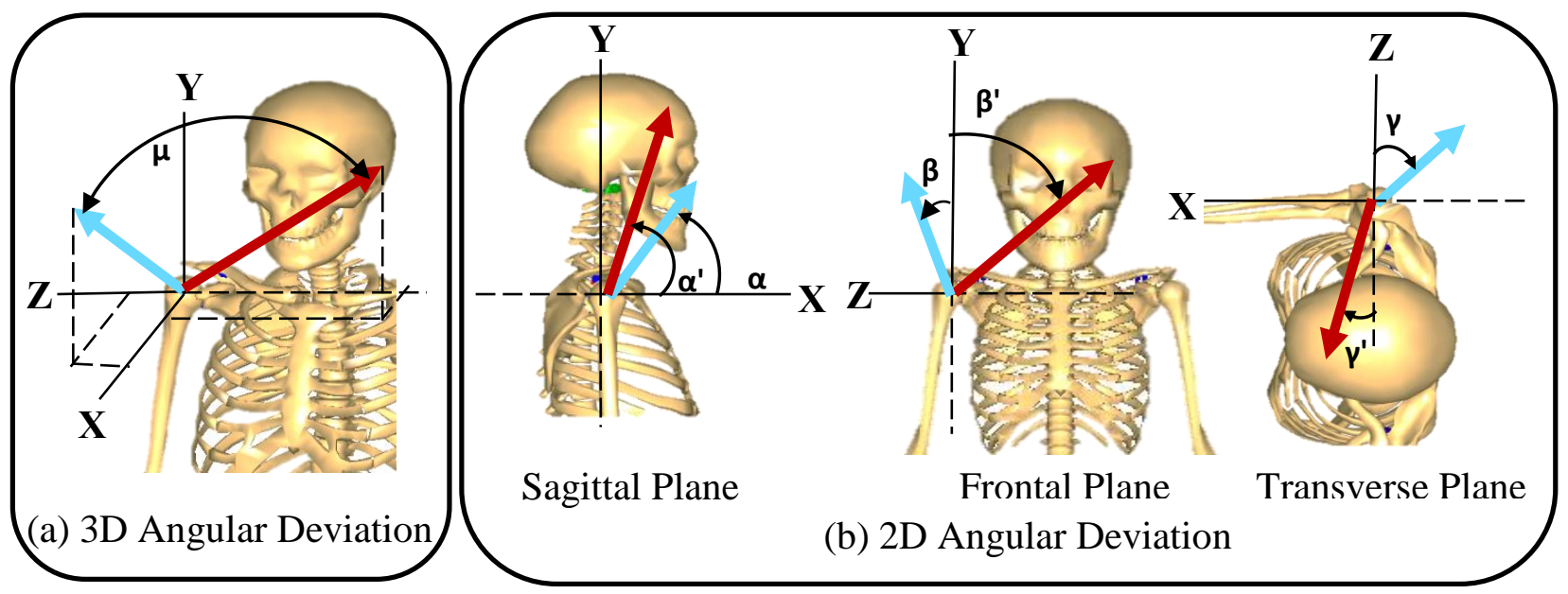

Figure 4.7: Calculation of the three dimensional (a) and two dimensional (b) angular deviations between the resultant force under the without-muscle condition (blue) and the with-muscle condition (red)

The average reaction forces acting at the glenohumeral joint in the anterior-posterior $(\mathrm{X})$, inferior-superior $(\mathrm{Y})$, and distraction $(\mathrm{Z})$ directions obtained from the biomechanical model output were used in the development of the strain indices (Table 4.2).

Table 4.2: Strain index equations

\begin{tabular}{|c|c|c|l|}
\hline $\begin{array}{c}\text { Strain } \\
\text { Index: }\end{array}$ & Equation: & Range: & \multicolumn{1}{|c|}{ Description: } \\
\hline 1 & $\mu$ & $0-1$ & $\begin{array}{l}\text { Based on the three-dimensional angular deviation } \\
\text { between the resultant reaction forces produced } \\
\text { for the without and with-muscle conditions } \\
\text { (Figure 4.7(a)). The angular deviation between } \\
\text { the two vectors is determined by taking the dot } \\
\text { product between the two resultant forces. The } \\
\text { calculated angular deviation is normalized with } \\
\text { respect to the maximum expected angular } \\
\text { deviation. }\end{array}$ \\
\hline 2 & $\begin{array}{lll}\text { Based on the three-dimensional angular deviation } \\
\text { as calculated by the first strain index and } \\
\text { summing it with the normalized resultant force } \\
\text { magnitude difference between the without and } \\
\text { with-muscle conditions. }\end{array}$ \\
\hline 3 & $0-M)$ & $0-1$ & $\begin{array}{l}\text { Based on the two-dimensional angular deviation } \\
\text { in the frontal plane between the resultant reaction } \\
\text { forces produced for the without and with-muscle }\end{array}$ \\
\hline
\end{tabular}




\begin{tabular}{|c|c|c|c|}
\hline & & & $\begin{array}{l}\text { conditions. The resultant reaction force vectors } \\
\text { are mirrored onto the frontal (YZ) plane. The } \\
\text { angular deviation is estimated using angles } \beta \text { and } \\
\beta^{\prime} \text {. The calculated angular deviation is } \\
\text { normalized with respect to the maximum } \\
\text { expected value. }\end{array}$ \\
\hline 4 & $A_{2}+\frac{\left(M^{\prime}-M\right)}{\left(M^{\prime}-M\right)_{\max }}$ & $0-2$ & $\begin{array}{l}\text { Based on the two-dimensional angular deviation } \\
\text { as calculated by the third strain index and } \\
\text { summing it with the normalized resultant force } \\
\text { magnitude difference between the without and } \\
\text { with-muscle conditions. }\end{array}$ \\
\hline 5 & $A_{1}+A_{2}+A_{3}$ & $0-3$ & $\begin{array}{l}\text { Based on the sum of the two-dimensional angular } \\
\text { deviations in the sagittal (XY), frontal (ZY), and } \\
\text { transverse (XZ) planes between the resultant } \\
\text { reaction forces produced for the without and } \\
\text { with-muscle conditions. Similar to strain index } 3 \text {, } \\
\text { the angular deviations are estimated by using } \\
\text { planar angles } \alpha, \gamma \text { and } \alpha^{\prime}, \beta^{\prime} \text {, and } \gamma^{\prime} \text { (Figure } \\
4.7(b)) \text {. } A_{1} \text { is estimated using angles } \alpha \text { and } \alpha^{\prime}, A_{2} \\
\text { is estimated using angles } \beta \text { and } \beta^{\prime} \text {, and } A_{3} \text { is } \\
\text { estimated using angles } \gamma \text { and } \gamma^{\prime} \text {. All angular } \\
\text { deviations }\left(A_{1}, A_{2}, A_{3}\right) \text { are normalized with } \\
\text { respect to the maximum value. }\end{array}$ \\
\hline 6 & $\begin{array}{l}A_{1}+A_{2}+A_{3} \\
+\frac{\left(M^{\prime}-M\right)}{\left(M^{\prime}-M\right)_{\max }}\end{array}$ & $0-4$ & $\begin{array}{l}\text { Based on the two-dimensional angular deviations } \\
\text { as calculated by the fifth strain index and } \\
\text { summing it with the normalized resultant force } \\
\text { magnitude difference between the without and } \\
\text { with-muscle conditions. }\end{array}$ \\
\hline 7 & $\mu+A_{2}+\frac{\left(M^{\prime}-M\right)}{\left(M^{\prime}-M\right)_{\max }}$ & $0-3$ & $\begin{array}{l}\text { Based on both the three-dimensional angular } \\
\text { deviation and the two-dimensional frontal plane } \\
\text { angular deviations as calculated by the first and } \\
\text { third strain indices. The angular deviations are } \\
\text { then summed together along with the normalized } \\
\text { resultant force magnitude difference between the } \\
\text { without and with-muscle conditions. }\end{array}$ \\
\hline 8 & $\begin{array}{l}\mu+A_{1}+A_{2}+A_{3} \\
+\frac{\left(M^{\prime}-M\right)}{\left(M^{\prime}-M\right)_{\max }}\end{array}$ & $0-5$ & $\begin{array}{l}\text { Based on both the three-dimensional angular } \\
\text { deviation and the two-dimensional sagittal, } \\
\text { frontal, and transverse plane angular deviations } \\
\text { as calculated by the first and third strain indices. } \\
\text { The angular deviations are then summed together } \\
\text { along with the normalized resultant force } \\
\text { magnitude difference between the without and } \\
\text { with-muscle conditions. }\end{array}$ \\
\hline 9 & $\begin{array}{l}A_{2}+\frac{M^{\prime}}{\left(M^{\prime}\right)_{\max }} \\
+D I S_{\text {medial }}\end{array}$ & $0-3$ & $\begin{array}{l}\text { Based on the two-dimensional angular deviation } \\
\text { as calculated by the third strain index summed } \\
\text { with the normalized resultant force magnitude }\end{array}$ \\
\hline
\end{tabular}




\begin{tabular}{|l|l|l|l|}
\hline & $\begin{array}{l}\text { from the with-muscle condition and the } \\
\text { normalized medial distraction force from the } \\
\text { without-muscle condition. }\end{array}$ \\
\hline
\end{tabular}

The three-dimensional angular deviation, $\mu$, between the without-muscle and with-muscle resultant force vectors was calculated using the dot product which is defined as follows (Equation 4.1):

$$
\mu=\frac{\text { dot product }}{180^{\circ}} ; \quad \text { dot product }=\cos ^{-1}\left(\frac{\left(f x * f x^{\prime}\right)+\left(f y * f y^{\prime}\right)+\left(f z * f y^{\prime}\right)}{\sqrt{\left(f x^{2}+f y^{2}+f z^{2}\right)} * \sqrt{\left(f x^{\prime 2}+f y^{\prime 2}+f{z^{\prime}}^{2}\right)}}\right)
$$

Where $f x, f y$, and $f z$ are the reaction forces acting at the glenohumeral joint obtained from the without-muscle model condition and fx', fy', and fz' are the reaction forces acting at the glenohumeral joint obtained from the with-muscle model condition.

Equation 4.2 represents the normalized resultant force magnitude difference between the without and with-muscle conditions:

$$
\frac{\left(M^{\prime}-M\right)}{\left(M^{\prime}-M\right)_{\max }} ; \quad M=\sqrt{\left(f x^{2}+f y^{2}+f z^{2}\right)} \quad M^{\prime}=\sqrt{\left(f x^{\prime 2}+f{y^{\prime}}^{2}+f z^{\prime 2}\right)}
$$

Where fx, fy, fz, fx', fy', and fz' are defined the same as above and $M$ and $M^{\prime}$ are the resultant force magnitudes for the without-muscle and with-muscle model conditions, respectively.

The medial distraction force from the without muscle condition is shown in equation 4.3.

$$
D I S_{\text {medial }}\left\{\begin{array}{cc}
0 & \text { if distraction force }>0 \\
\frac{\text { distraction force }}{(\text { distraction } \text { force })_{\max }} & \text { if distraction force }<0
\end{array}\right.
$$

The medial distraction force takes on a value of zero when the distraction force acting on the glenohumeral joint under the without-muscle condition is positive, meaning that there is no 
medially (-Z) directed force but instead a laterally $(+Z)$ directed force (Figure 4.6). Conversely when the distraction force is negative, this indicates that there is medially $(-Z)$ directed force placed on the glenohumeral joint which may not be ideally orientated to a produce stabilizing force for the shoulder and instead creates strain on the surrounding muscle and tissues.

The two-dimensional angular deviations, $A_{1}, A_{2}$, and $A_{3}$, between the without-muscle and with-muscle resultant force vectors were calculated based on the specific cases that were seen from the obtained model output from the two model conditions. These cases deal with varying combinations of positive and negative reaction forces for both model conditions which result in differences in resultant force vector orientation and thus require a unique set of equations in order to calculate the angular deviation between the two vectors across all three anthropometric planes. A total of 13 unique cases were found and are detailed in Appendix E.

Note that the angular deviations $\mu, A_{1}, A_{2}$ and $A_{3}$ are normalized by their maximum expected angular deviation in order to standardize their values to range between zero and one. In this case the expected maximum angular deviation between the two vectors is $180^{\circ}$, which would mean that they are exactly opposite from one another, forming a straight line, with one vector pointing towards one direction and the other pointing in the exact opposite direction. Similarly, the change in the resultant force magnitude $\left(\frac{\left(M^{\prime}-M\right)}{\left(M^{\prime}-M\right)_{\max }}\right)$ between the two model conditions is normalized by the maximum difference observed for each participant in order to standardize this value to range between zero and one. The resultant force magnitude $\left(\frac{M^{\prime}}{\left(M^{\prime}\right)_{\max }}\right)$ for the withmuscle condition is normalized with respect to the maximum resultant force for each participant giving it a range between zero and one. The medial distraction force $\left(D I S_{\text {medial }}\right)$ is normalized to range between zero and one by taking the medial distraction force obtained for an exertion and dividing it by the maximum medial distraction force observed for the participant. Since the 
individual components of each strain index are set to vary between zero and one, the strain index scores will vary, with the highest potential strain index value equaling the number of individual strain index components that the equation contains. For example, strain index 4 has two individual components, $A_{2}$, representing the two-dimensional angular deviation between the with-muscle and without-muscle resultant force vectors in the frontal anatomical plane, and $\frac{\left(M^{\prime}-M\right)}{\left(M^{\prime}-M\right)_{\max }}$, which is the normalized resultant force magnitude difference. Since this strain index has two individual components, each capable of ranging from zero to one, the highest value that strain index 4 can achieve is two.

To demonstrate the proposed strain indices listed above, a forceful arm exertion performed in the superior $(+\mathrm{Y})$ direction at a force level of $40 \mathrm{~N}$ with the following data (Table 4.3) obtained from the biomechanical model output will be used as an example.

Table 4.3: Reaction forces at the glenohumeral joint obtained for a forceful arm exertion of $40 \mathrm{~N}$ performed in the superior direction $(+Y)$ and maximum resultant force values observed for the superior direction

\begin{tabular}{|c|c|}
\hline \multicolumn{2}{|c|}{ Resultant Force (N) } \\
\hline Without-muscle & With-muscle \\
\hline$F x=-3.16$ & $\mathrm{Fx}=-94.42$ \\
\hline $\mathrm{Fy}=70.12$ & $\mathrm{Fy}=331.37$ \\
\hline $\mathrm{Fz}=23.14$ & $\mathrm{Fz}=-368.83$ \\
\hline \multicolumn{2}{|c|}{ Maximum Resultant Force (N) } \\
\hline 94.05 & 1223.21 \\
\hline
\end{tabular}

The three-dimensional angular deviation, $\mu$, is calculated by using equation 4.1 . The twodimensional angular deviations, $A_{1}, A_{2}$ and $A_{3}$, are found by first examining the specific orientation the resultant force vector for each model condition by looking at the reaction force components acting in the three directions. In this example, the reaction forces fit the profile of case 2 (Appendix E) and the equations for $A_{1}, A_{2}$ and $A_{3}$ for this case are used. Substituting the 
reaction force values from Table 4.3 into the above listed equations yields the following angular deviations:

$$
\begin{aligned}
& 3 \mathrm{D}\left\{\begin{array}{l}
\text { dot product }=\cos ^{-1}\left(\frac{\left(f x * f x^{\prime}\right)+\left(f y * f y^{\prime}\right)+\left(f z * f y^{\prime}\right)}{\sqrt{\left(f x^{2}+f y^{2}+f z^{2}\right)} * \sqrt{\left(f x^{\prime 2}+f y^{\prime 2}+f z^{\prime 2}\right)}}\right) \\
=\cos ^{-1}\left(\frac{(-3.16 *-94.42)+(70.12 * 331.37)+(23.14 *-368.83)}{\sqrt{\left((-3.16)^{2}+70.12^{2}+23.14^{2}\right)} * \sqrt{\left((-94.42)^{2}+331.37^{2}+(-368.83)^{2}\right)}}\right)=66^{\circ}
\end{array}\right. \\
& \boldsymbol{\mu}=\frac{\text { dot product }}{180^{\circ}}=\frac{66^{\circ}}{180^{\circ}}=\mathbf{0 . 3 7} \\
& \alpha=\tan ^{-1}\left(\frac{f y}{f x}\right) ; \alpha=\tan ^{-1}\left(\frac{70.12}{-3.16}\right)=-87^{\circ} ; \alpha^{\prime}=\tan ^{-1}\left(\frac{331.37}{-94.42}\right)=-74^{\circ} \\
& \boldsymbol{A}_{1}=\frac{\left.\left(|\alpha|-\left|\alpha^{\prime}\right|\right)\right)}{180^{\circ}}=\frac{\left(\left|-87^{\circ}\right|-\left|-74^{\circ}\right|\right)}{180^{\circ}}=\mathbf{0 . 0 7} \\
& \beta=\tan ^{-1}\left(\frac{f z}{f y}\right) ; \beta=\tan ^{-1}\left(\frac{23.14}{70.12}\right)=18^{\circ} ; \beta^{\prime}=\tan ^{-1}\left(\frac{-368.83}{331.37}\right)=-48^{\circ} \\
& 2 \mathrm{D} \\
& \boldsymbol{A}_{2}=\frac{\left(|\beta|+\left|\beta^{\prime}\right|\right)}{180^{\circ}}=\frac{\left(\left|18^{\circ}\right|+\left|-48^{\circ}\right|\right)}{180^{\circ}}=\mathbf{0 . 3 7} \\
& \gamma=\tan ^{-1}\left(\frac{f x}{f z}\right) ; \gamma=\tan ^{-1}\left(\frac{-3.16}{23.14}\right)=-8^{\circ} ; \gamma^{\prime}=\tan ^{-1}\left(\frac{-94.42}{-368.83}\right)=14^{\circ} \\
& \boldsymbol{A}_{3}=\frac{\left(\left(90^{\circ}-|\gamma|\right)+\left(90^{\circ}-\left|\gamma^{\prime}\right|\right)\right)}{180^{\circ}}=\frac{\left(\left(90^{\circ}-\left|-8^{\circ}\right|\right)+\left(90^{\circ}-\left|14^{\circ}\right|\right)\right)}{180^{\circ}}=\mathbf{0 . 8 8}
\end{aligned}
$$

Next, the resultant force magnitude difference between the two model conditions is determined by calculating the resultant force for both the without-muscle (M) and with-muscle (M') model conditions using equation 4.2. These values are then subtracted from one another and 
then normalized by the maximum difference observed between the values for all forceful arm exertions in that particular direction for that participant as shown below:

$$
\begin{gathered}
M=\sqrt{\left(f x^{2}+f y^{2}+f z^{2}\right)}=\sqrt{\left((-3.16)^{2}+70.12^{2}+23.14^{2}\right)}=73.91 \\
M^{\prime}=\sqrt{\left(f{x^{\prime}}^{2}+f{y^{\prime}}^{2}+f{z^{\prime}}^{2}\right)}=\sqrt{\left((-94.42)^{2}+331.37^{2}+(-368.83)^{2}\right)}=504.73 \\
\frac{\left(\boldsymbol{M}^{\prime}-\boldsymbol{M}\right)}{\left(\boldsymbol{M}^{\prime}-\boldsymbol{M}\right)_{\max }}=\frac{(504.73-73.91)}{(1223.21-94.05)}=\mathbf{0 . 3 8}
\end{gathered}
$$

The normalized resultant force magnitude is calculated by simply taking the resultant force as calculated above and dividing it by the maximum resultant force.

$$
\frac{\boldsymbol{M}^{\prime}}{\left(\boldsymbol{M}^{\prime}\right)_{\max }}=\frac{504.73}{1223.21}=\mathbf{0 . 4 1}
$$

Table 4.4: Example problem strain index values

\begin{tabular}{|c|c|}
\hline $\begin{array}{c}\text { Strain } \\
\text { Index: }\end{array}$ & $\begin{array}{c}\text { Example Problem } \\
\text { Strain Index Value: }\end{array}$ \\
\hline 1 & 0.37 \\
\hline 2 & 0.75 \\
\hline 3 & 0.37 \\
\hline 4 & 0.75 \\
\hline 5 & 1.32 \\
\hline 6 & 1.70 \\
\hline 7 & 1.12 \\
\hline 8 & 2.07 \\
\hline 9 & 0.78 \\
\hline
\end{tabular}


For this particular exertion, the distraction forces $(\mathrm{Fz})$ for the without-muscle condition are positive indicating that they are directed laterally outward. Therefore, the medial distraction force in this case is zero.

With these initial strain index components calculated for the example problem, they are then substituted into the above listed strain index equations (Table 4.2) to obtain the total strain index values (Table 4.4).

\subsubsection{Statistical Analysis}

In total, each participant performed 54 randomized experimental trials (6 directions $\times 3$ force exertion levels $\times 3$ repetitions) during the experiment. Three repetitions were averaged together for the statistical analysis.

\subsubsection{Statistical Model}

This research evaluated how the varying levels of force, the direction of applied exertion, and gender alter the calculated strain index for the shoulder complex. The statistical model for this is shown below:

$y R_{i j k l}=\mu+\alpha_{i}+\beta_{j}+\tau_{k}+\gamma_{l}+(\alpha \beta)_{i j}+(\alpha \tau)_{i k}+(\beta \tau)_{j k}+(\alpha \beta \tau)_{i j k}+\epsilon_{i j k l}\left\{\begin{array}{l}i=1, \ldots, a \\ j=1, \ldots, b \\ k=1, \ldots, c \\ l=1, \ldots, n\end{array}\right.$

Where,

$y R$ represents the strain index for the forceful arm exertions.

$\mu$ is the overall mean common to all treatments.

$\alpha_{i}$ is the effect of direction of force exertion at $+\mathrm{X},-\mathrm{X},+\mathrm{Y},-\mathrm{Y},+\mathrm{Z},-\mathrm{Z}$, so $i=1,2,3,4,5,6$.

$\beta_{j}$ is the effect of force exertion level at 20,40 , and $60 \mathrm{~N}$, so $j=1,2,3$.

$\tau_{k}$ is the effect of gender, so $k=1,2$. 
$\gamma_{l}$ is the effect of participants (block), $n$ represents the number of participants recruited in the study.

$(\alpha \beta)_{i j}$ is the interaction effect of direction of force exertion and force exertion level.

$(\alpha \tau)_{i k}$ is the interaction effect of direction of force exertion and gender.

$(\beta \tau)_{j k}$ is the interaction effect of force exertion level and gender.

$(\alpha \beta \tau)_{i j k}$ is the three-way interaction effect of direction of force exertion, force exertion level,

and gender.

$\epsilon_{i j k l}$ is a random error term.

In the model, the direction of force exertion $\left(\alpha_{i}\right)$, force exertion level $\left(\beta_{j}\right)$, and gender $\left(\tau_{k}\right)$ are treated as fixed factors. It is assumed that each factor and the two-way or three-way interaction factors have no effect on the calculated strain index. That is:

$$
\begin{gathered}
\sum_{i=1}^{a} \alpha_{i}=0, \quad \sum_{j=1}^{b} \beta_{j}=0, \quad \sum_{k=1}^{c} \tau_{k}=0 \\
\sum_{i=1}^{a} \sum_{j=1}^{b}(\alpha \beta)_{i j}=0, \quad \sum_{i=1}^{a} \sum_{k=1}^{c}(\alpha \tau)_{i k}=0, \quad \sum_{j=1}^{b} \sum_{k=1}^{c}(\beta \tau)_{j k}=0, \\
\sum_{i=1}^{a} \sum_{j=1}^{b} \sum_{k=1}^{c}(\alpha \beta \tau)_{i j k}=0
\end{gathered}
$$

Participants $\left(\gamma_{l}\right)$ are treated as a random factor and it is assumed that it is a normally and independently distributed (NID) $\left(0, \sigma_{\gamma}{ }^{2}\right)$ random variable. The random error $\epsilon_{i j k l}$ is also assumed to also follow $\operatorname{NID}\left(0, \sigma^{2}\right)$. 
The appropriate $F$ tests were applied in testing if the means of the fixed factor effects were equal to zero:

$$
\begin{gathered}
H_{0}: \alpha_{i}=0, \beta_{j}=0, \tau_{k}=0 \text { and } \\
(\alpha \beta)_{i j}=0,(\alpha \tau)_{i k}=0,(\beta \tau)_{j k}=0, \text { and }(\alpha \beta \tau)_{i j k}=0, \\
H_{1} \text { : at least one } \alpha_{i} \neq 0, \beta_{j} \neq 0, \tau_{k} \neq 0 \text { and } \\
\text { at least one }(\alpha \beta)_{i j} \neq 0,(\alpha \tau)_{i k} \neq 0,(\beta \tau)_{j k} \neq 0 \text {, and }(\alpha \beta \tau)_{i j k} \neq 0
\end{gathered}
$$

Appropriate $F$ tests were also applied in testing the variance of the random factor, $H_{0}$ :

$\sigma_{\gamma}{ }^{2}=0$. The Type I error probability, $\alpha=0.05$, and Power of the test (1- $\beta$ ), which equals 0.90 , were chosen for hypothesis testing and sample size determination discussed is in 4.6.2.2.

Significant effects were further evaluated by conducting comparison between means using Tukey's Honestly Significant Difference (HSD) all-pairwise comparison test. For fixed factors such as direction of force exertion and force exertion level, if the null hypothesis was rejected, the factors' effects were estimated. Minitab 16 statistical analysis software (Minitab Inc., PA, USA) was used to perform the statistical analysis.

\subsubsection{Power Analysis and Sample Size Determination}

The choice of sample size is an important component in the experimental design. Operating characteristics curves (OC curves) can be used to provide guidance in making this selection. As a plot of the probability of a type II error $(\beta)$ for various samples sizes against a measure of the difference in means, OC curves were used in this study to conduct a power analysis to determine the number of participants to be recruited for this research. 
The random factor, participant $\left(\gamma_{l}\right)$, is treated as a block, so determining the number of participants is actually calculating the number of blocks. For the model the OC curves are used with the formula:

$$
\lambda=\sqrt{1+\frac{c \sigma_{\gamma}^{2}}{\sigma^{2}}}
$$

Where,

$$
\sigma_{\gamma}^{2}=M S B L, \quad \sigma^{2}=M S E
$$

Preliminary data collected from four participants $(c=4)($ Cutlip et al., 2014) were used to calculate $M S B L$ and $M S E$.

Table 4.5 shows the power for different numbers of participants. Note that five participants give a $\beta$ risk of about 0.025 , or a power of $97.5 \%$. Therefore, five participants were sufficient for the current study. However, the sample size was increased to 7 participants per gender to guard against the possibility that the prior estimate of the standard deviation was too conservative. Appendix D shows more detailed calculations of the sample size required to achieve the required power of at least 0.90 .

Table 4.5: Power values for different number of participants.

\begin{tabular}{|c|c|c|c|}
\hline $\mathrm{c}$ & $\lambda$ & $\beta$ & Power $(1-\beta)$ \\
\hline 2 & 2.96 & 0.75 & 0.25 \\
\hline 3 & 3.56 & 0.23 & 0.77 \\
\hline 4 & 4.07 & 0.175 & 0.825 \\
\hline 5 & 4.52 & 0.025 & 0.975 \\
\hline
\end{tabular}




\subsubsection{Missing Values}

If observations were missing from the data, their values were estimated by writing the error sum of squares as a function of the missing values, differentiating with respect to each missing value, equating the results to zero, and solving the resulting equations. Alternatively, the missing values could be obtained iteratively by first arbitrarily estimating the first missing value and then using this value with the rest of the data to estimate the second. The first value could then be re-estimated, followed by the second, and so on until convergence could be obtained (Montgomery, 2012).

In this study, two missing values were encountered. The first missing value was for subject number six for the lateral $(+Z) 60 \mathrm{~N}$ condition. The second was for subject number nine for the same condition (lateral $(+Z) 60 \mathrm{~N}$ ). Both of these missing values were due to the fact that both of the subjects had difficulty in maintaining the required force level.

\subsubsection{Data Transformation}

If the data proved to not follow a normal distribution, it was transformed in order to achieve normality to complete the statistical analysis. Several commonly used transforms such as square root, logarithmic, power, and reciprocal transformations were first utilized to try and

achieve normality (Bartlett, 1947; Montgomery, 2012). If the above transforms failed to improve normality, the Johnson transformation was the next method used. The Johnson transformation optimally selects a function from three "families" of distributions for a variable (Johnson, 1949). 
The general form of the transformation is given by:

$$
\begin{gathered}
z=\gamma+\eta * \tau(x ; \varepsilon, \lambda) \\
\eta>0, \quad-\infty<\gamma<\infty \\
\lambda>0, \quad-\infty<\varepsilon<\infty
\end{gathered}
$$

Where $\mathrm{z}$ is a standard normal variable and $\mathrm{x}$ is the variable to be fitted by a Johnson family distribution. The four parameters, $\gamma, \eta, \varepsilon$, and $\lambda$ are estimated values and $\tau$ is an arbitrary function which may take on one of the functions of the Johnson family.

The Johnson distributions are labeled as SB, SL, and SU, and refer to the variable being bounded, lognormal, and unbounded, respectively (Table 4.6).

Table 4.6: Johnson transform families and corresponding functions

\begin{tabular}{|c|c|}
\hline Johnson Family: & Transformation Function: \\
\hline SB & $\gamma+\eta * \ln \left[\frac{(x-\varepsilon)}{(\lambda+\varepsilon-x)}\right]$ \\
\hline SL & $\gamma+\eta * \ln (x-\varepsilon)$ \\
\hline SU & $\gamma+\eta * \sinh ^{-1}\left[\frac{(x-\varepsilon)}{\lambda}\right]$ \\
& $\begin{array}{c}\text { where, } \\
\sinh ^{-1}(x)=\ln \left[x+\sqrt{1+x^{2}}\right]\end{array}$ \\
\hline
\end{tabular}

Minitab has a built-in function for the Johnson transformation and selects the most appropriate transformation function from the Johnson family as well as the four parameter values that will achieve the highest normality. 


\section{Chapter 5: Results}

\subsection{Resultant Force Orientation Cases}

The specific resultant force orientation cases for each direction are summarized in Table 5.1 The most common cases seen for each of the six directions was case 1 for the anterior $(+\mathrm{X})$ direction, case 2 for the superior $(+Y)$, lateral $(+Z)$, and posterior $(-X)$ directions, case 9 for the inferior (-Y) direction, and case 6 for the medial $(-Z)$ direction..

Table 5.1: Resultant force orientation

\begin{tabular}{|c|c|c|c|c|c|c|c|c|c|c|c|c|c|}
\cline { 2 - 17 } \multicolumn{1}{c|}{} & \multicolumn{10}{c|}{} & \multicolumn{10}{c|}{ Case } \\
\hline Direction & 1 & 2 & 3 & 4 & 5 & 6 & 7 & 8 & 9 & 10 & 11 & 12 & 13 \\
\hline$+\mathrm{X}$ & 114 & 10 & 6 & 2 & - & - & - & 2 & - & - & - & - & - \\
\hline$+\mathrm{Y}$ & 21 & 104 & - & - & - & - & - & - & - & 9 & 1 & - & - \\
\hline$+\mathrm{Z}$ & 6 & 109 & - & - & - & - & 8 & - & - & - & - & - & - \\
\hline$-\mathrm{X}$ & 26 & 59 & 18 & 30 & - & - & - & 1 & - & - & 1 & - & - \\
\hline$-\mathrm{Y}$ & 20 & 23 & 3 & 7 & 25 & 8 & 2 & 12 & 34 & - & - & - & 1 \\
\hline$-\mathrm{Z}$ & - & - & - & 37 & - & 90 & - & - & - & - & - & 5 & - \\
\hline
\end{tabular}

\subsection{Data Normality}

The strain index and perceived exertion rating data did not appear to follow a normal distribution. The results of the Anderson-Darling test are presented in Appendix F. Square root, logarithmic, power, and reciprocal transformations were applied but did not improve the normality. Finally Johnson transformation was applied to the perceived exertion ratings and strain index 9 in order to achieve normality (see section 5.4 for reason why strain index 9 was selected for normalization). A bounded (SB) type distribution of Johnson transformation accomplished the normality for both the strain index scores and perceived exertion ratings data. The exact optimal transformation function as well as parameter values for each data set are shown in Table 5.2. 
Table 5.2: Johnson transformation for strain index and perceived exertion rating data

\begin{tabular}{|c|c|c|}
\hline & Strain Index 9 & Perceived Exertion Ratings \\
\hline Johnson transform type & $\mathrm{SB}$ & $\mathrm{SB}$ \\
\hline $\begin{array}{c}\text { Johnson transformation } \\
\text { function }\end{array}$ & $\begin{array}{c}1.40301+0.907729 \\
\text { (n }\left[\frac{(x-0.404140)}{(2.67575-x)}\right]\end{array}$ & $* \ln \left[\frac{(x+1.30001)}{(48.0509-x)}\right]$ \\
\hline$\gamma$ & 1.40301 & 3.88816 \\
\hline$\eta$ & 0.907729 & 1.70278 \\
\hline$\varepsilon$ & 0.404140 & -1.30001 \\
\hline$\lambda$ & 2.27161 & 49.35091 \\
\hline $\begin{array}{c}\text { p-value } \\
\text { before transformation }\end{array}$ & $<0.005$ & $<0.005$ \\
\hline $\begin{array}{c}\mathrm{p} \text {-value } \\
\text { after transformation }\end{array}$ & 0.796 & 0.093 \\
\hline
\end{tabular}

The newly transformed data had improved p-values that were sufficient to assume that the data now followed an approximately normal distribution.

For the transformed data, the equality of variance test using the multiple comparison test showed that the assumption of the homoscedasticity condition was valid (Appendix F)

\subsection{Maximum Strength}

As part of ensuring that participants were able to perform the exertions required in this study, strength data for each participant were collected. The mean maximum forces that participants were able to exert in six anatomical directions are shown in Table 5.3. Statistics related to strength data is not reported as it was not within the focus of this study. Data for individual participants can be found in Appendix J. 
Table 5.3: Average (SD) maximum strength (N)

\begin{tabular}{|c|c|c|c|}
\cline { 2 - 3 } \multicolumn{1}{c|}{} & \multicolumn{2}{c|}{ Gender } & \multirow{2}{*}{ All } \\
\hline \multirow{2}{*}{ Direction } & Male & Female & \multirow{2}{*}{$246.46(12.88)$} \\
\hline$+\mathrm{X}$ & $276.64(13.56)$ & $211.97(12.10)$ & $98.78(4.57)$ \\
\hline$+\mathrm{Y}$ & $110.48(4.49)$ & $85.41(4.65)$ & $84.01(4.09)$ \\
\hline$+\mathrm{Z}$ & $94.16(5.26)$ & $72.41(2.75)$ & $138.28(3.57)$ \\
\hline$-\mathrm{X}$ & $152.47(3.61)$ & $122.06(3.53)$ & $248.85(11.28)$ \\
\hline$-\mathrm{Y}$ & $271.23(13.00)$ & $223.28(9.32)$ & $130.73(5.44)$ \\
\hline$-\mathrm{Z}$ & $145.73(4.30)$ & $113.59(6.74)$ & \\
\hline
\end{tabular}

In general the participants displayed high strength $(148.5-328.1 \mathrm{~N})$ in the anterior $(+\mathrm{X})$ and inferior $(-\mathrm{Y})$ directions. Medium strength $(83.10-225.6 \mathrm{~N})$ was observed for the posterior $(-\mathrm{X})$ and medial $(-\mathrm{Z})$ directions. Strengths were low $(57.8-144.8 \mathrm{~N})$ in the superior $(+\mathrm{Y})$ and medial $(+Z)$ directions. Higher strength capability was observed for males compared to females (Figure 5.1).

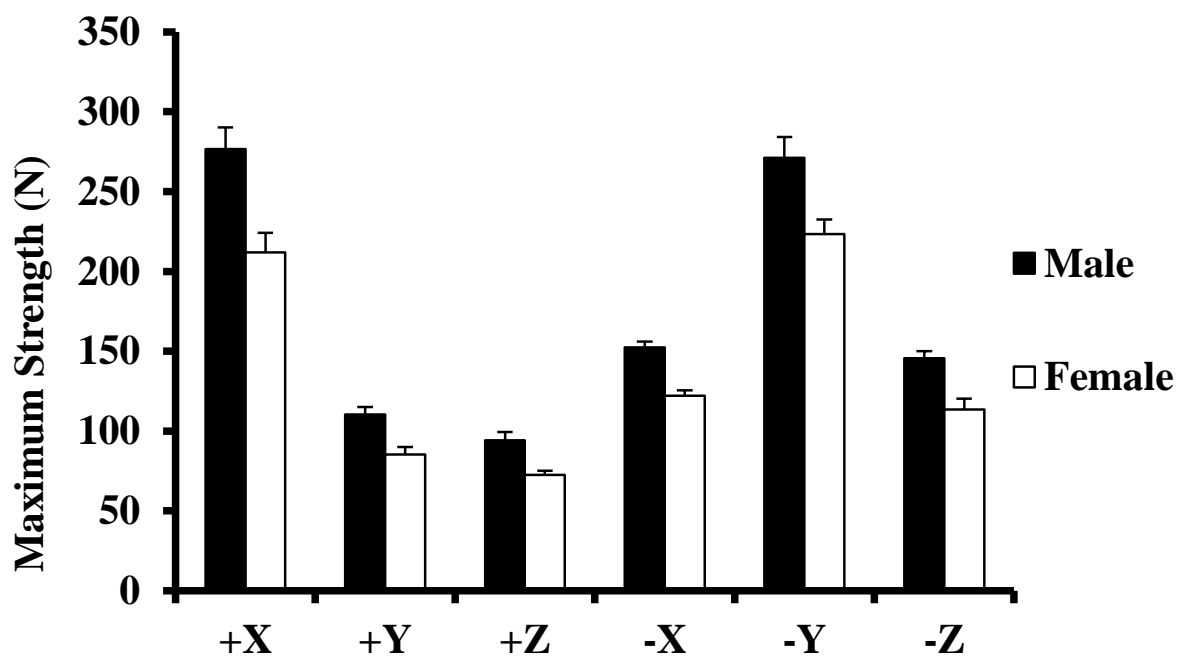

Direction of Force Exertion

Figure 5.1: Mean maximum strength by the direction of force exertion. Error bars represent one standard deviation 


\subsection{Strain Indices and Perceived Exertion Rating}

Correlation analysis showed that out of the nine proposed strain indices, strain indices 2 , $4,6,7,8$, and 9 displayed significant correlation with the ratings of perceived exertion while strain indices 1, 3, and 5 failed to show any form of relationship (Table 5.4).

Table 5.4: Correlation strength between strain index values and perceived exertion ratings

\begin{tabular}{|c|c|c|}
\hline $\begin{array}{c}\text { Strain } \\
\text { Index: }\end{array}$ & Correlation Coefficient: & P-value: \\
\hline 1 & 0.01 & $\mathrm{p}=0.868$ \\
\hline 2 & 0.52 & $\mathrm{p}<0.001$ \\
\hline 3 & 0.07 & $\mathrm{p}=0.261$ \\
\hline 4 & 0.55 & $\mathrm{p}<0.001$ \\
\hline 5 & -0.07 & $\mathrm{p}=0.227$ \\
\hline 6 & 0.26 & $\mathrm{p}<0.001$ \\
\hline 7 & 0.43 & $\mathrm{p}<0.001$ \\
\hline 8 & 0.20 & $\mathrm{p}<0.001$ \\
\hline 9 & 0.70 & $\mathrm{p}<0.001$ \\
\hline
\end{tabular}

The strain index that displayed the strongest correlation with the perceived exertion ratings was selected for further analysis. In this case, strain index 9 was chosen as it displayed the highest correlation (0.70) to test the effects of direction and magnitude of force exertion, and gender.

The trend between the perceived exertion ratings and strain index 9 showed that the strain index scores followed a pattern similar to the exertion ratings (Figure 5.2). The highest strain index scores occurred in the medial $(-Z)$ direction and were accompanied by higher perceived exertion ratings. Additionally, as the force level increased, both the strain index scores and perceived exertion ratings increased in response. 


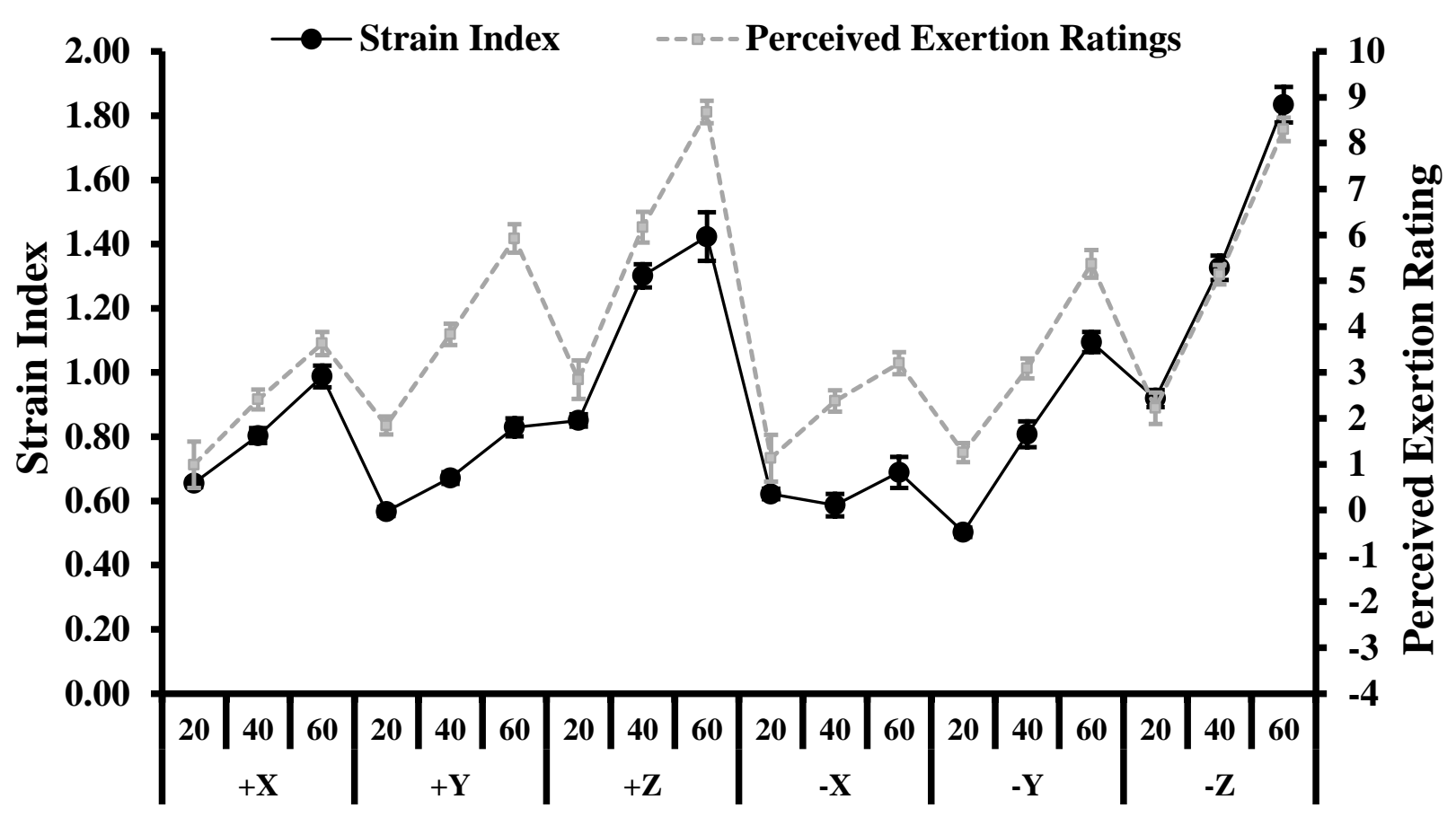

Figure 5.2: Correlation between strain index scores and perceived exertion. Error bars represent $\mathbf{9 5 \%}$ confidence interval

\subsection{Strain Index and the Effect of Direction, Force Level, and Gender}

Table 5.5: Main effects table

\begin{tabular}{|l|l|c|}
\hline Source & Mean (SD) & P-value \\
\hline Gender & $0.90(0.38)$ & 0.070 \\
Male & $0.93(0.39)$ & \\
Female & $0.82(0.18)$ & \\
\hline Direction & $0.69(0.15)$ & \\
$+\mathrm{X}$ & $1.19(0.34)$ & $<0.001$ \\
$+\mathrm{Y}$ & $0.63(0.17)$ & \\
$+\mathrm{Z}$ & $0.80(0.28)$ & \\
$-\mathrm{X}$ & $1.36(0.43)$ & \\
$-\mathrm{Y}$ & & \\
$-\mathrm{Z}$ & $0.69(0.17)$ & \\
\hline Force Level & $0.92(0.33)$ & $<0.001$ \\
$20 \mathrm{~N}$ & $1.14(0.45)$ & \\
$40 \mathrm{~N}$ &
\end{tabular}


The effect of gender on the strain index scores was statistically insignificant $(p=0.070)$

(Table 5.5) and were not further evaluated with respect to the direction of force exertion or force exertion level.

(a) Transformed data

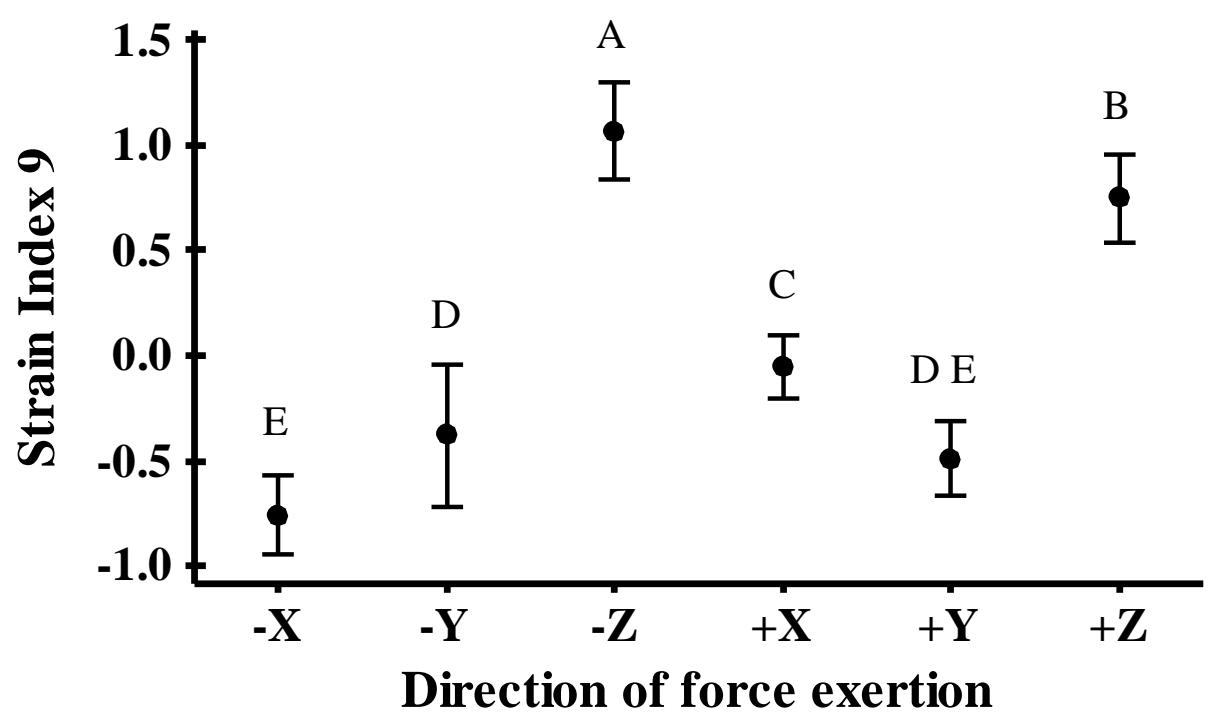

(b) Back transformed data

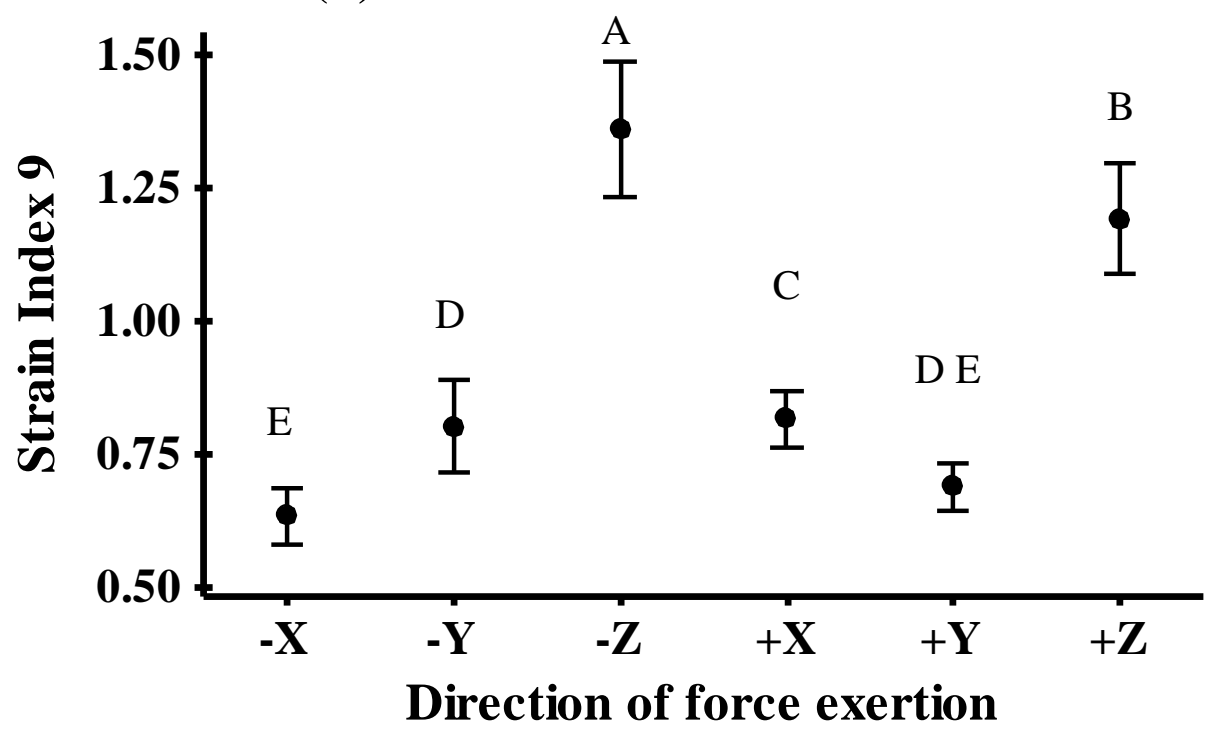

Figure 5.3: Mean strain index scores vs. direction of force exertion. Means that do not share a letter are significantly different. Error bars represent $95 \%$ confidence interval 
The strain index scores were significantly affected by the direction of force exertion $(\mathrm{p}<0.001)$ (Table 5.5). In general, an average trend showed high strain index scores for forceful arm exertions performed in the lateral $(+Z)$ and medial $(-Z)$ directions while the low scores were typically seen in the posterior $(-\mathrm{X})$ and superior $(+\mathrm{Y})$ directions.

Post hoc analysis also showed that the strain index scores for the forceful exertions in the lateral $(+Z)$, medial $(-Z)$, and anterior $(+X)$ directions were significantly different from one another and from the exertions performed in the other directions (Figure 5.3). The strain index scores for the exertions performed in the superior $(+Y)$ direction were not found to be different from inferior (-Y) or posterior (-X) exertions while the strain index scores for the latter two were different from each other.

The strain index scores were also significantly affected by the force exertion level $(\mathrm{p}<0.001)$ (Table 5.5). As expected, an increase in the force exertion level significantly increased the strain index scores. Results of post hoc analysis also showed that all three force exertion levels were significantly different from one another (Figure 5.4).

The two-way interaction between the direction of force exertion and force exertion level was found to be significant $(\mathrm{p}<0.001)$ (Figure 5.5). For exertions performed in some directions an increase in the force exertion level resulted in an increase in the strain index scores. For exertions performed in the superior $(+Y)$, inferior $(-Y)$, and medial $(-Z)$ directions, the strain index scores increased with the force exertion level at each level $(20,40,60 \mathrm{~N})$ and displayed a clear, linear trend. For other directions, however, the strain index did not appear to follow a linear trend with the force exertion level. For the anterior $(+X)$ and lateral $(+Z)$ directions, the strain index increased between 20 and $40 \mathrm{~N}$ but not between 40 and $60 \mathrm{~N}$. No change in strain index score was observed for exertions in the posterior $(-X)$ direction for all force levels. 
(a) Transformed data

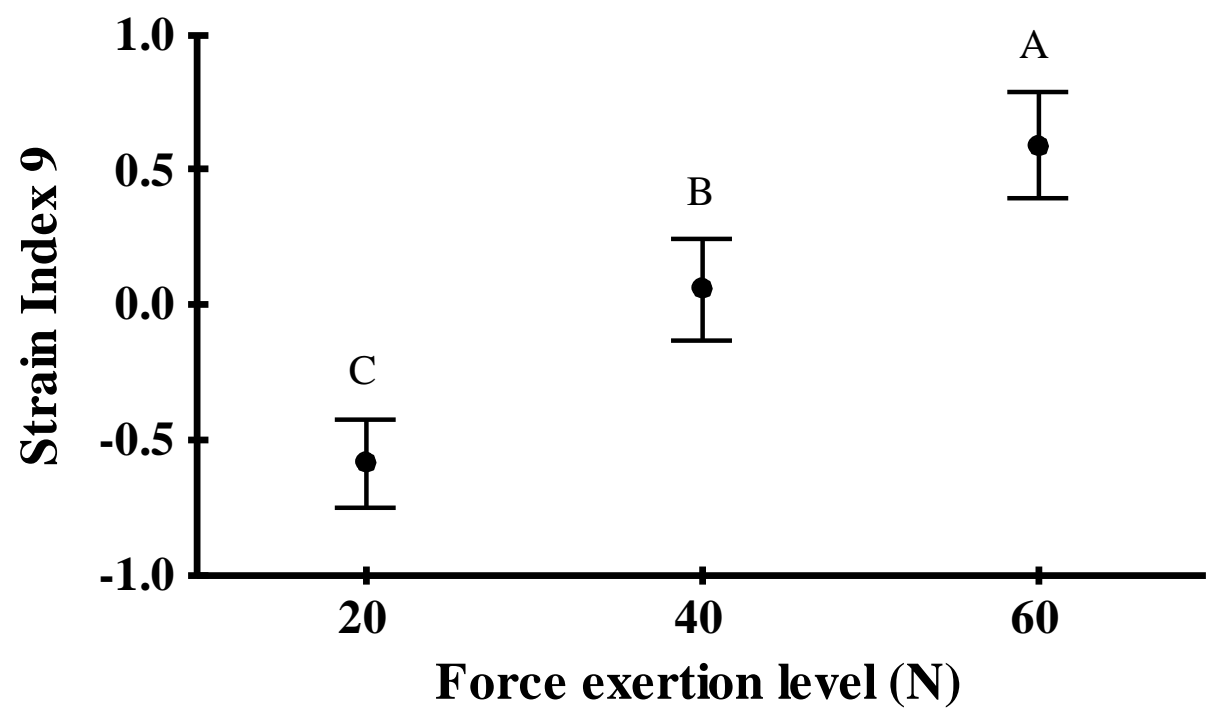

(b) Back transformed data

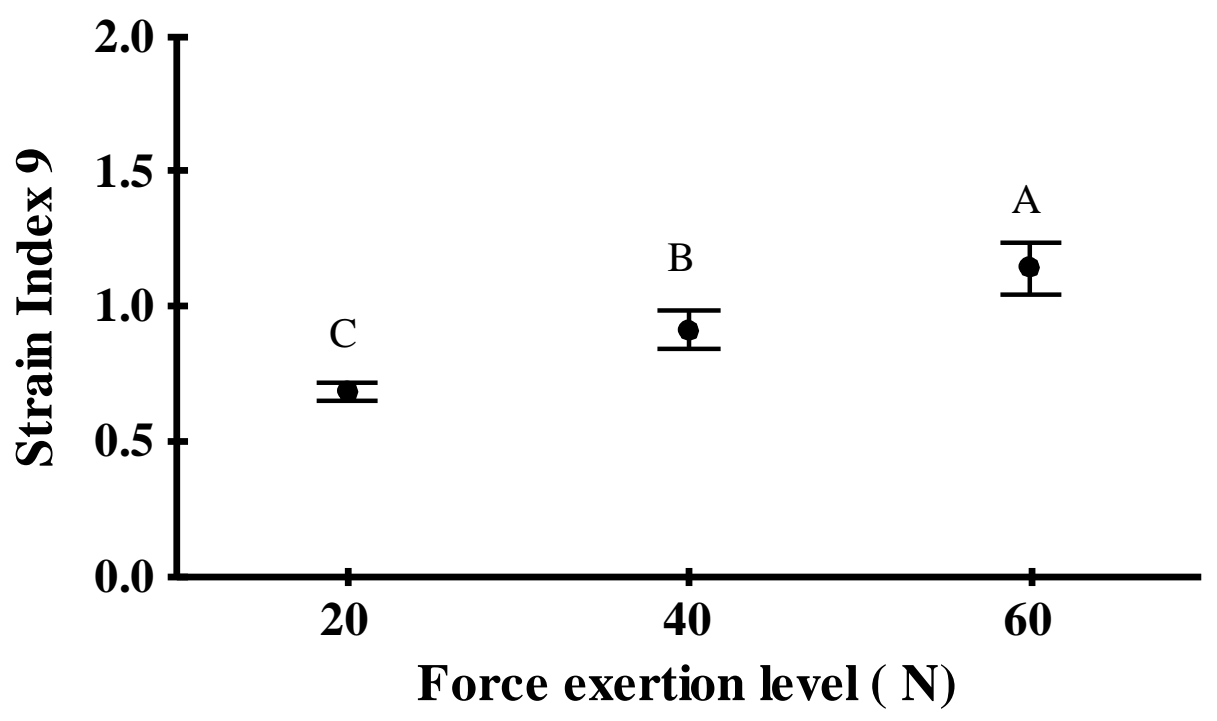

Figure 5.4: Mean strain index scores vs. force exertion level. Means that do not share a letter are significantly different. Error bars represent $95 \%$ confidence interval 
(a) Transformed data

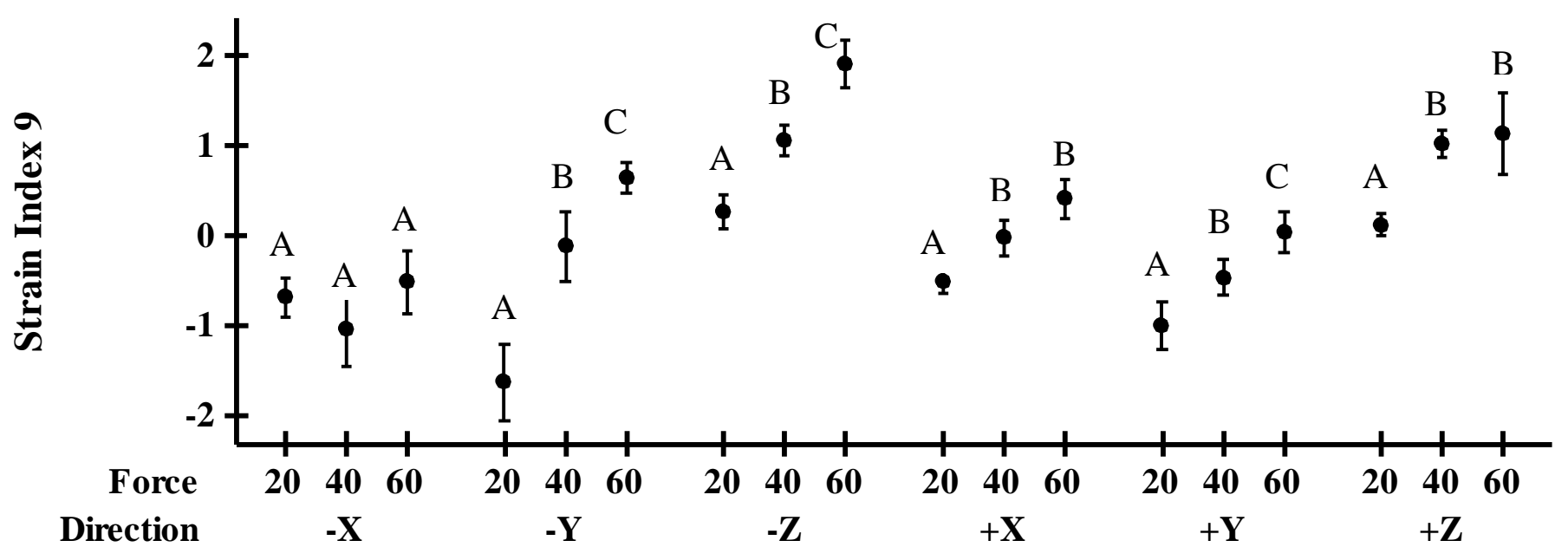

(b) Back transformed data

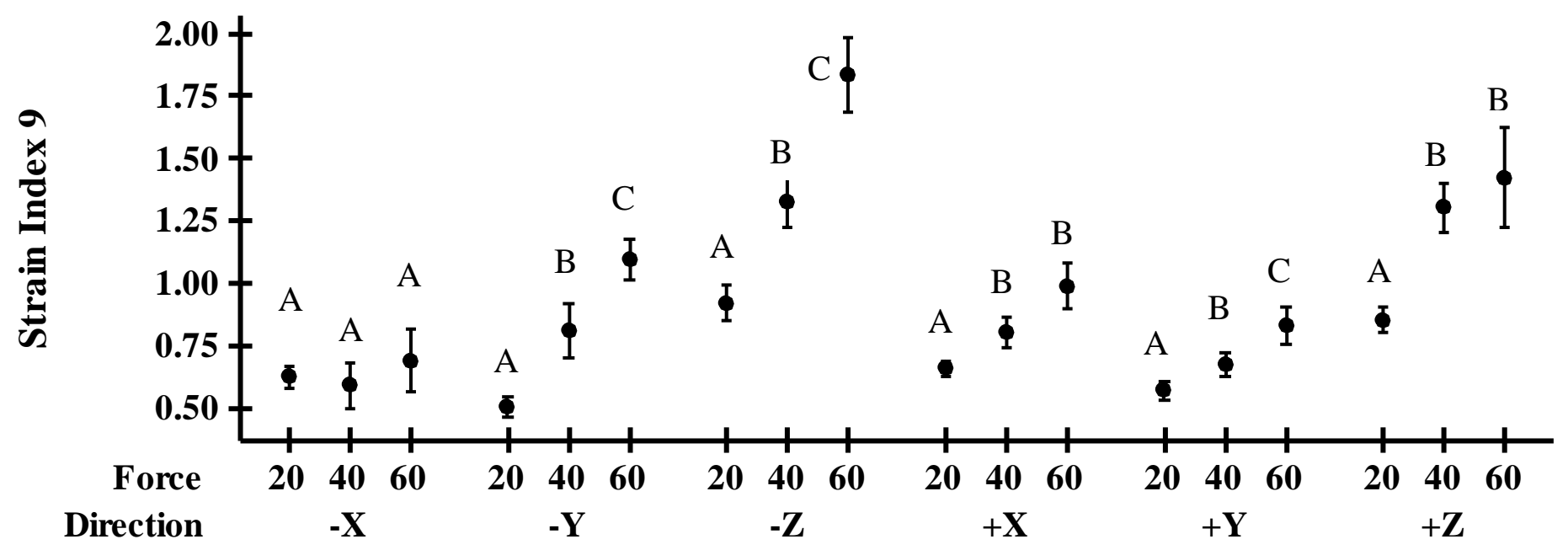

Figure 5.5: Interaction effect between direction of force exertion and force exertion level. Means that do not share a letter are significantly different. Error bars represent $95 \%$ confidence interval 


\section{Chapter 6: Discussion and Conclusion}

In this study strain indices were developed to describe the work demand placed on the shoulder during a forceful arm exertion. Biomechanical measurements based on the concept of concavity compression mechanism were used in the development of these strain indices. Examples of some of these measurements include reaction forces, angular deviation of the resultant reaction force vectors, and magnitude of muscle forces.

The indices that were based purely on the angular deviation between the two resultant force vectors (without-muscle and with-muscle) failed to exhibit a strong relationship with the participant perceived exertion ratings. This was due to the fact that the resultant force vectors generated by the shoulder muscles were almost always directed posteriorly, medially, and superiorly, independent of the level of external force application in order to promote concavity compression (Figure 6.1). However, the magnitude of muscle force vector changed with the increase in the level of force exertion.
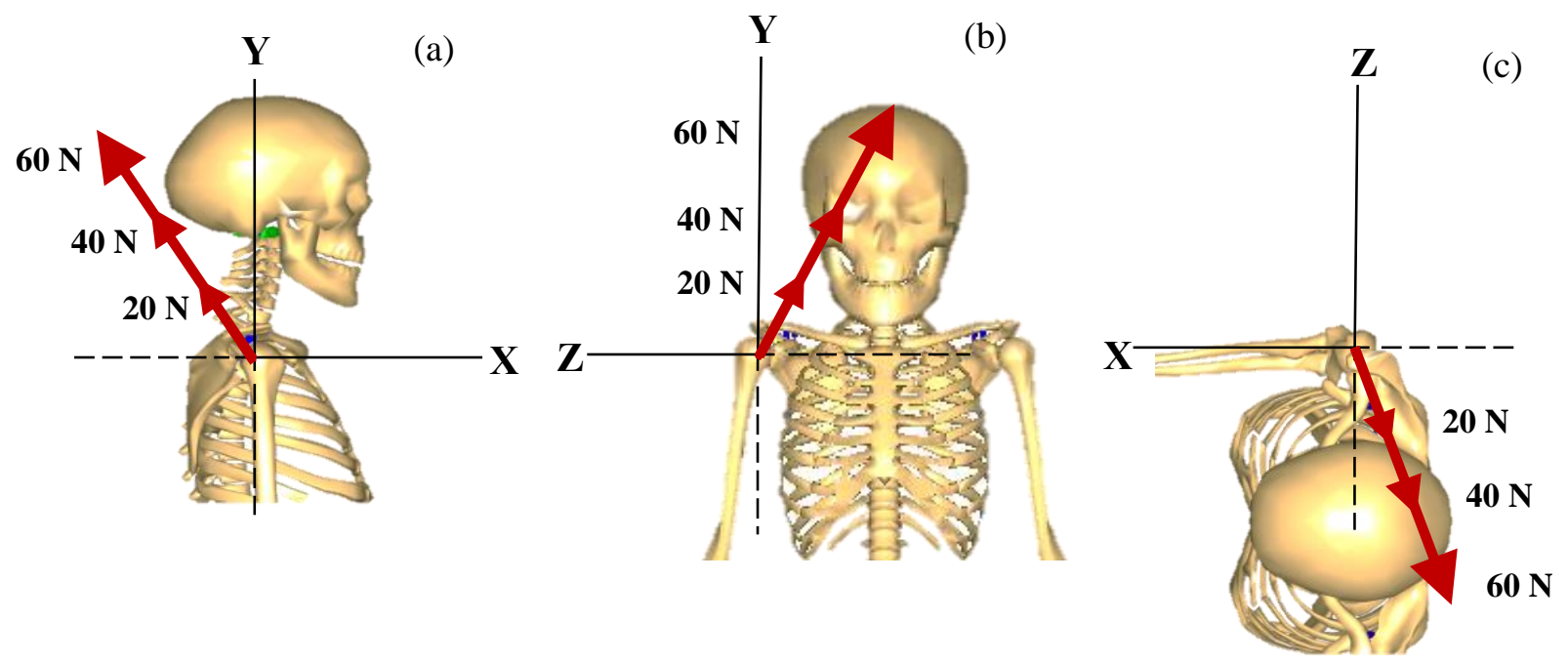

Figure 6.1: General orientation of the shoulder muscle resultant force vector in the (a) sagittal, (b) frontal, and (c) transverse plane 
The ability of the proposed strain indices to predict strain experienced by the shoulder complex during forceful arm exertions was evaluated by performing a correlation analysis between the strain index scores and the ratings of perceived exertion. Although there are no set rules for describing the correlation strength between variables, there are some guidelines that can be used to help roughly define the strength of association. The Salkin scale uses the following ranges to rate the strength of the correlation coefficient, $r$, between variables: very strong relationship $(0.80 \leq \mathrm{r} \leq 1)$, strong relationship $(0.60 \leq \mathrm{r}<0.80)$, moderate relationship $(0.40 \leq \mathrm{r}<$ 0.60), weak relationship $(0.20 \leq \mathrm{r}<0.40)$, and very weak or no relationship $(0.20<\mathrm{r} \leq 0)$ (Green et al., 2000). Another scale by Cohen (1988) rates the effect size as small ( $r \geq 0.10)$, medium ( $r$ $\geq 0.30)$, and large $(r \geq 0.50)$.

Based on the aforementioned correlation strength criterion, strain index $9(\mathrm{r}=0.70)$ showed a strong relationship with the perceived exertion ratings. An effect size was also found to be large between strain index 9 and the ratings of perceived exertion. This strain index was comprised of three normalized components: (1) angular deviation between the resultant force vectors (without-muscle and with-muscle) in the frontal plane $\left(A_{2}\right),(2)$ resultant reaction force acting on the glenohumeral joint due to the muscle activation, and (3) compression force generated as reaction due to the exertion of external force (i.e. force acting in the distraction direction under the without-muscle condition).

The angular deviation in the frontal plane is likely produced by the action of the major shoulder muscles that are located mediolaterally. There are several major shoulder muscles such as the pectoralis major, subscapularis, rhomboids, trapezius, infraspinatus, and supraspinatus that are located mediolaterally within the frontal plane (Culham and Peat, 1993). Together, these muscles and their collective activation to improve the concavity compression by pulling the 
humeral head into glenoid may produce a substantial amount of stress on the shoulder complex. The angular deviation in the frontal plane used in the calculation of the proposed strain index is a possible measurement of that strain.

The resultant reaction force, another component used in the computation of strain index 9, is a proven measure of joint strain. Several studies have established that joint reaction forces are directly associated with the risk of injury. The lifting equation developed by NIOSH uses compression and shear forces on the lumbosacral joint as risk assessment criterion to evaluate the potential for injury during lifting tasks (Waters et al., 1993; Waters et al., 1994). The resultant reaction force due to the muscle activation is a direct measure of the work done by the muscles as they attempt to stabilize a joint against the forces caused by external loading.

In addition to the components based on the angular deviation and the magnitude of resultant reaction forces, a compression force component was included in the strain index. This component is independent of the muscle force and primarily assesses the contact pressure between the humeral head and glenoid produced as a result of the reaction due to external force application (i.e. model output under without-muscle condition). Although compression of the humeral head against the glenoid is desirable and most of the shoulder complex muscles strive to achieve it, there seems to be a lack of a mechanism that could prevent the passive compression (pinching) of the musculature. This is especially critical and strenuous if the reaction force due to the external force application pinches the passive structures (joint capsule, ligaments, etc.) which can potentially lead to tendinitis, rotator cuff tears, nerve impingement, etc. (Staal et al., 2007; van Rijn et al., 2010). The compression force in the distraction direction included in strain index 9 measures this strain on the passive tissues. 
The direction of force exertion had a notable effect on the calculated strain index scores. The highest strain index scores were generally observed for exertions performed in the lateral $(+Z)$ and medial $(-Z)$ directions. For the lateral $(+Z)$ exertions, the resultant forces due to the external loading (without-muscle condition) were largely directed laterally outward from the shoulder in the distraction direction. In order to counteract this, the forces generated by the shoulder muscles redirect the resultant force in towards the shoulder socket to improve joint stability through the concavity compression mechanism. The shoulder muscles have to work under duress to achieve this change in orientation of the resultant force, resulting in high strain index scores. Exertions in the medial (-Z) direction however created increased contact pressure between the humeral head and glenoid leading to greater strain in the surrounding passive tissues and resulting in higher strain index scores. These findings for the mediolateral direction and the high level of strain they impose is consistent with a previous study by Haslegrave (2004) who also reported that exerting force in either the medial or lateral direction should be avoided as the body encounters difficulty in maintaining stability. On the other hand, exertions such as those performed in the posterior $(-\mathrm{X})$ direction resulted in both lower strain index scores. The resultant forces due to the external loading (without-muscle condition) for these exertions were oftentimes oriented posteriorly, medially, and superiorly (see case 4 in Appendix E) and therefore required less effort for the shoulder muscles to redirect towards the shoulder socket, resulting in lower strain index scores.

The force exertion level also had a considerable, but unsurprising, effect on the strain index scores. A clear pattern could be seen that as the force exertion level increased, the strain index scores increased in turn. However, the relationship between the strain index scores and the force exertion level was not comparable between different directions. For the exertions 
performed in the medial-lateral directions, strain index scores (range: $0.63-1.09$ ) for the $20 \mathrm{~N}$ force level condition were much higher than the other directions. Furthermore, exertions performed in these directions also exhibited a much higher increment in the strain index scores for every $20 \mathrm{~N}$ increase in the force. On the other hand for exertions performed in the posterior ($\mathrm{X})$ and superior $(+\mathrm{Y})$ directions, even a $60 \mathrm{~N}$ exertion produced low strain index scores (range: $0.44-0.74)$. This finding suggests that forceful exertions performed in certain directions may potentially impose a higher amount of strain on the shoulder. The risk of injury due to such exertions could be high if performed repetitively or for a prolonged duration both of which are risk factors for the development of shoulder MSDs (da Costa and Vieira, 2010; Nordander et al., 2009; van der Windt et al., 2000; van Rijn et al., 2010).

The strain index developed in this study was found to be loosely associated with the participants' maximum strength. Mean strain index scores of 0.82 and 0.69 were observed for the exertions performed in the anterior $(+\mathrm{X})$ and superior $(+\mathrm{Y})$ directions, respectively. The participants exerted forces equivalent to $16.3 \%$ and $40.8 \%$ of their maximum strength in these two respective directions. Similarly, for the exertions performed in the lateral $(+Z)$ and medial $(-$ Z) directions, mean strain index scores of 1.19 and 1.36, respectively, were observed. The forces exerted in the lateral $(+Z)$ direction were $47.8 \%$ of the participant's maximum strength. The corresponding value for the medial (-Z) direction was $30.8 \%$. This may further suggest that although there is sufficient strength to carry out an exertion, it may not necessarily result in lower strain placed on the shoulder caused by the exertion. This is consistent with the findings of Wiker et al. (1990) who found that strength capability did not affect the onset of fatigue or discomfort to the shoulder complex during a manual assembly task. 
A few previous studies have reported higher prevalence of shoulder disorders among females compared to males (Hooftman et al., 2009; Treaster and Burr, 2004; Wijnhoven et al., 2006). Males also have a higher strength capacity compared to females (Chaffin et al., 1983; Coury et al., 1998; Heyward et al., 1986; Westrick et al., 2013). This difference in strength capability is due to several factors such as muscle mass, muscle composition, fat distribution, and slight variations in bone geometry. Results of this study indicate that the females did not significantly differ from their male counterparts in their strain index scores. This lack of difference could possibly be due to the relatively short duration of exertion which could have been not long enough to allow differences between genders to appear. Another possible reason could be explained by the lack of association between participant strength capability and the strain index scores. Since there was no observable statistically significant trend between strength and the strain index scores, the inherent strength differences between males and females did not cause variation in the strain index scores for either gender. Additionally, this lack of gender difference could have potentially been caused by one female participant (subject number eight) whose relatively large height and weight anthropometric characteristics created a large standard deviation among the female participants. This large difference in height and weight between this participant compared to the rest of the female participants could have potentially caused the difference in strain index values for females as a whole to narrow with the strain index scores of the males. Furthermore, the biomechanical model itself could have potentially been the cause for the lack of difference between male and female strain index scores. Although the model was adjusted for each gender based on segment masses and lengths as well as body fat percentage calculation, the factors related to muscle physiology were not considered in the model calculations. Females have smaller cross-sectional fiber areas and a higher proportion of type I 
fibers (slow twitch) compared to males (Esbjörnsson-Liljedahl et al., 1999; Maher et al., 2009; Miller et al., 1993). Smaller cross-sectional fiber areas and fewer type II muscle fibers may result in different firing rate and activation patterns in females than males to meet a similar force demand (Gamet et al., 1993).

Overall, the results of this study indicate that the proposed strain index can reasonably predict the physical loading taking place on the shoulder during forceful arm exertions. In general, the proposed strain index was found to increase with the increase in force level and was found to differ between directions, indicating that certain force levels and exertion directions, as well as their combination, may place strain in the shoulder complex and have the potential for increased risk of injury. Based on the findings, the proposed strain index detailed in this study is a first step in evaluating shoulder strain and may have the potential as a new method for the evaluation of the physical risk factors associated with work-related exertions.

\subsection{Study Limitations}

Several limitations should be considered while interpreting the findings of this study. Standardized static exertions performed while in a fixed, seated posture were used in the estimation of the proposed strain index detailed in this study. This was done in order to simplify the development of the strain index as much as possible by limiting the effects of potentially confounding factors such as participant posture and dynamic exertion magnitude and direction that would have increased the difficulty of the development process. Oftentimes however, the exertions normally performed in an occupational or workplace setting are dynamic in nature and may involve the use of complex upper extremity postures. Additionally, the duration of the exertions was kept relatively short in order to reduce the risk of injury or discomfort to the 
participant. A longer exertion duration, combined with more dynamic postures and exertions, may yield different results.

Only participants with little manual material handling experience were tested in this study. Experienced individuals may exhibit different force exertion strategies and ratings of perceived exertion compared to a less experienced population.

The estimation of the proposed strain index requires the use of the AnyBody Modeling System or a similar type of biomechanical modeling system or method capable of estimating joint forces. This may pose difficulty in using the proposed strain index in practice if such methods are not available. Additionally, AnyBody uses an optimization based algorithm that perfectly balances the net joint moment to quantify the muscle forces. This approach ignores the individual muscle activation strategies and may not be sensitive to inter individual differences.

Additionally, it must be mentioned that an error was made when formulating the ANOVA output. When performing the statistical analysis, the degrees of freedom lost by the model due to the two missing values were erroneously left in the model. However, due to the highly significant nature of the p-values obtained from the model with the degrees of freedom fully intact, it is unlikely that the subtraction of two degrees of freedom from the model would largely change the study conclusions. The main effects of direction of force exertion and force exertion level as well as their two-way interaction all had highly significant p-values (all $\mathrm{p}<0.001$ ), the reduced model would likely yield the same findings of significance for these effects. However, the main effect of gender $(p=0.07)$ could potentially achieve significance under the reduced model due to its p-value being relatively close to the tested level of significance. If the gender effect is found to achieve significance under the reduced model, this 
would mean that there is indeed a difference in the mean strain index scores between males and females.

\subsection{Future Work}

The proposed strain index presented in this study is a first step in attempting to describe the level of stain experienced by the shoulder during forceful exertions that generate different levels of concavity compression. The information gathered in this study can be used to continually develop and refine the strain index as a method to evaluate forceful exertions and their potential to cause injury.

Future studies investigating the continued development and refinement of the proposed strain index should first look at improving upon the limitations identified in this study. One such improvement would be using a larger, more diverse population, particularly participants from a working class background with manual material handling experience, to determine how well the trends observed in the current study could be applied to the working population. Second, future work should consider a broader set of physical exertions (dynamic, repetitive, non-neutral posture, longer duration, etc.) to determine whether the strain index can be applied to these types of exertions. In future work, models incorporating the activation strategies of individual muscles could also be used to further refine the strain index developed in this study using electromyography data. A more sophisticated hybrid model using electromyography as well as optimization techniques could also be used.

Most importantly, however, is the development of a rating scale to act as an accompaniment to the strain index. This rating scale would act as a way to precisely determine if a particular exertion poses an increased risk of injury based on the strain index score and place it in an 
appropriate category similar to the NIOSH lifting equation. One possible method to accomplish this would be to weigh the strain index scores against the perceived exertion ratings and formulate an appropriate scale using a set exertion rating limit such as the one by Garg et al. (2006) who recommended a perceived exertion limit of 3.5 on the Borg CR-10 scale to limit the risk of injury. 


\section{References}

Anton D, Shibley L, Fethke N, Hess J, Cook T, Rosecrance J. 2001. The effect of overhead drilling position on shoulder moment and electromyography. Ergonomics 44:489-501.

Bartlett MS. 1947. The use of transformations. Biometrics 3:39-52.

Borg G. 1982. Psychophysical bases of perceived exertion. Med sci sports exerc 14:377-381.

Borg G. 1990. Psychophysical scaling with applications in physical work and the perception of exertion. Scandinavian Journal of Work Environment \& Health 16:55-58.

Bureau of Labor Statistics. 2012. Nonfatal occupational injuries and illnesses requiring days away from work, 2011. Release no: USDL 12-2204 http://:www.bls.gov/news.release/pdf/osh2.pdf.

Chaffin D, Andersson G, Martin B. 2006. Occupational Biomechanics, 4th ed: WileyInterscience.

Chaffin DB, Andres RO, Garg A. 1983. Volitional postures during maximal push/pull exertions in the sagittal plane. Human Factors: The Journal of the Human Factors and Ergonomics Society 25:541-550.

Chopp J, Fischer S, Dickerson C. 2010. The impact of work configuration, target angle and hand force direction on upper extremity muscle activity during sub-maximal overhead work. Ergonomics 53:83-91.

Chow AY, Dickerson CR. 2009. Shoulder strength of females while sitting and standing as a function of hand location and force direction. Applied Ergonomics 40:303-308.

Cohen J. 1988. Statistical power analysis for the behavioral sciencies, 2nd ed. Hillsdale, N.J.: Lawrence Erlbaum Associates.

Coury HJCG, Kumar S, Rodgher S, Narayan Y. 1998. Measurements of shoulder adduction strength in different postures. International Journal of Industrial Ergonomics 22:195-206.

Criswell E. 2010. Cram's introduction to surface electromyography: Jones \& Bartlett Publishers.

Culham E, Peat M. 1993. Functional-anatomy of the shoulder complex. Journal of Orthopaedic \& Sports Physical Therapy 18:342-350.

Cutlip K, Nimbarte AD, Moore C. 2013. Stability of the Shoulder Complex During Manual Exertions. In: XXV Annual Occupational Ergonomics and Safety Conference. Atlanta, GA.

Cutlip K, Nimbarte AD, Ning X, Jaridi M. 2014. A Biomechanical Strain Index to Evaluate Shoulder Stress. In: Guan Y, Liao H, editors. Industrial and Systems Engineering Research Conference. Montreal, Canada.

da Costa B, Vieira E. 2010. Risk Factors for Work-Related Musculoskeletal Disorders: A Systematic Review of Recent Longitudinal Studies. American Journal of Industrial Medicine 53:285-323.

Damsgaard M, Rasmussen J, Christensen ST, Surma E, de Zee M. 2006. Analysis of musculoskeletal systems in the AnyBody Modeling System. Simulation Modelling Practice and Theory 14:1100-1111.

de Looze MP, van Greuningen K, Rebel J, Kingma I, Kuijer PPFM. 2000. Force direction and physical load in dynamic pushing and pulling. Ergonomics 43:377-390.

De Luca CJ. 1997. The use of surface electromyography in biomechanics. Journal of applied biomechanics 13:135-163. 
Dempsey PG. 1998. A critical review of biomechanical, epidemiological, physiological and psychophysical criteria for designing manual materials handling tasks. Ergonomics 41:73-88.

Dickerson C, Martin B, Chaffin D. 2006. The relationship between shoulder torques and the perception of muscular effort in loaded reaches. Ergonomics 49:1036-1051.

Dickerson C, Martin B, Chaffin D. 2007. Predictors of perceived effort in the shoulder during load transfer tasks. Ergonomics 50:1004-1016.

Dubowsky SR, Rasmussen J, Sisto SA, Langrana NA. 2008. Validation of a musculoskeletal model of wheelchair propulsion and its application to minimizing shoulder joint forces. Journal of biomechanics 41:2981-2988.

Dunning K, Davis K, Cook C, Kotowski S, Hamrick C, Jewell G, Lockey J. 2010. Costs by Industry and Diagnosis Among Musculoskeletal Claims in a State Workers Compensation System: 1999-2004. American Journal of Industrial Medicine 53:276-284.

Engin A, Chen S. 1986. Statistical data base for the biomechanical properties of the human shoulder complex--I: Kinematics of the shoulder complex. Journal of Biomechanical Engineering 108:215.

Esbjörnsson-Liljedahl M, Sundberg CJ, Norman B, Jansson E. 1999. Metabolic response in type I and type II muscle fibers during a 30-s cycle sprint in men and women. Journal of Applied Physiology 87:1326-1332.

Favre P, Snedeker J, Gerber C. 2009. Numerical modelling of the shoulder for clinical applications. Philosophical Transactions of the Royal Society a-Mathematical Physical and Engineering Sciences 367:2095-2118.

Frankenfield DC, Rowe WA, Cooney RN, Smith JS, Becker D. 2001. Limits of body mass index to detect obesity and predict body composition. Nutrition 17:26-30.

Gamet D, Duchene J, Garapon-Bar C, Goubel F. 1993. Surface electromyogram power spectrum in human quadriceps muscle during incremental exercise. Journal of Applied Physiology 74:2704-2704.

Garg A. 1983. Physiological responses to one-handed lift in the horizontal plane by female workers. The American Industrial Hygiene Association Journal 44:190-200.

Garg A. 1989. An evaluation of the NIOSH guidelines for manual lifting, with special reference to horizontal distance. American Industrial Hygiene Association Journal 50:157-164.

Garg A, Badger D. 1986. Maximum acceptable weights and maximum voluntary isometric strengths for asymmetric lifting. Ergonomics 29:879-892.

Garg A, Banaag J. 1988. Maximum acceptable weights, heart rates and RPEs for one hour's repetitive asymmetric lifting. Ergonomics 31:77-96.

Garg A, Hegmann K, Kapellusch J. 2006. Short-cycle overhead work and shoulder girdle muscle fatigue. International Journal of Industrial Ergonomics 36:581-597.

Garg A, Hermann K, Schwoerer B, Kapellusch J. 2002. The effect of maximum voluntary contraction on endurance times for the shoulder girdle. International Journal of Industrial Ergonomics 30:103-113.

Garg A, Saxena U. 1982. Maximum frequency acceptable to female workers for one-handed lifts in the horizontal plane. Ergonomics 25:839-853.

Green S, Salkin N, Akey T. 2000. Using SPSS for Windows: Analyzing and understanding data. New Jersey: PrenticeHall. 
Hall L, Dickerson C. 2010. Perceived shoulder moment load during load transfer tasks following a novel moment-based perception training program. International Journal of Industrial Ergonomics 40:402-405.

Haslegrave CM. 2004. Force exertion. Dellman, NJ, Haslegrave, CM, Chaffin, DB, Working postures and movements: tools for evaluation and engineering. CRC Press, London:367402.

Hatze H. 1974. The meaning of the term 'biomechanics'. Journal of Biomechanics 7:189-190.

Heyward VH, Johannes-Ellis SM, Romer JF. 1986. Gender differences in strength. Research Quarterly for exercise and sport 57:154-159.

Hooftman WE, Van Der Beek AJ, Bongers PM, Van Mechelen W. 2009. Is there a gender difference in the effect of work-related physical and psychosocial risk factors on musculoskeletal symptoms and related sickness absence? Scandinavian journal of work, environment \& health:85-95.

Hoozemans M, Kuijer P, Kingma I, van Dieen J, de Vries W, van der Woude L, Veeger D, van der Beek A, Frings-Dresen M. 2004. Mechanical loading of the low back and shoulders during pushing and pulling activities. Ergonomics 47:1-18.

Hoozemans M, van der Beek A, Frings-Dresen M, van der Woude L, van Dijk F. 2002. Pushing and pulling in association with low back and shoulder complaints. Occupational and Environmental Medicine 59:696-702.

House J, Mooradian A. 2010. Evaluation and management of shoulder pain in primary care clinics. Southern medical journal 103:1129-1137.

Johnson NL. 1949. Systems of frequency curves generated by methods of translation. Biometrika:149-176.

Kee D, Lee I. 2012. Relationships between subjective and objective measures in assessing postural stresses. Applied Ergonomics 43:277-282.

Keir P, Brown M. 2012. Force, frequency and gripping alter upper extremity muscle activity during a cyclic push task. Ergonomics 55:813-824.

Knudson DV. 2007. Fundamentals of biomechanics: Springer.

Konrad G, Jolly J, Labriola J, McMahon P, Debski R. 2006. Thoracohumeral muscle activity alters glenohumeral joint biomechanics during active abduction. Journal of Orthopaedic Research 24:748-756.

Kumar S, Mital A. 1996. Electromyography in ergonomics: CRC Press.

Larsson B, Sogaard K, Rosendal L. 2007. Work related neck-shoulder pain: a review on magnitude, risk factors, biochemical characteristics, clinical picture and preventive interventions. Best Practice \& Research in Clinical Rheumatology 21:447-463.

Lippitt SB, Vanderhooft JE, Harris SL, Sidles JA, Harryman II DT, Matsen III FA. 1993. Glenohumeral stability from concavity-compression: a quantitative analysis. Journal of Shoulder and Elbow Surgery 2:27-35.

Lotters F, Meerding W, Burdorf A. 2005. Reduced productivity after sickness absence due to musculoskeletal disorders and its relation to health outcomes. Scandinavian Journal of Work Environment \& Health 31:367-374.

Maher AC, Fu MH, Isfort RJ, Varbanov AR, Qu XA, Tarnopolsky MA. 2009. Sex differences in global mRNA content of human skeletal muscle. PLoS One 4:e6335.

Marras WS, Radwin RG. 2005. Biomechanical modeling. Reviews of human factors and ergonomics 1:1-88. 
McCluskey G, Getz B. 2000. Pathophysiology of anterior shoulder instability. Journal of Athletic Training 35:268-272.

McDonald A, Picco B, Belbeck A, Chow A, Dickerson C. 2012. Spatial dependency of shoulder muscle demands in horizontal pushing and pulling. Applied Ergonomics 43:971-978.

Miller AEJ, MacDougall J, Tarnopolsky M, Sale D. 1993. Gender differences in strength and muscle fiber characteristics. European Journal of Applied Physiology and Occupational Physiology 66:254-262.

Montgomery DC. 2012. Design and analysis of experiments, 8th ed: John Wiley \& Sons.

Nimbarte AD, Aghazadeh F, Ikuma L, Sun Y. 2012a. Evaluation of the loading of neck and shoulder musculature in overhead pushing and pulling exertions. Human Factors and Ergonomics in Manufacturing \& Service Industries 22:317-327.

Nimbarte AD, Al Hassan MJ, Guffey SE, Myers WR. 2012b. Influence of psychosocial stress and personality type on the biomechanical loading of neck and shoulder muscles. International Journal of Industrial Ergonomics 42:397-405.

Nimbarte AD, Sun Y, Jaridi M, Hsiao H. 2013. Biomechanical loading of the shoulder complex and lumbosacral joints during dynamic cart pushing task. Applied ergonomics.

NIOSH W. 1981. Work practices guide for manual lifting. US Department of Health and Human Services 199.

Nordander C, Ohlsson K, Åkesson I, Arvidsson I, Balogh I, Hansson G-Å, Strömberg U, Rittner R, Skerfving S. 2009. Risk of musculoskeletal disorders among females and males in repetitive/constrained work. Ergonomics 52:1226-1239.

Nussbaum M, Lang A. 2005. Relationships between static load acceptability, ratings of perceived exertion, and biomechanical demands. International Journal of Industrial Ergonomics 35:547-557.

Ostor A, Richards C, Prevost A, Speed C, Hazleman B. 2005. Diagnosis and relation to general health of shoulder disorders presenting to primary care. Rheumatology 44:800-805.

Putz-Anderson V, Bernard BP, Burt SE, Cole LL, Fairfield-Estill C, Fine LJ, Grant KA, Gjessing C, Jenkins L, Hurrell Jr JJ. 1997. Musculoskeletal disorders and workplace factors. National Institute for Occupational Safety and Health (NIOSH).

Rasmussen J, Damsgaard M, Voigt M. 2001. Muscle recruitment by the min/max criterion-a comparative numerical study. Journal of Biomechanics 34:409-415.

Silverstein B, Adams D. 2007. Work-related Musculoskeletal Disorders of the Neck, Back, and Upper Extremity in Washington State, 1997-2005. In: Industries WSDoLa, editor. Safety \& Health Assessment \& Research for Prevention (SHARP). Technical Report, (40-11).

Staal J, de Bie R, Hendriks E. 2007. Aetiology and management of work-related upper extremity disorders. Best Practice \& Research in Clinical Rheumatology 21:123-133.

Strasser H, Muller K. 1999. Favorable movements of the hand-arm system in the horizontal plane assessed by electromyographic investigations and subjective rating. International Journal of Industrial Ergonomics 23:339-347.

Treaster D, Burr D. 2004. Gender differences in prevalence of upper extremity musculoskeletal disorders. Ergonomics 47:495-526.

van der Windt DA, Thomas E, Pope DP, de Winter AF, Macfarlane GJ, Bouter LM, Silman AJ. 2000. Occupational risk factors for shoulder pain: a systematic review. Occupational and environmental medicine 57:433-442. 
van Rijn RM, Huisstede BM, Koes BW, Burdorf A. 2010. Associations between work-related factors and specific disorders of the shoulder - a systematic review of the literature. Scandinavian journal of work, environment \& health:189-201.

Veeger H, van der Helm F. 2007. Shoulder function: The perfect compromise between mobility and stability. Journal of Biomechanics 40:2119-2129.

Walker-Bone K, Cooper C. 2005. Hard work never hurt anyone: or did it? A review of occupational associations with soft tissue musculoskeletal disorders of the neck and upper limb (Retracted article. See vol. 68, pg. 1170, 2009). Annals of the Rheumatic Diseases 64:1391-1396.

Waters TR, Putz-Anderson V, Garg A, Fine LJ. 1993. Revised NIOSH equation for the design and evaluation of manual lifting tasks. Ergonomics 36:749-776.

Waters TR, Putz-Anderson V, Garg A, Health NIfOSa. 1994. Applications manual for the revised NIOSH lifting equation.

Westrick RB, Duffey ML, Cameron KL, Gerber JP, Owens BD. 2013. Isometric shoulder strength reference values for physically active collegiate males and females. Sports Health: A Multidisciplinary Approach 5:17-21.

Wijnhoven HA, De Vet HC, Picavet HSJ. 2006. Prevalence of musculoskeletal disorders is systematically higher in women than in men. The Clinical journal of pain 22:717-724.

Wiker SF, Chaffin DB, Langolf GD. 1990. Shoulder postural fatigue and discomfort: A preliminary finding of no relationship with isometric strength capability in a light-weight manual assembly task. International Journal of Industrial Ergonomics 5:133-146. 
Appendix A: Physical Activity Readiness Questionnaire (PAR-Q) 


\section{PAR-Q \& YOU}

(A Questionnaire for People Aged 15 to 69)

Regular physical activity is fun and healthy, and increasingly more people are starting to become more active every day. Being more active is very safe for most people. However, some people should check with their doctor before they start becoming much more physically active.

If you are planning to become much more physically active than you are now, start by answering the seven questions in the box below. If you are between the ages of 15 and 69 , the PAR-Q will tell you if you should check with your doctor before you start. If you are over 69 years of age, and you are not used to being very active, check with your doctor.

Common sense is your best guide when you answer these questions. Please read the questions carefully and answer each one honestly: check YES or NO.

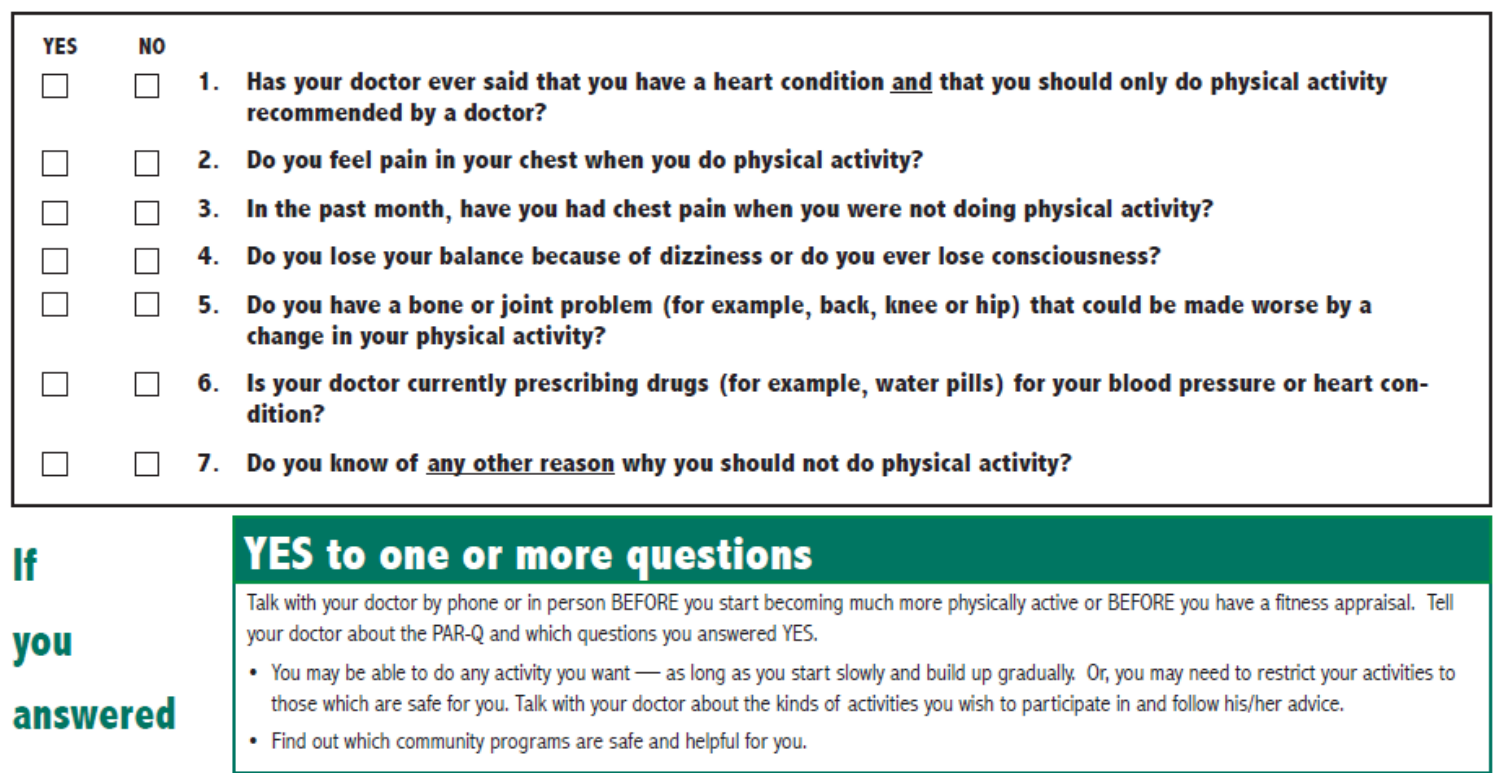

\section{NO to all questions}

If you answered NO honestly to all PAR-Q questions, you can be reasonably sure that you can:

- start becoming much more physically active - begin slowly and build up gradually. This is the safest and easiest way to go.

- take part in a fitness appraisal - this is an excellent way to determine your basic fitness so that you can plan the best way for you to live actively. It is also highly recommended that you have your blood pressure evaluated. If your reading is over 144/94, talk with your doctor before you start becoming much more physically active.

\section{DELAY BECOMING MUCH MORE ACTIVE:}

- if you are not feeling well because of a temporary illness such as a cold or a fever - wait until you feel better; or

- if you are or may be pregnant - talk to your doctor before you start becoming more active.

PLEASE NOTE: If your health changes so that you then answer YES to any of the above questions, tell your fitness or health professional. Ask whether you should change your physical activity plan.

Informed Use of the PAR-Q: The Canadian Society for Exercise Physiology, Health Canada, and their agents assume no liability for persons who undertake physical activity, and if in doubt after completing this questionnaire, consult your doctor prior to physical activity.

No changes permitted. You are encouraged to photocopy the PAR-Q but only if you use the entire form.

NOTE: If the PAR-Q is being given to a person before he or she participates in a physical activity program or a fitness appraisal, this section may be used for legal or administrative purposes.

"I have read, understood and completed this questionnaire. Any questions I had were answered to my full satisfaction."

NAME

SIGNATURE

SIGNATURE OF PARENT

or GUARDIAN (for participants under the age of majority)

DATE

WTTNESS

Note: This physical activity clearance is valid for a maximum of 12 months from the date it is completed and becomes invalid if your condition changes so that you would answer YES to any of the seven questions. 


\section{Appendix B: West Virginia University Institutional Review Board and Participant Consent Form}




\author{
Only Minimal Risk \\ Consent Information Form (without HIPAA)
}

Principal Investigator

Dr. Ashish Nimbarte

Department

Industrial and Management Systems Engineering

Protocol Number

1308080986

Study Title

Stability of the Shoulder Complex during Manual Exertions

Co-Investigator(s)

Kasey Cutlip

Sponsor (if any)

\title{
Contact Persons
}

In the event you experience any side effects or injury related to this research, you should contact Dr. Ashish Nimbarte at (304) 293-9473. (After hours contact: Dr. Ashish Nimbarte at (304) 226-8813. If you have any questions, concerns, or complaints about this research, you can contact Dr. Ashish Nimbarte at the above number or Kasey Cutlip at (304) 680-2770.

For information regarding your rights as a research subject, to discuss problems, concerns, or suggestions related to the research, to obtain information or offer input about the research, contact the Office of Research Integrity \& Compliance at (304) 293-7073.

In addition if you would like to discuss problems, concerns, have suggestions related to research, or would like to offer input about the research, contact the Office of Research Integrity and Compliance at 304-293-7073.

Introduction

You, have been asked to participate in this research study, which has been explained to you by Dr. Ashish Nimbarte, Ph.D. and Kasey Cutlip, B.S. This study is being conducted by Dr. Ashish Nimbarte, Ph.D. and Kasey Cutlip, B.S. in the Department of Industrial and Management Systems Engineering at West Virginia University. This research is being conducted to fulfill the requirements for a master's thesis in the area of ergonomics in the Department of Industrial and Management Systems Engineering at West Virginia University under the supervision of Dr. Ashish Nimbarte, Ph.D.

Phone: 304-293-7073

Fax: 304-293-3098

http://oric.research.wvu.edu
Chestnut Ridge Research Building

886 Chestnut Ridge Road

PO Box 6845

Morgantown, WV 26506-6845
P a g e $\mid \mathbf{2}$

Subject's
Initials
Date 


\section{Purpose(s) of the Study}

The purpose of this study is to learn more about the stability of the shoulder during pushing and pulling tasks performed in different directions.

\section{Description of Procedures}

Prior to data collection, the participant will answer the Physical Activity Readiness Questionnaire (PAR-Q) to determine eligibility for participation the study. If the participant is deemed suitable for participation, they will be asked to read and sign a consent form to indicate they are willing to be included in the study and fully understand the experimental procedures and requirements. Anthropometric measures will then be recorded (age, height, weight, etc.). Next, a set of reflective markers will be placed on the skin of the participant using double-sided tape for use with the optical motion-capture camera system and be seated and secured into a chair using a four-point body harness, isolating the shoulder complex. This chair will face a bar-handle assembly where the handle contains a force/torque sensor for use in determining force levels exerted by the participant. Participants' maximum force exertion ability will then collected in order to determine the maximal amount of force they can generate in each anatomical direction. After the maximum force abilities for each direction are obtained, the participant will then perform randomized pushing/pulling exertions of varying magnitudes based on a percentage of their maximum force exertion ability. After each trial, the participant will be asked to give a subjective perceived exertion rating for the shoulder using Borg's CR-10 scale and be given a brief rest period. The study will take approximately 1.5 hours to complete from the time the participant arrives in the lab.

\section{Discomforts}

There are no known or expected risks from participating in this study, except for possible discomfort of the shoulder during and after the exertions completed in the study. With sufficient rest periods designed between each trial of the study, the risk of injury as a result of participation is minimal.

\section{Alternatives}

You do not have to participate in this study.

\section{Benefits}

You may not receive any direct benefit from this study. The knowledge gained from this study may eventually benefit others.

Phone: 304-293-7073

Fax: 304-293-3098

http://oric.research.wvu.edu
Chestnut Ridge Research Building

886 Chestnut Ridge Road

PO Box 6845

Morgantown, WV 26506-6845
P a g e $\mid \mathbf{3}$

Subject's

Initials
Date 


\section{Financial Considerations}

There are no special fees for participating in this study. No monetary compensation will be given to participants for participating in this study and that involvement is on a purely voluntary basis. It is important for participants to understand that neither the investigators nor WVU or its associated affiliates has the funds set aside to pay for the cost of lost work wages or any care or treatment that might be necessary because of injury or sickness sustained from taking part in this study. Any injuries that may result from this study would not be eligible for Workers Compensation as this is not a job-related injury. Understand that any treatment necessary will be billed to the participant or to the participant's personal health insurance, and they may wish to consult their insurance provider before participating in this study.

\section{Confidentiality}

Any information about you that is obtained as a result of your participation in this research will be kept as confidential as legally possible. Your research records and test results, just like hospital records, may be subpoenaed by court order or may be inspected by the study sponsor or federal regulatory authorities without your additional consent.

In addition, there are certain instances where the researcher is legally required to give information to the appropriate authorities. These would include mandatory reporting of infectious diseases, mandatory reporting of information about behavior that is imminently dangerous to you or to others, such as suicide, child abuse, etc.

In any publications that result from this research, neither your name nor any information from which you might be identified will be published without your consent.

\section{Voluntary Participation}

Participation in this study is voluntary. You are free to withdraw your consent to participate in this study at any time. Refusal to participate or withdrawal will not affect your class standing or grades and will involve no penalty to you. In the event new information becomes available that may affect your willingness to participate in this study, this information will be given to you so that you can make an informed decision about whether or not to continue your participation. You have been given the opportunity to ask questions about the research, and you have received answers concerning areas you did not understand. Upon signing this form, you will receive a copy. I willingly consent to participate in this research.

Phone: $304-293-7073$

Fax: 304-293-3098

http://oric.research.wvu.edu
Chestnut Ridge Research Building

886 Chestnut Ridge Road

PO Box 6845

Morgantown, WV 26506-6845
P a g e $\mid \mathbf{4}$

Subject's

Initials
Date 
Signatures

Signature of Subject

Printed Name

Date

Time

The participant has had the opportunity to have questions addressed. The participant willingly agrees to be in the study.

Signature of Investigator or Co-Investigator

Printed Name

Date

Time

Phone: 304-293-7073

Fax: 304-293-3098

http://oric.research.wvu.edu
Chestnut Ridge Research Building

886 Chestnut Ridge Road

PO Box 6845

Morgantown, WV 26506-6845
$\mathrm{P}$ a g e $\mid \mathbf{5}$

Subject's

Initials

Date 
Appendix C: Participant Demographic Data 


\section{Appendix C-1: Participant mean (SD) anthropometric and characteristic data}

\begin{tabular}{|c|c|c|c|c|}
\hline Participant & $\begin{array}{c}\text { Gender } \\
(\mathrm{M} / \mathrm{F})\end{array}$ & Height $(\mathrm{cm})$ & Weight $(\mathrm{kg})$ & Age(yrs) \\
\hline 1 & M & 178 & 67 & 21 \\
\hline 2 & $\mathrm{~F}$ & 175 & 62 & 23 \\
\hline 3 & M & 183 & 78 & 25 \\
\hline 4 & $\mathrm{M}$ & 175 & 74 & 29 \\
\hline 5 & $\mathrm{M}$ & 177 & 73 & 24 \\
\hline 6 & $\mathrm{~F}$ & 167 & 61 & 25 \\
\hline 7 & $F$ & 166 & 48 & 37 \\
\hline 8 & $\mathrm{~F}$ & 182 & 123 & 24 \\
\hline 9 & $\mathrm{~F}$ & 156 & 49 & 30 \\
\hline 10 & $\mathrm{M}$ & 178 & 75 & 26 \\
\hline 11 & $M$ & 175 & 64 & 28 \\
\hline 12 & M & 167 & 81 & 29 \\
\hline 13 & $\mathrm{~F}$ & 157 & 63 & 24 \\
\hline 14 & $\mathrm{~F}$ & 165 & 92 & 33 \\
\hline \multirow[t]{4}{*}{15} & $\mathrm{M}$ & 165 & 78 & 27 \\
\hline & $\mathrm{M}$ & $174.8(6.0)$ & $73.8(5.8)$ & $26.1(2.7)$ \\
\hline & $\mathrm{F}$ & $166.9(9.3)$ & $71.1(27.1)$ & $28.0(5.4)$ \\
\hline & All & $171.1(8.4)$ & 72.5 (18.2) & $27.0(4.2)$ \\
\hline
\end{tabular}




\section{Appendix D: Power Calculations for Determining the Number of Participants}




\section{Appendix D-1: Sample size calculations}

\begin{tabular}{|c|c|c|c|c|c|c|c|c|c|c|c|c|c|c|c|c|c|c|c|c|c|c|c|c|}
\hline $\begin{array}{c}\text { Dependent } \\
\text { Variable }\end{array}$ & $\mathbf{c}$ & $\boldsymbol{\lambda}$ & $\boldsymbol{v}_{\mathbf{1}}$ & $\boldsymbol{v}_{\mathbf{2}}$ & $\boldsymbol{\beta}$ & $\begin{array}{c}\text { Power } \\
(\mathbf{1}-\boldsymbol{\beta})\end{array}$ & $\mathbf{c}_{\mathbf{1}}$ & $\boldsymbol{\lambda}$ & $\boldsymbol{v}_{\mathbf{1}}$ & $\boldsymbol{v}_{\mathbf{2}}$ & $\boldsymbol{\beta}$ & $\begin{array}{c}\text { Power } \\
(\mathbf{1}-\boldsymbol{\beta})\end{array}$ & $\mathbf{c}_{\mathbf{2}}$ & $\boldsymbol{\lambda}$ & $\boldsymbol{v}_{\mathbf{1}}$ & $\boldsymbol{v}_{\mathbf{2}}$ & $\boldsymbol{\beta}$ & $\begin{array}{c}\text { Power } \\
(\mathbf{1}-\boldsymbol{\beta})\end{array}$ & $\mathbf{c}_{\mathbf{3}}$ & $\boldsymbol{\lambda}$ & $\boldsymbol{v}_{\mathbf{1}}$ & $\boldsymbol{v}_{\mathbf{2}}$ & $\boldsymbol{\beta}$ & $\begin{array}{c}\text { Power } \\
(\mathbf{1}-\boldsymbol{\beta})\end{array}$ \\
\hline $\begin{array}{c}\text { Strain } \\
\text { Index 4 }\end{array}$ & 2 & 2.96 & 1 & 35 & 0.75 & 0.25 & 3 & 3.56 & 2 & 53 & 0.23 & 0.77 & 4 & 4.07 & 3 & 71 & 0.175 & 0.825 & 5 & 4.52 & 4 & 89 & 0.025 & 0.975 \\
\hline
\end{tabular}




\section{Appendix E: Glenohumeral Joint Resultant Force Orientation Cases}




\section{Appendix E-1: Resultant force orientation case examples}

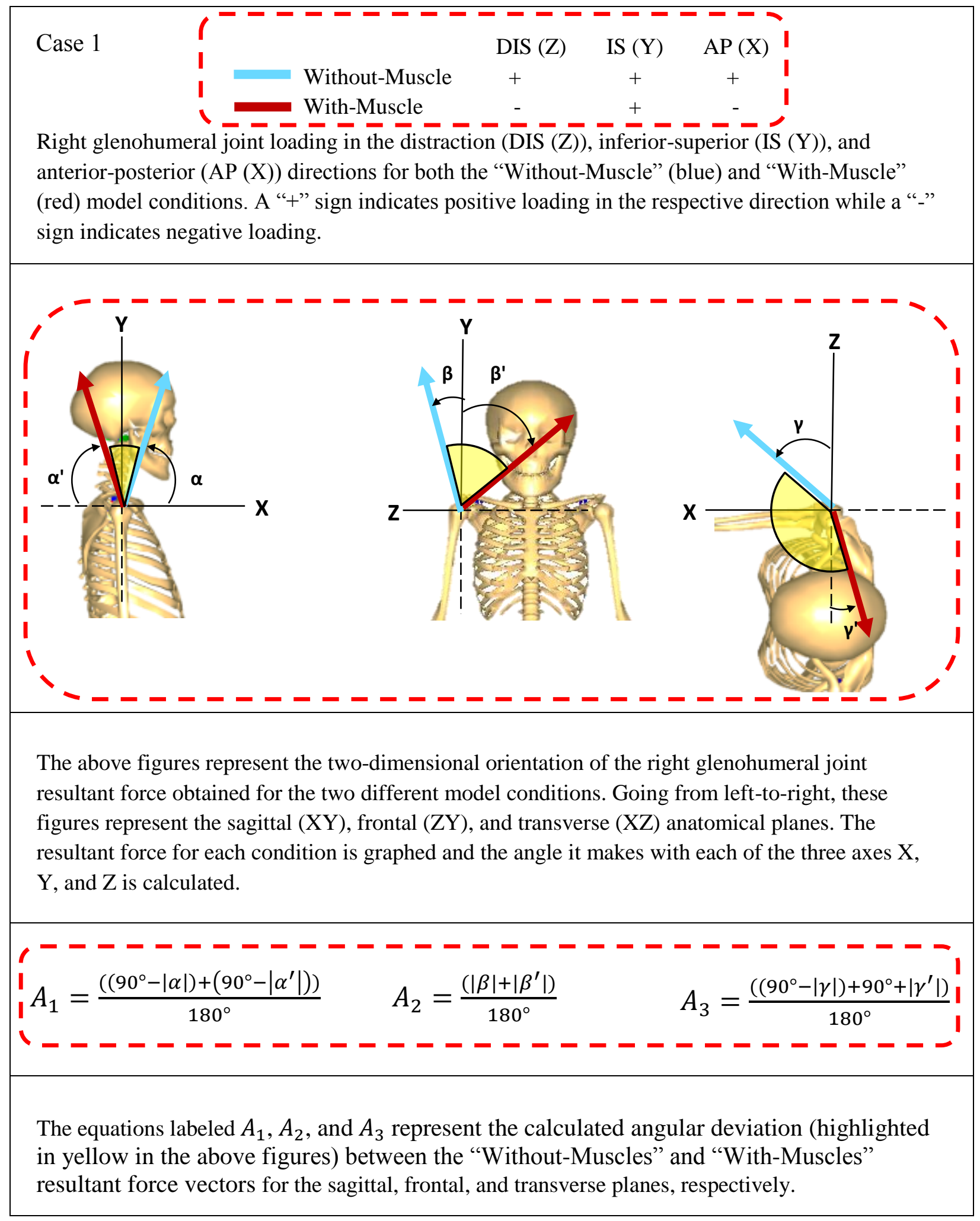




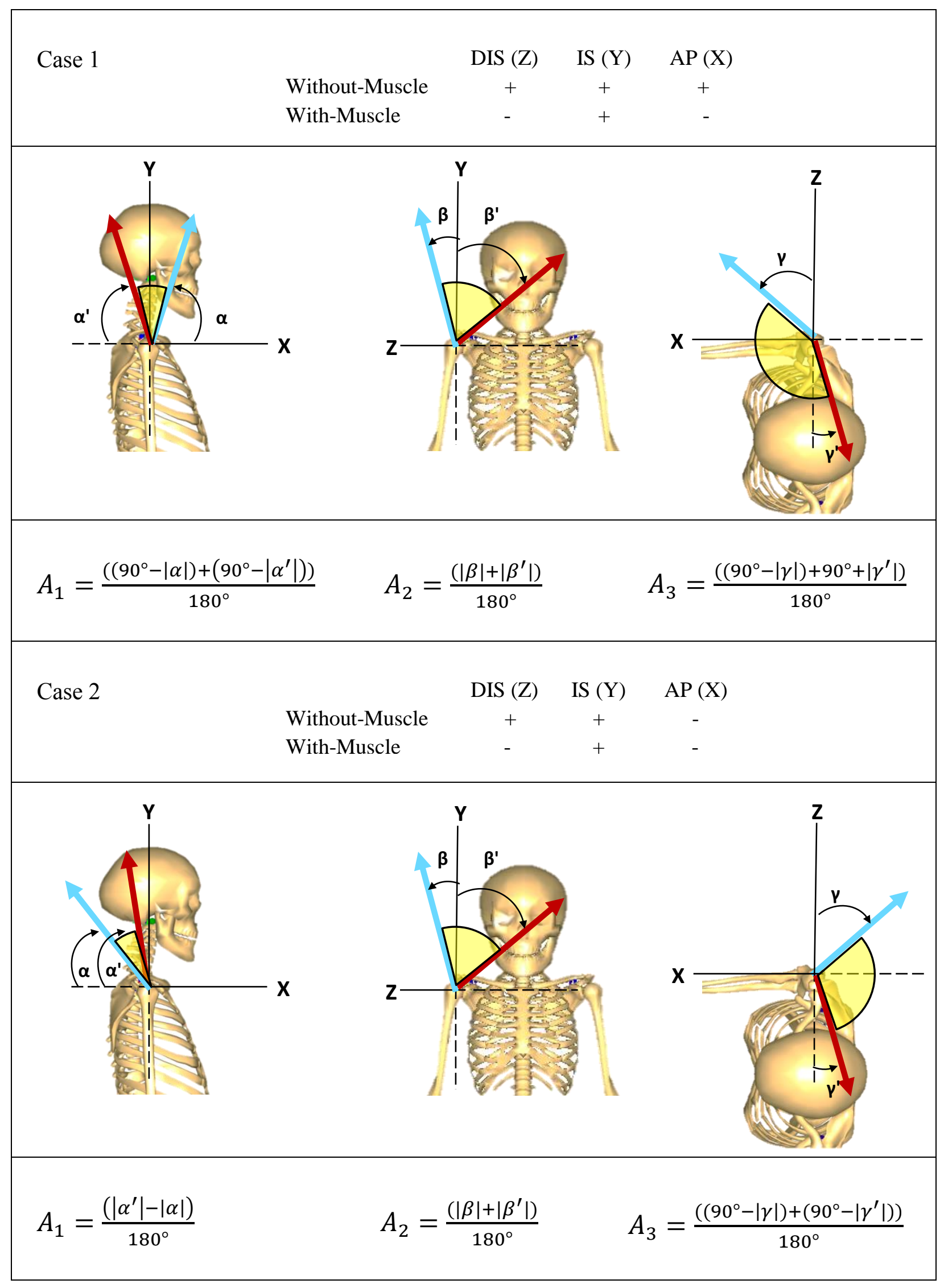

E-3 


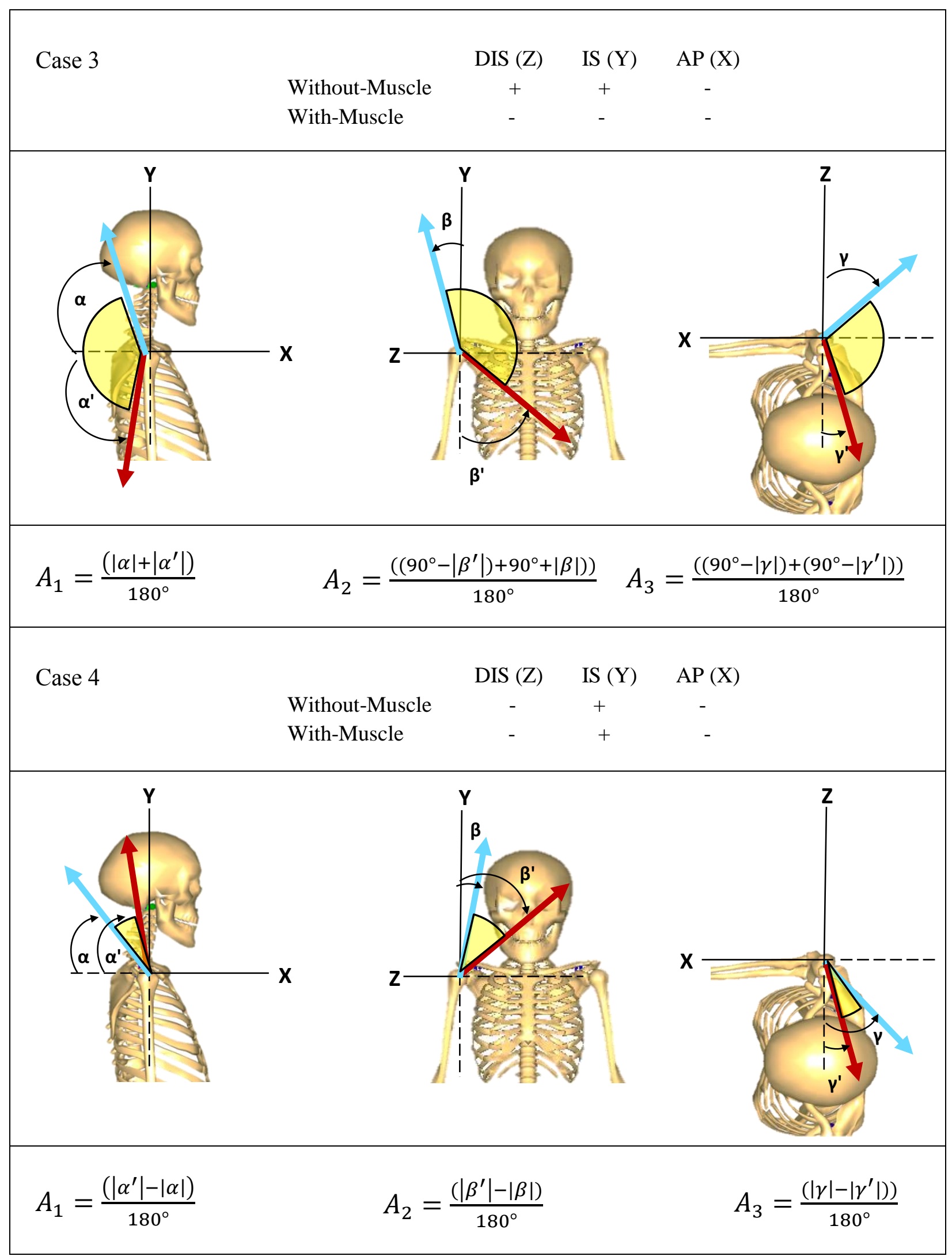




Case 5




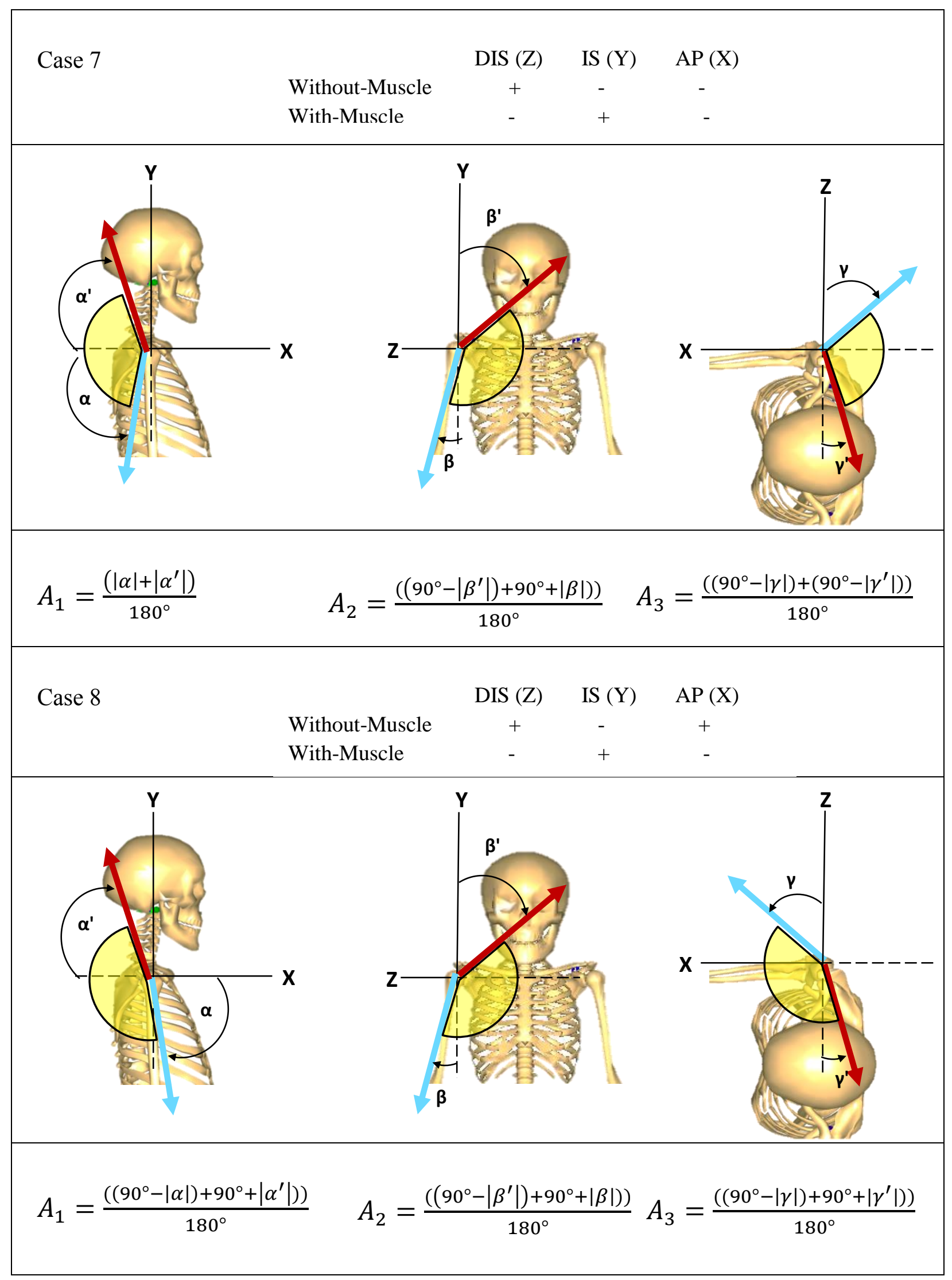




Case 9




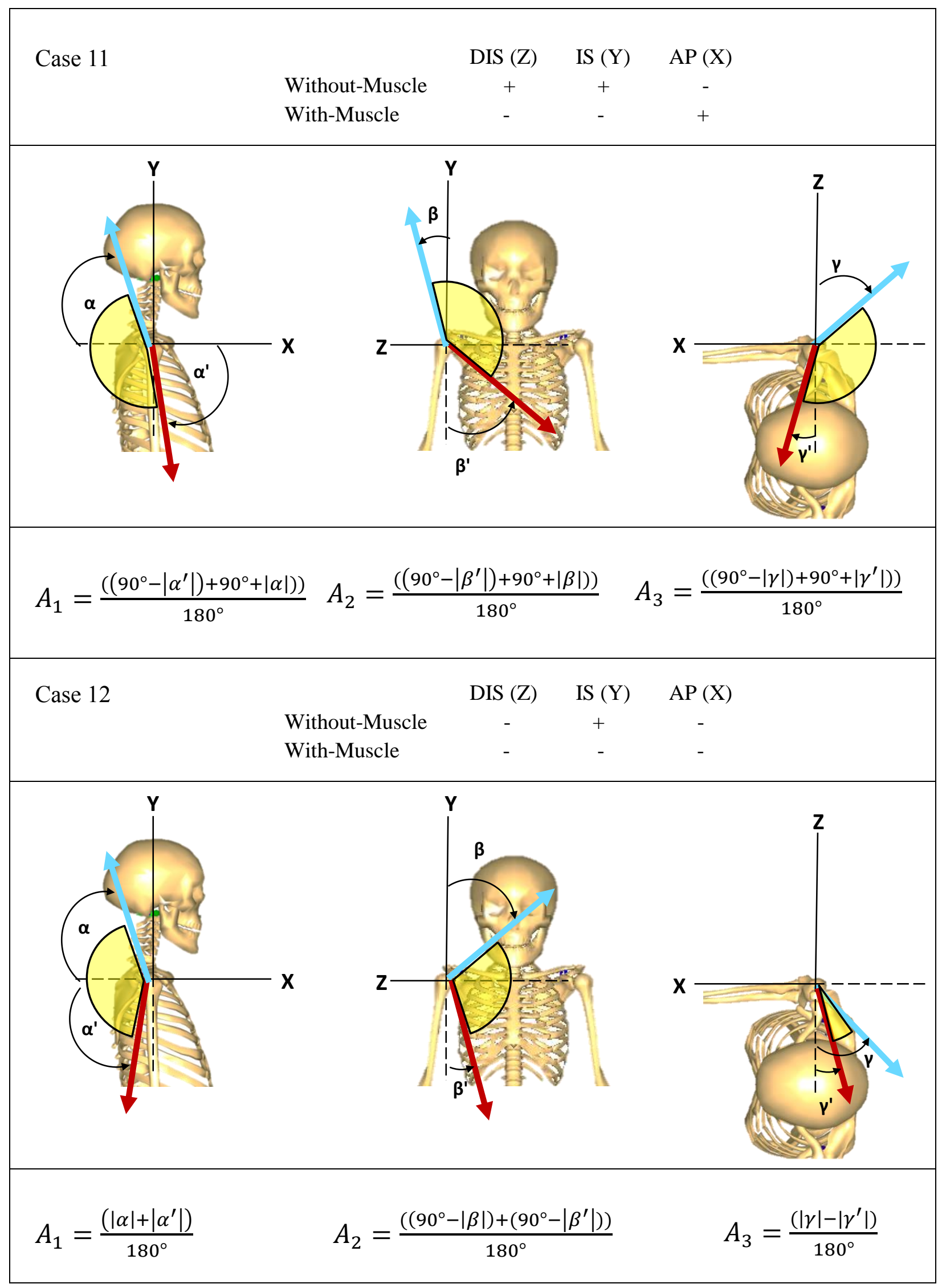




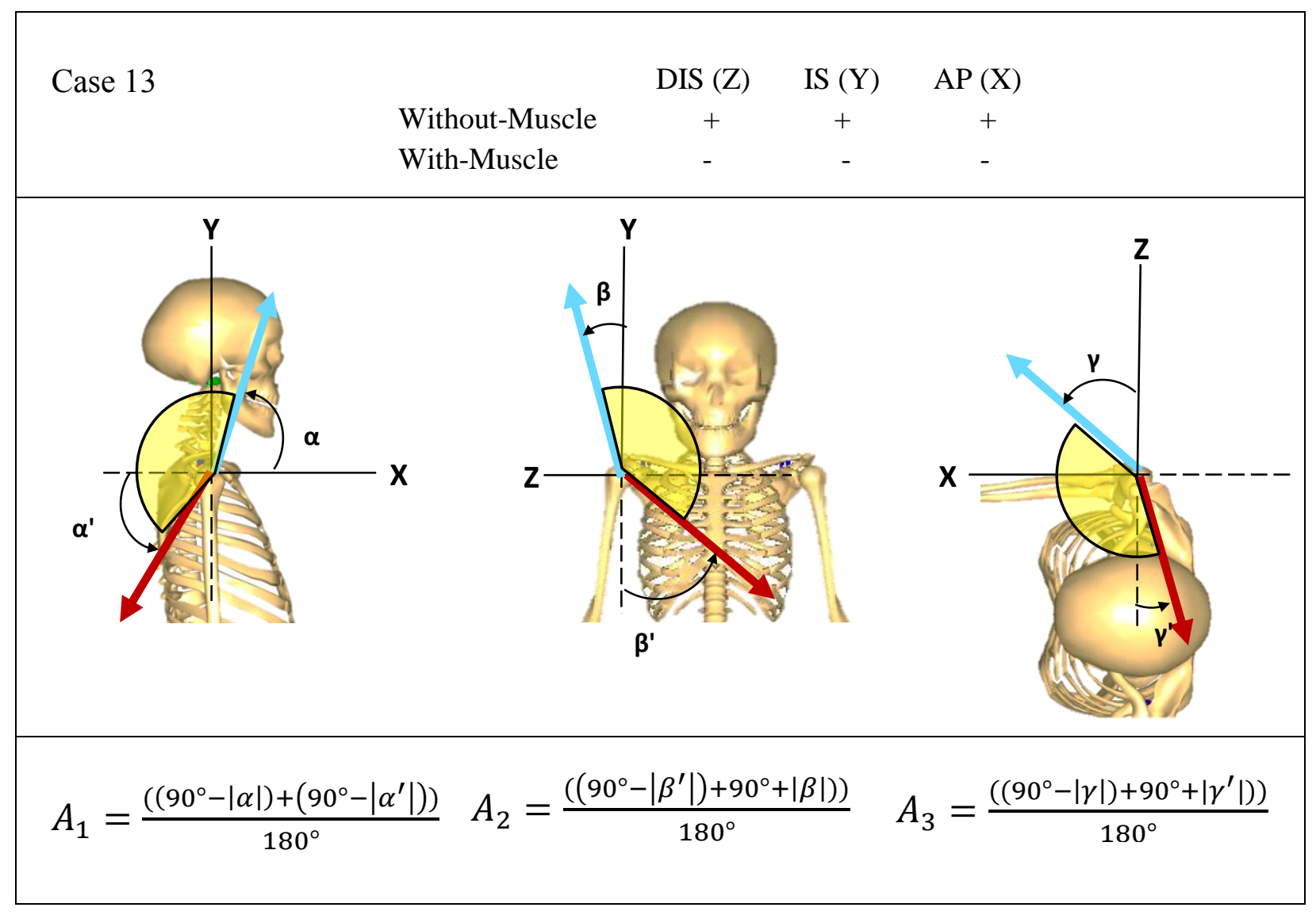


Appendix F: Data Normality of Strain Index 9 and Perceived Exertion Ratings 


\section{Appendix F-1: Normality plot of strain index 9 (SI 9)}

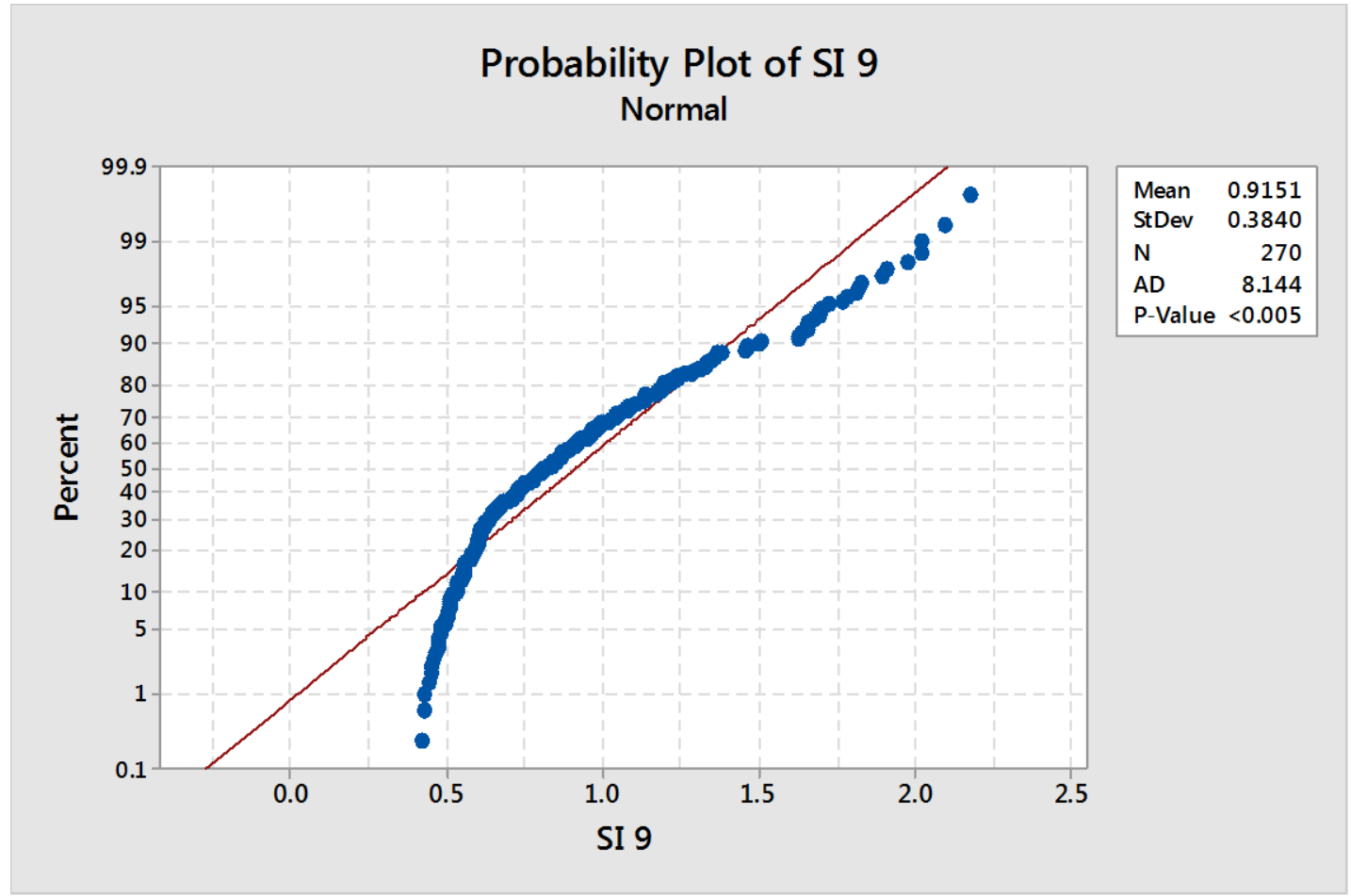

Appendix F-2: Normality plot of perceived exertion ratings (PER)

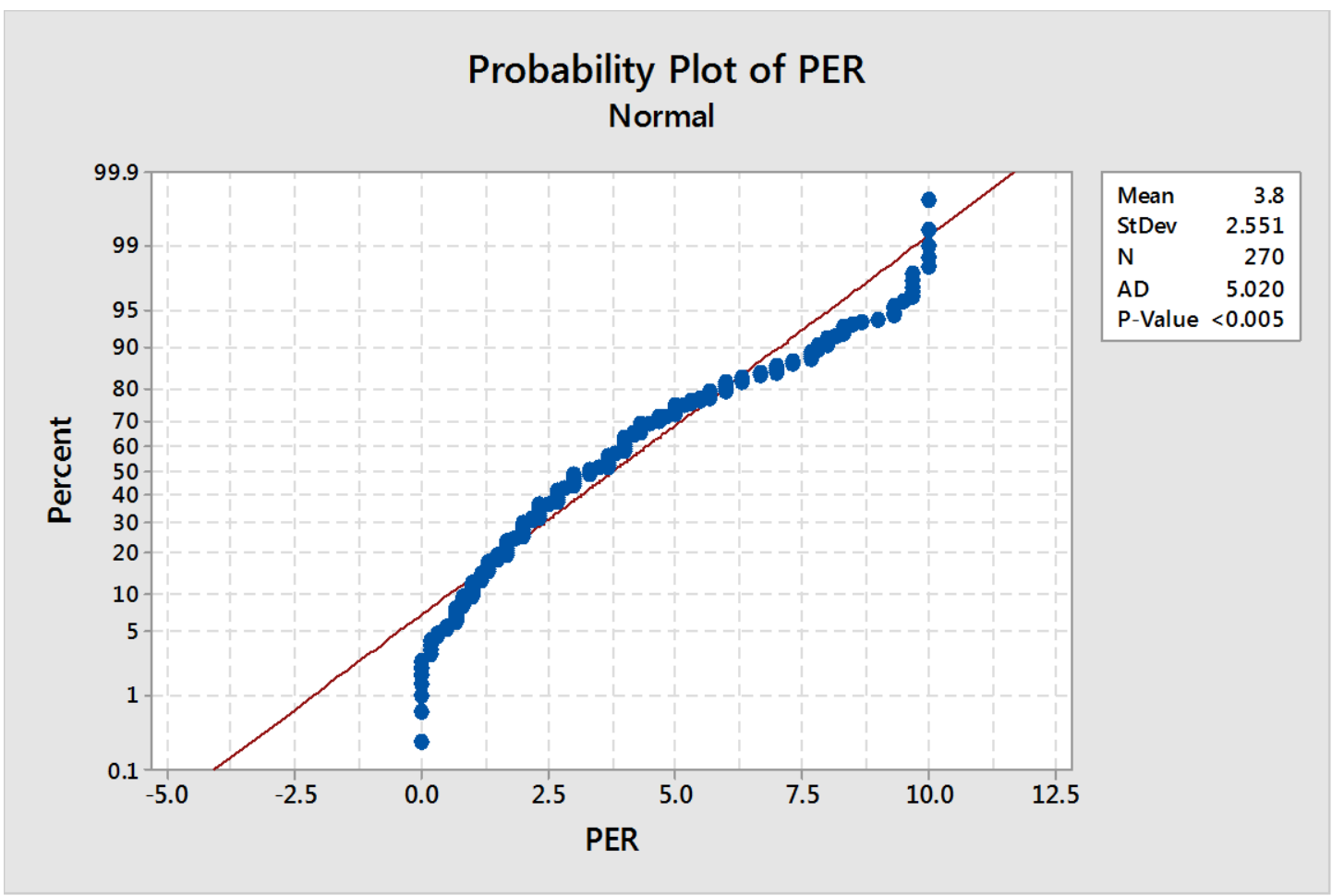




\section{Appendix F-3: Johnson transformation of strain index 9}

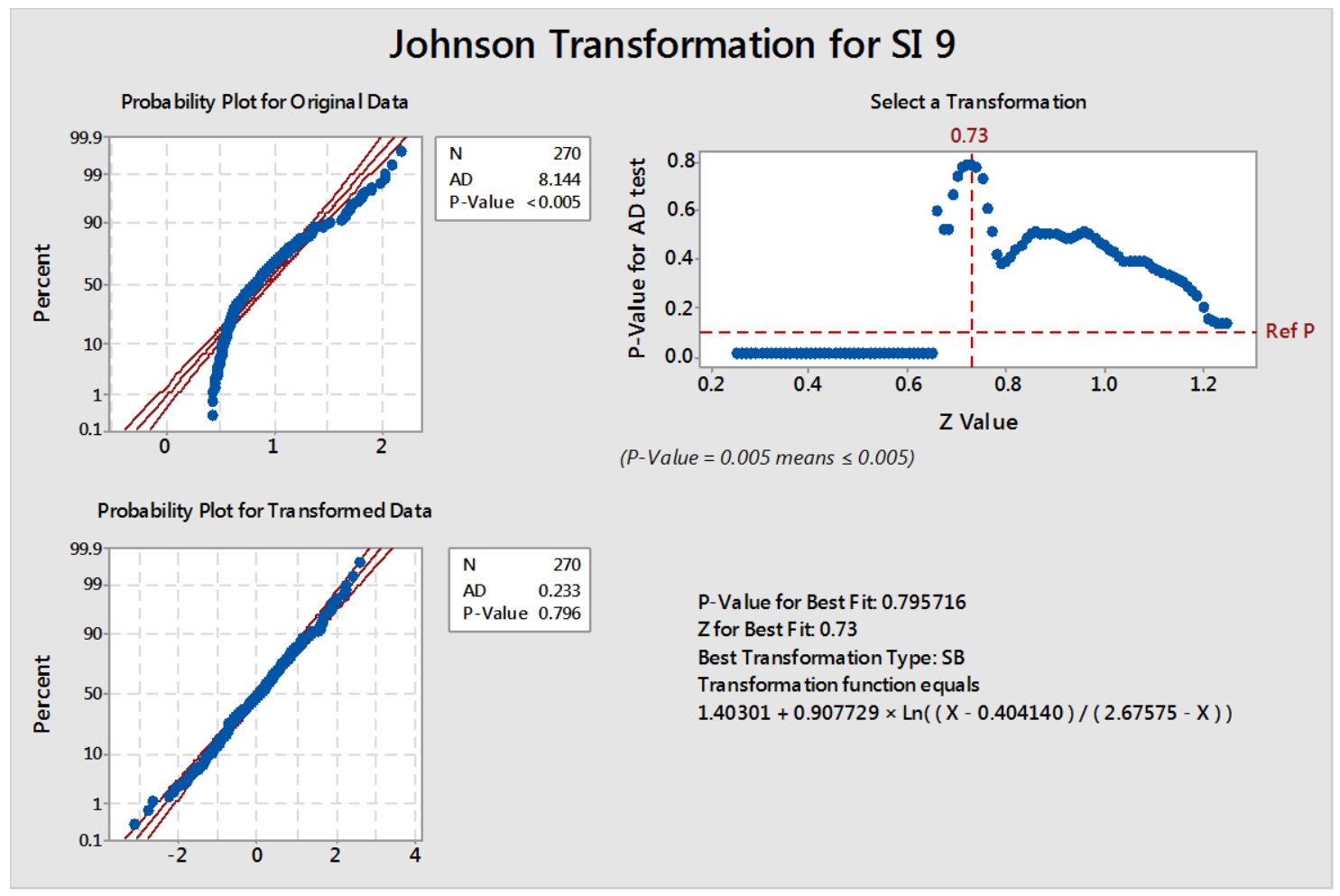

\section{Appendix F-4: Johnson transformation of perceived exertion ratings}

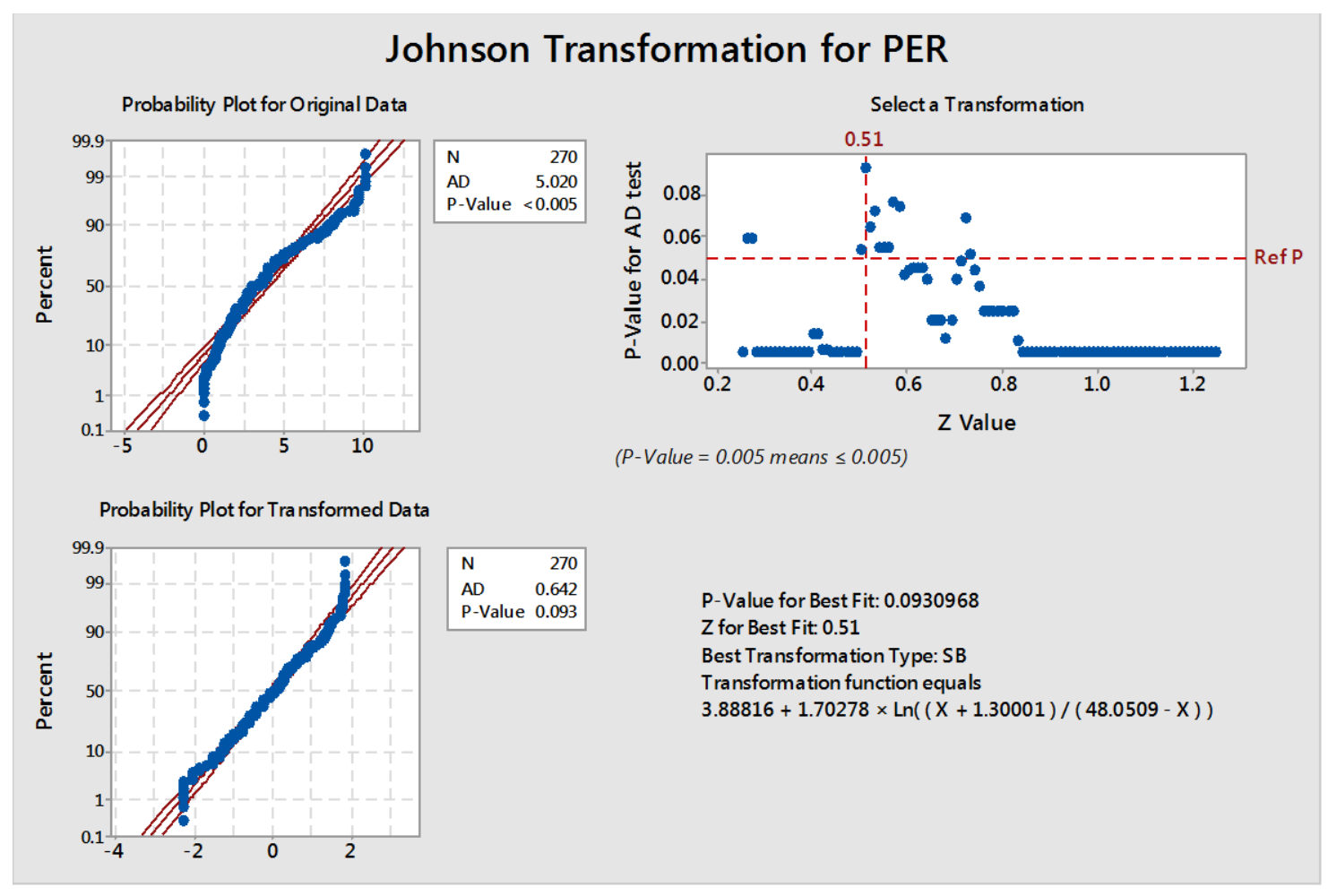




\section{Appendix F-5: Equality of variance for strain index 9 vs. gender, direction, and force level}

Test for Equal Variances: SI 9 johnson vs Gender, Direction, Force Ivl

Multiple comparison intervals for the standard deviation, $\alpha=0.05$

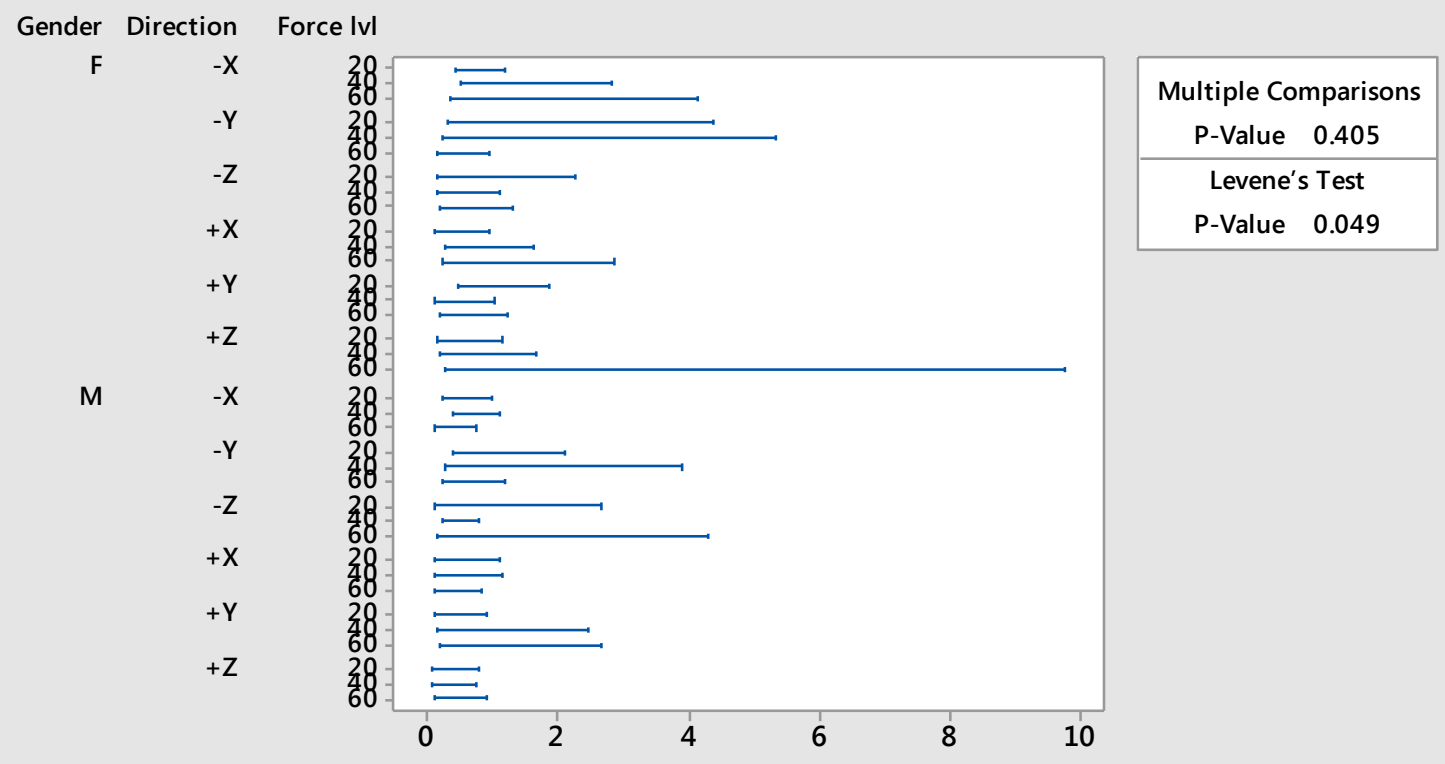

If intervals do not overlap, the corresponding stdevs are significantly different. 


\section{Appendix G: ANOVA Output for Strain Index 9}




\section{Appendix G-1: ANOVA table for strain index 9}

\begin{tabular}{|c|c|c|c|c|c|}
\hline \multicolumn{6}{|l|}{ Analysis of Variance } \\
\hline Source & $\mathrm{DF}$ & Adj $S S$ & Adj MS & F-Value & P-Value \\
\hline Gender & 1 & 0.743 & 0.7429 & 3.32 & 0.070 \\
\hline Direction & 5 & 118.154 & 23.6308 & 105.52 & 0.000 \\
\hline Force lvl & 2 & 61.897 & 30.9485 & 138.20 & 0.000 \\
\hline Direction*Force lvl & 10 & 23.307 & 2.3307 & 10.41 & 0.000 \\
\hline Gender*Direction & 5 & 3.723 & 0.7446 & 3.32 & 0.006 \\
\hline Gender*Force lvl & 2 & 0.253 & 0.1265 & 0.56 & 0.569 \\
\hline Gender*Direction*Force lvl & 10 & 4.252 & 0.4252 & 1.90 & 0.046 \\
\hline Error & 234 & 52.403 & 0.2239 & & \\
\hline Total & 269 & 267.521 & & & \\
\hline \multicolumn{6}{|l|}{ Model Summary } \\
\hline $\begin{array}{lll}S & R-s q & R-s q(\operatorname{adj})\end{array}$ & \multirow{2}{*}{\multicolumn{5}{|c|}{$\begin{array}{r}\text { R-sq (pred) } \\
73.73 \%\end{array}$}} \\
\hline $\begin{array}{lll}0.473228 & 80.41 \% & 77.48 \%\end{array}$ & & & & & \\
\hline
\end{tabular}

\section{Appendix G-2: Residuals plots for strain index 9}

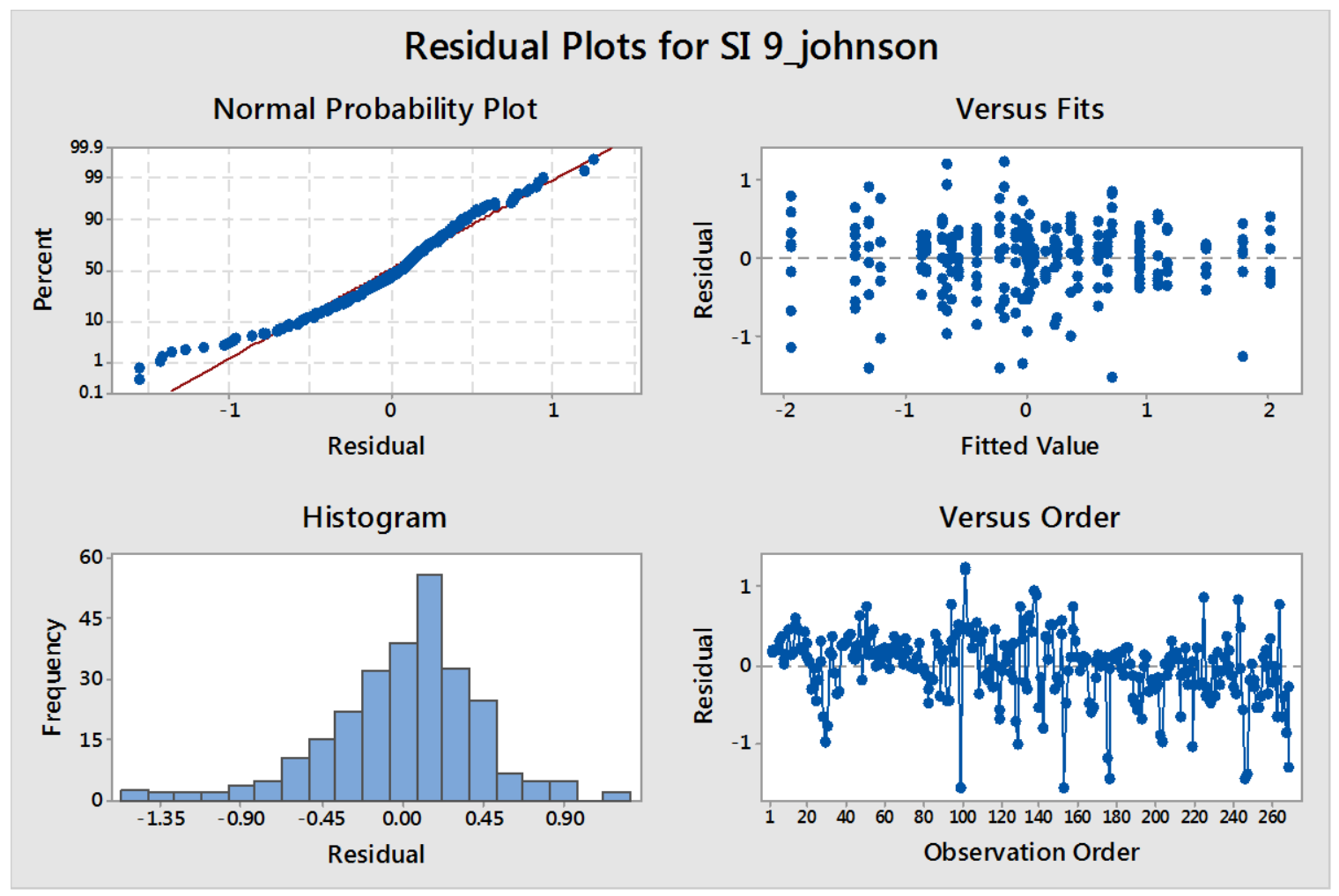




\section{Appendix G-3: Minitab output: Tukey comparisons for direction}

\section{Tukey Pairwise Comparisons: Response = SI 9_johnson, Term = Direction}

\begin{tabular}{|c|c|c|c|c|c|}
\hline Direction & $\mathrm{N}$ & Mean & & Gro & suping \\
\hline$-\mathrm{Z}$ & 45 & 1.07278 & A & & \\
\hline$+\mathrm{Z}$ & 45 & 0.74084 & & B & \\
\hline$+\mathrm{X}$ & 45 & -0.05045 & & & $\mathrm{C}$ \\
\hline$-Y$ & 45 & -0.37113 & & & $\mathrm{D}$ \\
\hline$+\mathrm{Y}$ & 45 & -0.49620 & & & $\mathrm{D}$ \\
\hline$-X$ & 45 & -0.74495 & & & \\
\hline
\end{tabular}

Means that do not share a letter are significantly different.

Tukey Simultaneous Tests for Differences of Means

Difference

of Direction

Levels

$-Y--X$

$-Z--X$

$+X--X$

$+\mathrm{Y}-\mathrm{X}$

$+Z--X$

$-Z--Y$

$+X--Y$

$+Y--Y$

$+Z--Y$

$+X--Z$

$+Y--Z$

$+Z--Z$

$+Y-+X$

$+\mathrm{Z}-+\mathrm{X}$

$+\mathrm{Z}-+\mathrm{Y}$
Difference

of Means

0.374

1.818

0.694

0.249

1.486

1.444

0.321

$-0.125$

1.112

$-1.123$

$-1.569$

$-0.332$

$-0.446$

0.791

1.237
SE of

Difference

0.100

0.100

0.100

0.100

0.100

0.100

0.100

0.100

0.100

0.100

0.100

0.100

0.100

0.100

0.100
Simultaneous 95\% CI

$(0.087,0.661)$

( $1.531,2.105)$

$(0.407,0.982)$

$(-0.038,0.536)$

( 1.199, 1.773)

$(1.157,1.731)$

$(0.034,0.608)$

$(-0.412,0.162)$

$(0.825,1.399)$

$(-1.410,-0.836)$

$(-1.856,-1.282)$

$(-0.619,-0.045)$

$(-0.733,-0.159)$

$(0.504,1.078)$

$(0.950,1.524)$

$$
\begin{array}{r}
\text { T-Value } \\
3.74 \\
18.18 \\
6.95 \\
2.49 \\
14.86 \\
14.44 \\
3.21 \\
-1.25 \\
11.12 \\
-11.23 \\
-15.69 \\
-3.32 \\
-4.46 \\
7.91 \\
12.37
\end{array}
$$

Individual confidence level $=99.55 \%$

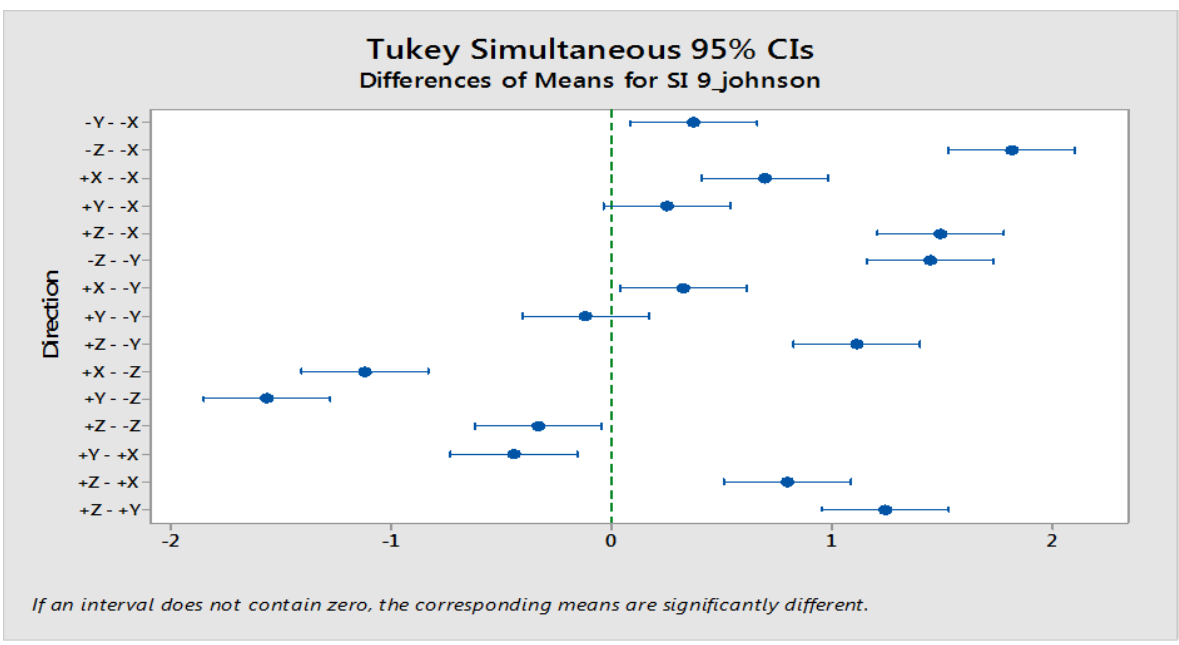




\section{Appendix G-4: Minitab output: Tukey comparisons for force level}

\section{Tukey Pairwise Comparisons: Response $=$ SI4j, Term $=$ Force Ivl}

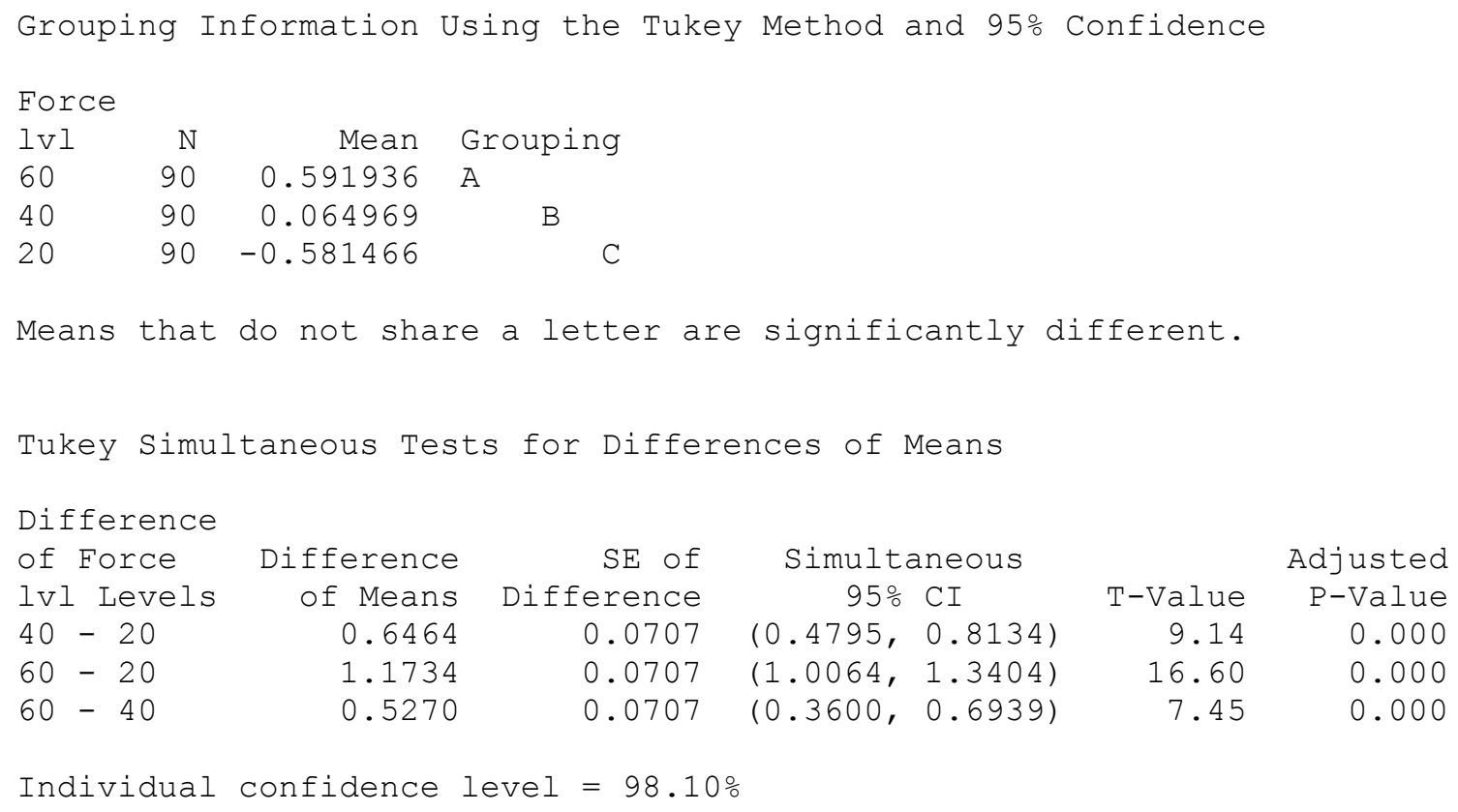

\section{Tukey Simultaneous 95\% CIs}

Differences of Means for SI 9.johnson

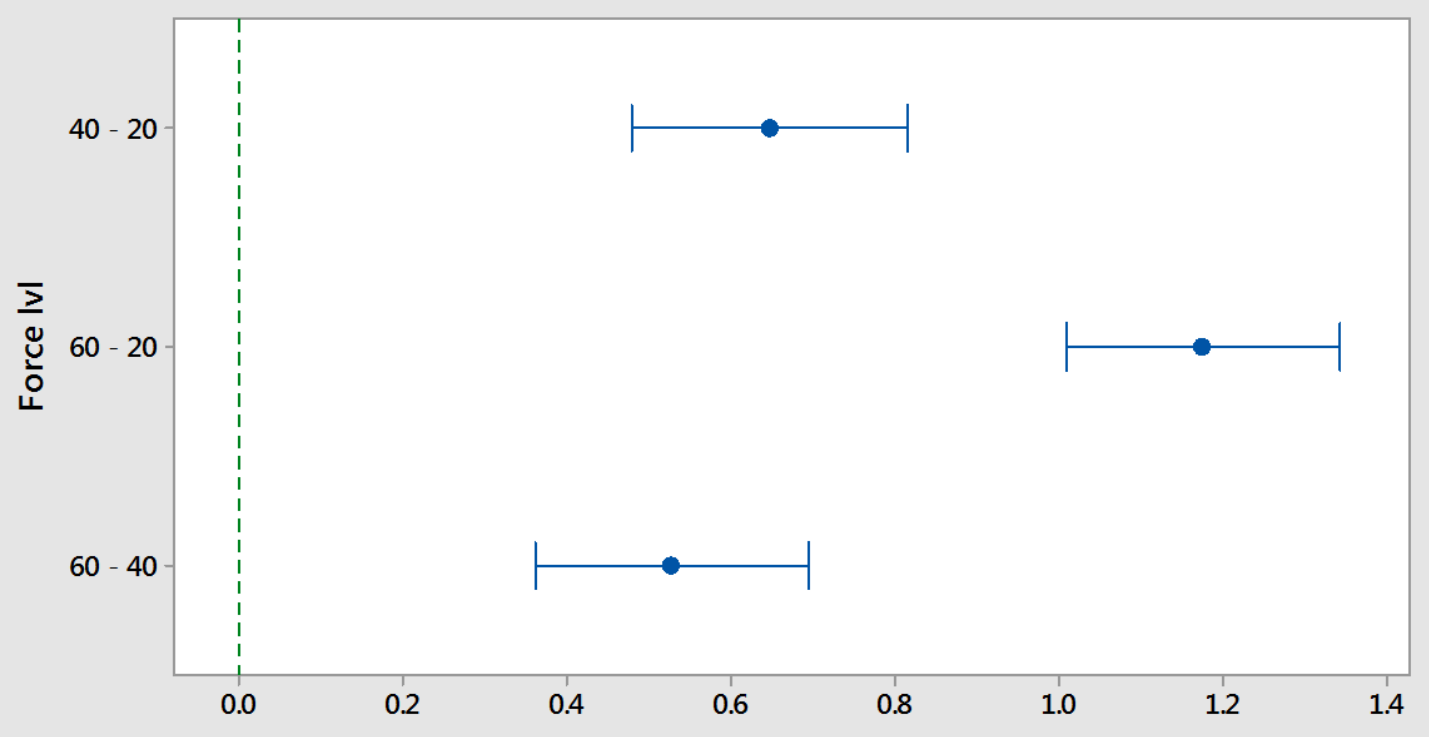

If an interval does not contain zero, the corresponding means are significantly different. 
Appendix H: Data for Strain Indices 1 through 9 and Perceived Exertion Ratings 


\begin{tabular}{|c|c|c|c|c|c|c|c|c|c|c|c|c|c|}
\hline Subject & Gender & Direction & $\begin{array}{c}\text { Force } \\
\text { Ivl }\end{array}$ & SI 1 & SI 2 & SI 3 & SI 4 & SI 5 & SI 6 & SI 7 & SI 8 & SI 9 & avg PER \\
\hline 1 & $\mathrm{M}$ & $+X$ & 20 & 0.468718 & 0.700106 & 0.424552 & 0.655939 & 1.517664 & 1.749052 & 1.124658 & 2.217770 & 0.674574 & 1.333333 \\
\hline 1 & $\mathrm{M}$ & $+X$ & 40 & 0.519609 & 0.911340 & 0.458124 & 0.849855 & 1.592697 & 1.984428 & 1.369464 & 2.504037 & 0.870475 & 3.666667 \\
\hline 1 & $M$ & $+X$ & 60 & 0.568644 & 1.112199 & 0.518957 & 1.062512 & 1.714441 & 2.257996 & 1.631156 & 2.826640 & 1.086331 & 4.666667 \\
\hline 1 & $\mathrm{M}$ & $+Y$ & 20 & 0.371048 & 0.589459 & 0.369017 & 0.587428 & 1.366567 & 1.584977 & 0.958476 & 1.956026 & 0.618336 & 3.000000 \\
\hline 1 & $\mathrm{M}$ & $+Y$ & 40 & 0.366164 & 0.737285 & 0.365631 & 0.736751 & 1.333259 & 1.704379 & 1.102916 & 2.070544 & 0.775179 & 4.333333 \\
\hline 1 & $\mathrm{M}$ & $+Y$ & 60 & 0.369321 & 0.908778 & 0.369019 & 0.908477 & 1.327248 & 1.866706 & 1.277798 & 2.236027 & 0.952654 & 4.6666667 \\
\hline 1 & $\mathrm{M}$ & $+Z$ & 20 & 0.535647 & 0.820955 & 0.548862 & 0.834170 & 1.436228 & 1.721535 & 1.369817 & 2.257183 & 0.851914 & 3.000000 \\
\hline 1 & $\mathrm{M}$ & $+Z$ & 40 & 0.625993 & 1.219942 & 0.660930 & 1.254880 & 1.621707 & 2.215656 & 1.880872 & 2.841649 & 1.266003 & 6.000000 \\
\hline 1 & $\mathrm{M}$ & $+Z$ & 60 & 0.656850 & 1.623837 & 0.698318 & 1.665305 & 1.704001 & 2.670988 & 2.322155 & 3.327838 & 1.674407 & 8.000000 \\
\hline 1 & $\mathrm{M}$ & $-x$ & 20 & 0.609551 & 0.636622 & 0.670526 & 0.697597 & 1.852944 & 1.880015 & 1.307148 & 2.489566 & 0.727825 & 1.666667 \\
\hline 1 & $\mathrm{M}$ & $-x$ & 40 & 0.330240 & 0.419454 & 0.361978 & 0.451192 & 0.811147 & 0.900362 & 0.781432 & 1.230602 & 0.519030 & 3.666667 \\
\hline 1 & $\mathrm{M}$ & $-x$ & 60 & 0.352402 & 0.466550 & 0.378246 & 0.492394 & 0.803017 & 0.917165 & 0.844796 & 1.269568 & 0.617519 & 4.333333 \\
\hline 1 & $\mathrm{M}$ & $-Y$ & 20 & 0.350684 & 0.469555 & 0.385772 & 0.504643 & 0.951438 & 1.070309 & 0.855327 & 1.420994 & 0.508880 & 2.000000 \\
\hline 1 & $\mathrm{M}$ & $-Y$ & 40 & 0.473294 & 0.745035 & 0.589827 & 0.861568 & 1.389052 & 1.660793 & 1.334862 & 2.134087 & 0.921408 & 3.333333 \\
\hline 1 & $M$ & $-Y$ & 60 & 0.557013 & 1.092997 & 0.630676 & 1.166660 & 1.510976 & 2.046960 & 1.723673 & 2.603973 & 1.332661 & 5.666667 \\
\hline 1 & $\mathrm{M}$ & $-Z$ & 20 & 0.262758 & 0.410164 & 0.636379 & 0.783784 & 1.111257 & 1.258662 & 1.046542 & 1.521420 & 1.004524 & 2.333333 \\
\hline 1 & $\mathrm{M}$ & $-Z$ & 40 & 0.203085 & 0.529168 & 0.421641 & 0.747724 & 0.826151 & 1.152234 & 0.950809 & 1.355319 & 1.369257 & 3.666667 \\
\hline 1 & $\mathrm{M}$ & $-Z$ & 60 & 0.184855 & 0.683922 & 0.509792 & 1.008858 & 0.935408 & 1.434475 & 1.193714 & 1.619330 & 2.017920 & 7.666667 \\
\hline 2 & $\mathrm{~F}$ & $+X$ & 20 & 0.546179 & 0.734237 & 0.499359 & 0.687417 & 1.698584 & 1.886642 & 1.233596 & 2.432821 & 0.703149 & 2.333333 \\
\hline 2 & $\mathrm{~F}$ & $+X$ & 40 & 0.607283 & 0.886878 & 0.574432 & 0.854027 & 1.829712 & 2.109306 & 1.461310 & 2.716589 & 0.873712 & 3.333333 \\
\hline 2 & $\mathrm{~F}$ & $+X$ & 60 & 0.608933 & 0.958618 & 0.607301 & 0.956987 & 1.862648 & 2.212333 & 1.565919 & 2.821266 & 0.985831 & 4.6666667 \\
\hline 2 & $\mathrm{~F}$ & $+Y$ & 20 & 0.368742 & 0.457635 & 0.373314 & 0.462206 & 1.150833 & 1.239726 & 0.830949 & 1.608468 & 0.494691 & 2.333333 \\
\hline 2 & $\mathrm{~F}$ & $+Y$ & 40 & 0.365770 & 0.581787 & 0.372821 & 0.588838 & 1.149916 & 1.365933 & 0.954608 & 1.731703 & 0.629587 & 4.666667 \\
\hline 2 & $\mathrm{~F}$ & $+Y$ & 60 & 0.362187 & 0.614821 & 0.369421 & 0.622055 & 1.093941 & 1.346575 & 0.984242 & 1.708762 & 0.676744 & 8.000000 \\
\hline 2 & $\mathrm{~F}$ & $+Z$ & 20 & 0.556263 & 0.759262 & 0.582810 & 0.785809 & 1.503618 & 1.706617 & 1.342072 & 2.262880 & 0.799058 & 4.333333 \\
\hline 2 & $\mathrm{~F}$ & $+Z$ & 40 & 0.669073 & 1.281974 & 0.747066 & 1.359967 & 1.890215 & 2.503116 & 2.029039 & 3.172189 & 1.365188 & 7.333333 \\
\hline 2 & $\mathrm{~F}$ & $+Z$ & 60 & 0.716342 & 1.619139 & 0.405179 & 1.307976 & 1.636013 & 2.538811 & 2.024318 & 3.255153 & 1.312777 & 9.333333 \\
\hline 2 & $\mathrm{~F}$ & $-X$ & 20 & 0.553341 & 0.573208 & 0.463471 & 0.483339 & 1.424146 & 1.444013 & 1.036679 & 1.997354 & 0.510118 & 2.000000 \\
\hline
\end{tabular}




\begin{tabular}{|c|c|c|c|c|c|c|c|c|c|c|c|c|c|}
\hline 2 & $\mathrm{~F}$ & $-x$ & 40 & 0.335101 & 0.454775 & 0.330257 & 0.449930 & 1.378210 & 1.497883 & 0.785032 & 1.832985 & 0.482291 & 2.6666667 \\
\hline 2 & $\mathrm{~F}$ & $-x$ & 60 & 0.342757 & 0.539564 & 0.322153 & 0.518959 & 1.391793 & 1.588599 & 0.861716 & 1.931356 & 0.561575 & 4.000000 \\
\hline 2 & $\mathrm{~F}$ & $-Y$ & 20 & 0.377789 & 0.485657 & 0.421913 & 0.529781 & 1.007085 & 1.114953 & 0.907570 & 1.492742 & 0.533690 & 1.333333 \\
\hline 2 & $\mathrm{~F}$ & $-Y$ & 40 & 0.557865 & 0.802208 & 0.665274 & 0.909617 & 1.609967 & 1.854310 & 1.467482 & 2.412175 & 0.947094 & 4.000000 \\
\hline 2 & $\mathrm{~F}$ & $-Y$ & 60 & 0.665136 & 1.097427 & 0.705138 & 1.137429 & 1.728295 & 2.160586 & 1.802565 & 2.825722 & 1.183995 & 7.666667 \\
\hline 2 & $\mathrm{~F}$ & $-Z$ & 20 & 0.247291 & 0.353358 & 0.516379 & 0.622446 & 0.909535 & 1.015602 & 0.869737 & 1.262894 & 0.871278 & 2.333333 \\
\hline 2 & $\mathrm{~F}$ & $-Z$ & 40 & 0.176487 & 0.402694 & 0.311368 & 0.537575 & 0.526794 & 0.753001 & 0.714062 & 0.929488 & 1.187287 & 5.000000 \\
\hline 2 & $\mathrm{~F}$ & $-Z$ & 60 & 0.178783 & 0.512614 & 0.416817 & 0.750648 & 0.787223 & 1.121054 & 0.929431 & 1.299837 & 1.720450 & 9.666667 \\
\hline 3 & $\mathrm{M}$ & $+X$ & 20 & 0.472587 & 0.709909 & 0.432032 & 0.669354 & 1.552948 & 1.790271 & 1.141941 & 2.262857 & 0.688723 & 0.000000 \\
\hline 3 & $\mathrm{M}$ & $+X$ & 40 & 0.592467 & 0.946262 & 0.546940 & 0.900735 & 1.783570 & 2.137365 & 1.493202 & 2.729832 & 0.918929 & 0.666667 \\
\hline 3 & $M$ & $+X$ & 60 & 0.597025 & 1.114299 & 0.563769 & 1.081043 & 1.801354 & 2.318629 & 1.678067 & 2.915653 & 1.103760 & 2.000000 \\
\hline 3 & $M$ & $+Y$ & 20 & 0.375622 & 0.612623 & 0.369680 & 0.606680 & 1.418705 & 1.655705 & 0.982302 & 2.031328 & 0.638754 & 0.500000 \\
\hline 3 & $M$ & $+Y$ & 40 & 0.372838 & 0.763031 & 0.368693 & 0.758886 & 1.383284 & 1.773477 & 1.131724 & 2.146315 & 0.797722 & 1.666667 \\
\hline 3 & $\mathrm{M}$ & $+Y$ & 60 & 0.374178 & 0.921890 & 0.373306 & 0.921018 & 1.340070 & 1.887782 & 1.295196 & 2.261960 & 0.965614 & 4.000000 \\
\hline 3 & M & $+Z$ & 20 & 0.560106 & 0.844800 & 0.566694 & 0.851388 & 1.478075 & 1.762768 & 1.411494 & 2.322875 & 0.865375 & 1.6666667 \\
\hline 3 & $\mathrm{M}$ & $+Z$ & 40 & 0.663227 & 1.289256 & 0.676912 & 1.302942 & 1.673212 & 2.299241 & 1.966168 & 2.962468 & 1.306094 & 5.666667 \\
\hline 3 & $M$ & $+Z$ & 60 & 0.705539 & 1.683319 & 0.725764 & 1.703544 & 1.739389 & 2.717169 & 2.409083 & 3.422708 & 1.702207 & 8.500000 \\
\hline 3 & $M$ & $-x$ & 20 & 0.568727 & 0.594938 & 0.612492 & 0.638703 & 1.667804 & 1.694015 & 1.207430 & 2.262742 & 0.669813 & 0.166667 \\
\hline 3 & $\mathrm{M}$ & $-x$ & 40 & 0.423272 & 0.517824 & 0.460843 & 0.555395 & 1.196363 & 1.290914 & 0.978667 & 1.714187 & 0.594831 & 0.833333 \\
\hline 3 & $M$ & $-x$ & 60 & 0.346825 & 0.507452 & 0.341859 & 0.502486 & 0.955666 & 1.116293 & 0.849311 & 1.463118 & 0.553200 & 1.333333 \\
\hline 3 & $M$ & $-Y$ & 20 & 0.415928 & 0.481099 & 0.406276 & 0.471447 & 1.421665 & 1.486836 & 0.887375 & 1.902764 & 0.482026 & 0.000000 \\
\hline 3 & $M$ & $-Y$ & 40 & 0.774630 & 0.998228 & 0.816754 & 1.040351 & 2.303897 & 2.527495 & 1.814981 & 3.302125 & 1.035846 & 0.833333 \\
\hline 3 & M & $-Y$ & 60 & 0.736918 & 1.123931 & 0.723887 & 1.110900 & 2.307503 & 2.694516 & 1.847818 & 3.431434 & 1.131386 & 3.666667 \\
\hline 3 & $\mathrm{M}$ & $-Z$ & 20 & 0.273145 & 0.405591 & 0.699822 & 0.832268 & 1.345705 & 1.478151 & 1.105413 & 1.751296 & 0.991394 & 0.333333 \\
\hline 3 & $M$ & $-Z$ & 40 & 0.243823 & 0.530961 & 0.611660 & 0.898798 & 1.190596 & 1.477734 & 1.142620 & 1.721556 & 1.506794 & 3.6666667 \\
\hline 3 & $M$ & $-Z$ & 60 & 0.240602 & 0.679480 & 0.574508 & 1.013386 & 1.184754 & 1.623632 & 1.253988 & 1.864234 & 2.024192 & 6.333333 \\
\hline 4 & $M$ & $+x$ & 20 & 0.464864 & 0.655265 & 0.417255 & 0.607656 & 1.513803 & 1.704204 & 1.072520 & 2.169068 & 0.627338 & 1.000000 \\
\hline 4 & $\mathrm{M}$ & $+X$ & 40 & 0.529681 & 0.890828 & 0.469537 & 0.830683 & 1.615711 & 1.976857 & 1.360365 & 2.506538 & 0.851371 & 1.6666667 \\
\hline 4 & $\mathrm{M}$ & $+X$ & 60 & 0.582271 & 1.096156 & 0.538847 & 1.052732 & 1.754664 & 2.268549 & 1.635003 & 2.850820 & 1.076250 & 2.000000 \\
\hline 4 & $M$ & $+Y$ & 20 & 0.355868 & 0.551782 & 0.352177 & 0.548091 & 1.379783 & 1.575696 & 0.903959 & 1.931565 & 0.581782 & 1.166667 \\
\hline
\end{tabular}




\begin{tabular}{|c|c|c|c|c|c|c|c|c|c|c|c|c|c|}
\hline 4 & $M$ & $+Y$ & 40 & 0.352019 & 0.691131 & 0.349423 & 0.688536 & 1.347545 & 1.686657 & 1.040554 & 2.038676 & 0.729546 & 2.6666667 \\
\hline 4 & $\mathrm{M}$ & $+Y$ & 60 & 0.357488 & 0.847806 & 0.357926 & 0.848244 & 1.292640 & 1.782958 & 1.205732 & 2.140446 & 0.895852 & 4.666667 \\
\hline 4 & $M$ & $+Z$ & 20 & 0.552286 & 0.848543 & 0.561163 & 0.857419 & 1.456245 & 1.752501 & 1.409705 & 2.304788 & 0.871507 & 2.333333 \\
\hline 4 & $\mathrm{M}$ & $+Z$ & 40 & 0.636375 & 1.209696 & 0.660463 & 1.233785 & 1.625384 & 2.198705 & 1.870160 & 2.835080 & 1.243132 & 4.333333 \\
\hline 4 & $M$ & $+Z$ & 60 & 0.680568 & 1.661725 & 0.716117 & 1.697273 & 1.763336 & 2.744492 & 2.377841 & 3.425061 & 1.696987 & 7.833333 \\
\hline 4 & $\mathrm{M}$ & $-X$ & 20 & 0.539723 & 0.562228 & 0.610980 & 0.633485 & 1.590922 & 1.613427 & 1.173208 & 2.153150 & 0.662641 & 1.166667 \\
\hline 4 & $M$ & $-x$ & 40 & 0.357248 & 0.410470 & 0.417218 & 0.470441 & 0.873193 & 0.926415 & 0.827689 & 1.283663 & 0.549934 & 2.166667 \\
\hline 4 & $M$ & $-x$ & 60 & 0.320864 & 0.461173 & 0.344470 & 0.484780 & 0.751671 & 0.891981 & 0.805643 & 1.212844 & 0.643661 & 3.000000 \\
\hline 4 & $\mathrm{M}$ & $-Y$ & 20 & 0.392564 & 0.462766 & 0.389065 & 0.459267 & 1.350719 & 1.420921 & 0.851831 & 1.813485 & 0.468034 & 1.000000 \\
\hline 4 & $\mathrm{M}$ & $-Y$ & 40 & 0.663099 & 0.857427 & 0.631380 & 0.825708 & 2.086641 & 2.280969 & 1.488807 & 2.944068 & 0.841369 & 2.6666667 \\
\hline 4 & $M$ & $-Y$ & 60 & 0.652693 & 0.962241 & 0.627145 & 0.936693 & 1.980388 & 2.289936 & 1.589386 & 2.942629 & 1.080595 & 4.000000 \\
\hline 4 & $M$ & $-Z$ & 20 & 0.285648 & 0.417701 & 0.676603 & 0.808655 & 1.348729 & 1.480781 & 1.094304 & 1.766430 & 0.966470 & 2.666667 \\
\hline 4 & $M$ & $-Z$ & 40 & 0.250781 & 0.561431 & 0.544602 & 0.855252 & 1.153991 & 1.464641 & 1.106033 & 1.715422 & 1.456494 & 4.833333 \\
\hline 4 & $\mathrm{M}$ & $-Z$ & 60 & 0.254011 & 0.710041 & 0.526527 & 0.982557 & 1.173881 & 1.629911 & 1.236568 & 1.883922 & 1.894626 & 8.166667 \\
\hline 5 & M & $+X$ & 20 & 0.463114 & 0.648440 & 0.418467 & 0.603792 & 1.508818 & 1.694144 & 1.066906 & 2.157258 & 0.623377 & 1.333333 \\
\hline 5 & $\mathrm{M}$ & $+X$ & 40 & 0.519498 & 0.852108 & 0.459308 & 0.791918 & 1.593587 & 1.926197 & 1.311416 & 2.445696 & 0.814005 & 3.666667 \\
\hline 5 & $M$ & $+X$ & 60 & 0.562618 & 0.994377 & 0.501252 & 0.933010 & 1.691207 & 2.122966 & 1.495628 & 2.685584 & 0.960288 & 5.000000 \\
\hline 5 & $M$ & $+Y$ & 20 & 0.376823 & 0.562969 & 0.380747 & 0.566894 & 1.252127 & 1.438274 & 0.943717 & 1.815097 & 0.598220 & 2.333333 \\
\hline 5 & $\mathrm{M}$ & $+Y$ & 40 & 0.371551 & 0.666181 & 0.375564 & 0.670194 & 1.227093 & 1.521723 & 1.041745 & 1.893274 & 0.710757 & 4.000000 \\
\hline 5 & $M$ & $+Y$ & 60 & 0.385441 & 0.864473 & 0.394557 & 0.873589 & 1.190393 & 1.669425 & 1.259030 & 2.054865 & 0.920527 & 6.000000 \\
\hline 5 & $M$ & $+Z$ & 20 & 0.530641 & 0.778554 & 0.543363 & 0.791275 & 1.439237 & 1.687149 & 1.321916 & 2.217790 & 0.807193 & 3.000000 \\
\hline 5 & $M$ & $+Z$ & 40 & 0.647525 & 1.218758 & 0.657559 & 1.228792 & 1.634928 & 2.206160 & 1.876317 & 2.853685 & 1.240259 & 6.666667 \\
\hline 5 & $M$ & $+Z$ & 60 & 0.687547 & 1.646586 & 0.547637 & 1.506677 & 1.871952 & 2.830991 & 2.194224 & 3.518539 & 1.509504 & 9.333333 \\
\hline 5 & $\mathrm{M}$ & $-x$ & 20 & 0.429957 & 0.472629 & 0.461910 & 0.504582 & 1.054140 & 1.096812 & 0.934539 & 1.526769 & 0.530315 & 1.666667 \\
\hline 5 & $M$ & $-x$ & 40 & 0.330445 & 0.448034 & 0.324636 & 0.442225 & 0.943495 & 1.061084 & 0.772670 & 1.391529 & 0.475498 & 4.000000 \\
\hline 5 & $M$ & $-x$ & 60 & 0.374469 & 0.514007 & 0.370821 & 0.510359 & 0.984812 & 1.124349 & 0.884828 & 1.498819 & 0.558595 & 4.333333 \\
\hline 5 & $M$ & $-Y$ & 20 & 0.334009 & 0.415554 & 0.360311 & 0.441856 & 0.976073 & 1.057618 & 0.775865 & 1.391627 & 0.450013 & 1.666667 \\
\hline 5 & $\mathrm{M}$ & $-Y$ & 40 & 0.436276 & 0.671453 & 0.592647 & 0.827824 & 1.350409 & 1.585586 & 1.264100 & 2.021862 & 0.866406 & 4.000000 \\
\hline 5 & $\mathrm{M}$ & $-Y$ & 60 & 0.514512 & 0.896414 & 0.588921 & 0.970823 & 1.398528 & 1.780430 & 1.485335 & 2.294942 & 1.221104 & 7.000000 \\
\hline 5 & $M$ & $-Z$ & 20 & 0.270240 & 0.387545 & 0.698532 & 0.815837 & 1.320289 & 1.437594 & 1.086077 & 1.707834 & 0.967692 & 2.333333 \\
\hline
\end{tabular}




\begin{tabular}{|c|c|c|c|c|c|c|c|c|c|c|c|c|c|}
\hline 5 & $M$ & $-Z$ & 40 & 0.188637 & 0.445915 & 0.171402 & 0.428680 & 0.388818 & 0.646096 & 0.617317 & 0.834733 & 1.048903 & 5.333333 \\
\hline 5 & $\mathrm{M}$ & $-Z$ & 60 & 0.191201 & 0.590609 & 0.443341 & 0.842750 & 0.828484 & 1.227893 & 1.033951 & 1.419093 & 1.816604 & 7.333333 \\
\hline 6 & $\mathrm{~F}$ & $+X$ & 20 & 0.610512 & 0.643325 & 0.649103 & 0.681917 & 1.945043 & 1.977856 & 1.292428 & 2.588368 & 0.731774 & 2.000000 \\
\hline 6 & $\mathrm{~F}$ & $+X$ & 40 & 0.373466 & 0.571882 & 0.387808 & 0.586224 & 0.998358 & 1.196775 & 0.959690 & 1.570240 & 0.646169 & 3.666667 \\
\hline 6 & $\mathrm{~F}$ & $+X$ & 60 & 0.361180 & 0.716482 & 0.347918 & 0.703220 & 1.035044 & 1.390346 & 1.064400 & 1.751526 & 0.779501 & 5.333333 \\
\hline 6 & $\mathrm{~F}$ & $+Y$ & 20 & 0.357808 & 0.624897 & 0.355530 & 0.622619 & 1.335060 & 1.602149 & 0.980428 & 1.959958 & 0.671241 & 2.333333 \\
\hline 6 & $\mathrm{~F}$ & $+Y$ & 40 & 0.326873 & 0.641121 & 0.331822 & 0.646070 & 1.069445 & 1.383693 & 0.972943 & 1.710566 & 0.718734 & 6.000000 \\
\hline 6 & $\mathrm{~F}$ & $+Y$ & 60 & 0.328520 & 0.736909 & 0.337342 & 0.745731 & 0.973510 & 1.381899 & 1.074251 & 1.710419 & 0.842217 & 8.000000 \\
\hline 6 & $\mathrm{~F}$ & $+Z$ & 20 & 0.571721 & 1.025471 & 0.581582 & 1.035333 & 1.516970 & 1.970720 & 1.607053 & 2.542441 & 1.049664 & 4.000000 \\
\hline 6 & $\mathrm{~F}$ & $+Z$ & 40 & 0.603778 & 1.603778 & 0.655835 & 1.655835 & 1.678249 & 2.678249 & 2.259614 & 3.282027 & 1.655835 & 9.666667 \\
\hline 6 & $\mathrm{~F}$ & $+Z$ & 60 & $*$ & $*$ & $*$ & 0.580000 & $*$ & $*$ & $*$ & $*$ & 0.580000 & 10.000000 \\
\hline 6 & $\mathrm{~F}$ & $-x$ & 20 & 0.491339 & 0.760313 & 0.430381 & 0.699355 & 1.545794 & 1.814768 & 1.190694 & 2.306107 & 0.723728 & 1.666667 \\
\hline 6 & $\mathrm{~F}$ & $-x$ & 40 & 0.599799 & 1.045123 & 0.568414 & 1.013738 & 1.814502 & 2.259826 & 1.613537 & 2.859625 & 1.040503 & 4.000000 \\
\hline 6 & $\mathrm{~F}$ & $-x$ & 60 & 0.641752 & 1.194341 & 0.738654 & 1.291243 & 2.051957 & 2.604546 & 1.932995 & 3.246298 & 1.332930 & 4.333333 \\
\hline 6 & $\mathrm{~F}$ & $-Y$ & 20 & 0.535205 & 0.636853 & 0.474412 & 0.576060 & 1.763934 & 1.865582 & 1.111265 & 2.400787 & 0.583616 & 2.000000 \\
\hline 6 & $\mathrm{~F}$ & $-Y$ & 40 & 0.741175 & 0.984077 & 0.717212 & 0.960114 & 2.324604 & 2.567506 & 1.701289 & 3.308681 & 0.970647 & 4.333333 \\
\hline 6 & $\mathrm{~F}$ & $-Y$ & 60 & 0.738619 & 1.195446 & 0.719432 & 1.176258 & 2.308785 & 2.765611 & 1.914877 & 3.504230 & 1.229041 & 6.666667 \\
\hline 6 & $\mathrm{~F}$ & $-Z$ & 20 & 0.248136 & 0.447734 & 0.664451 & 0.864048 & 1.165891 & 1.365488 & 1.112185 & 1.613624 & 1.092538 & 2.333333 \\
\hline 6 & $\mathrm{~F}$ & $-Z$ & 40 & 0.223773 & 0.655677 & 0.594992 & 1.026897 & 1.121507 & 1.553412 & 1.250670 & 1.777185 & 1.623836 & 6.333333 \\
\hline 6 & $\mathrm{~F}$ & $-Z$ & 60 & 0.250652 & 0.907524 & 0.536730 & 1.193602 & 1.191862 & 1.848734 & 1.444254 & 2.099386 & 2.180800 & 9.666667 \\
\hline 7 & $\mathrm{~F}$ & $+X$ & 20 & 0.515211 & 0.651514 & 0.445698 & 0.582001 & 1.584025 & 1.720328 & 1.097212 & 2.235539 & 0.596776 & 0.166667 \\
\hline 7 & $\mathrm{~F}$ & $+X$ & 40 & 0.622545 & 0.852039 & 0.641931 & 0.871425 & 1.920061 & 2.149554 & 1.493970 & 2.772099 & 0.892383 & 2.000000 \\
\hline 7 & $\mathrm{~F}$ & $+X$ & 60 & 0.660801 & 0.947071 & 0.859527 & 1.145797 & 2.206265 & 2.492534 & 1.806598 & 3.153336 & 1.177939 & 3.000000 \\
\hline 7 & $\mathrm{~F}$ & $+Y$ & 20 & 0.356033 & 0.481718 & 0.358656 & 0.484341 & 1.237464 & 1.363149 & 0.840375 & 1.719182 & 0.511340 & 1.166667 \\
\hline 7 & $\mathrm{~F}$ & $+Y$ & 40 & 0.351783 & 0.551457 & 0.359004 & 0.558677 & 1.101168 & 1.300841 & 0.910460 & 1.652624 & 0.598158 & 4.166667 \\
\hline 7 & $\mathrm{~F}$ & $+Y$ & 60 & 0.368387 & 0.727944 & 0.380276 & 0.739834 & 1.107917 & 1.467474 & 1.108220 & 1.835861 & 0.788504 & 6.333333 \\
\hline 7 & $\mathrm{~F}$ & $+Z$ & 20 & 0.630167 & 0.885711 & 0.640394 & 0.895938 & 1.639564 & 1.895108 & 1.526105 & 2.525275 & 0.906887 & 2.166667 \\
\hline 7 & $\mathrm{~F}$ & $+Z$ & 40 & 0.756395 & 1.334409 & 0.605353 & 1.183368 & 1.848905 & 2.426920 & 1.939762 & 3.183314 & 1.191015 & 7.000000 \\
\hline 7 & $\mathrm{~F}$ & $+Z$ & 60 & 0.734105 & 1.710148 & 0.406568 & 1.382611 & 1.608257 & 2.584300 & 2.116716 & 3.318405 & 1.384610 & 10.000000 \\
\hline 7 & $\mathrm{~F}$ & $-x$ & 20 & 0.511591 & 0.538443 & 0.555825 & 0.582677 & 1.358581 & 1.385433 & 1.094268 & 1.897024 & 0.606464 & 0.166667 \\
\hline
\end{tabular}




\begin{tabular}{|c|c|c|c|c|c|c|c|c|c|c|c|c|c|}
\hline 7 & $\mathrm{~F}$ & $-x$ & 40 & 0.355896 & 0.475578 & 0.356803 & 0.476486 & 0.980935 & 1.100617 & 0.832382 & 1.456513 & 0.509307 & 1.333333 \\
\hline 7 & $\mathrm{~F}$ & $-x$ & 60 & 0.376304 & 0.582762 & 0.346383 & 0.552841 & 1.073392 & 1.279850 & 0.929145 & 1.656154 & 0.597529 & 2.500000 \\
\hline 7 & $\mathrm{~F}$ & $-Y$ & 20 & 0.333193 & 0.419374 & 0.414640 & 0.500821 & 1.238720 & 1.324901 & 0.834014 & 1.658094 & 0.505742 & 0.666667 \\
\hline 7 & $\mathrm{~F}$ & $-Y$ & 40 & 0.632625 & 0.792956 & 0.592454 & 0.752784 & 1.953405 & 2.113736 & 1.385410 & 2.746361 & 0.896713 & 2.000000 \\
\hline 7 & $\mathrm{~F}$ & $-Y$ & 60 & 0.644503 & 0.885413 & 0.604198 & 0.845109 & 1.986927 & 2.227837 & 1.489611 & 2.872340 & 1.131635 & 4.000000 \\
\hline 7 & $\mathrm{~F}$ & $-Z$ & 20 & 0.246367 & 0.369627 & 0.590525 & 0.713786 & 1.130666 & 1.253927 & 0.960153 & 1.500293 & 0.990933 & 2.000000 \\
\hline 7 & $\mathrm{~F}$ & $-Z$ & 40 & 0.316085 & 0.556594 & 0.480697 & 0.721206 & 1.285840 & 1.526348 & 1.037291 & 1.842434 & 1.348115 & 5.500000 \\
\hline 7 & $\mathrm{~F}$ & $-Z$ & 60 & 0.292099 & 0.655246 & 0.471719 & 0.834866 & 1.234220 & 1.597366 & 1.126965 & 1.889465 & 1.816276 & 9.333333 \\
\hline 8 & $\mathrm{~F}$ & $+X$ & 20 & 0.659739 & 0.673306 & 0.695634 & 0.709201 & 2.059411 & 2.072978 & 1.368940 & 2.732718 & 0.758688 & 0.000000 \\
\hline 8 & $\mathrm{~F}$ & $+X$ & 40 & 0.387706 & 0.487170 & 0.438441 & 0.537905 & 0.975643 & 1.075107 & 0.925611 & 1.462813 & 0.589655 & 3.000000 \\
\hline 8 & $\mathrm{~F}$ & $+X$ & 60 & 0.321519 & 0.496728 & 0.360105 & 0.535313 & 0.756639 & 0.931847 & 0.856832 & 1.253367 & 0.622370 & 5.000000 \\
\hline 8 & $\mathrm{~F}$ & $+Y$ & 20 & 0.387033 & 0.610181 & 0.389334 & 0.612483 & 1.307784 & 1.530932 & 0.999516 & 1.917965 & 0.667962 & 1.500000 \\
\hline 8 & $\mathrm{~F}$ & $+Y$ & 40 & 0.366571 & 0.653568 & 0.372689 & 0.659686 & 1.157310 & 1.444307 & 1.026257 & 1.810878 & 0.728864 & 2.833333 \\
\hline 8 & $\mathrm{~F}$ & $+Y$ & 60 & 0.390014 & 0.995270 & 0.398016 & 1.003272 & 1.225057 & 1.830313 & 1.393286 & 2.220327 & 1.068075 & 7.666667 \\
\hline 8 & $\mathrm{~F}$ & $+Z$ & 20 & 0.478565 & 0.747413 & 0.486435 & 0.755283 & 1.349670 & 1.618518 & 1.233848 & 2.097083 & 0.791307 & 1.833333 \\
\hline 8 & $\mathrm{~F}$ & $+Z$ & 40 & 0.543100 & 1.128423 & 0.561446 & 1.146768 & 1.471411 & 2.056734 & 1.689868 & 2.599834 & 1.166722 & 6.000000 \\
\hline 8 & $\mathrm{~F}$ & $+Z$ & 60 & 0.565964 & 1.455741 & 0.599711 & 1.489488 & 1.573561 & 2.463338 & 2.055452 & 3.029302 & 1.503915 & 9.666667 \\
\hline 8 & $\mathrm{~F}$ & $-x$ & 20 & 0.435708 & 0.710472 & 0.406236 & 0.681000 & 1.514045 & 1.788809 & 1.116708 & 2.224517 & 0.715515 & 0.000000 \\
\hline 8 & $\mathrm{~F}$ & $-x$ & 40 & 0.490002 & 0.943995 & 0.438495 & 0.892488 & 1.564590 & 2.018583 & 1.382490 & 2.508585 & 0.921600 & 1.166667 \\
\hline 8 & $\mathrm{~F}$ & $-x$ & 60 & 0.516411 & 1.164151 & 0.457706 & 1.105446 & 1.592452 & 2.240191 & 1.621857 & 2.756603 & 1.134152 & 1.500000 \\
\hline 8 & $\mathrm{~F}$ & $-Y$ & 20 & 0.610941 & 0.609574 & 0.646228 & 0.644861 & 1.969962 & 1.968595 & 1.255802 & 2.579536 & 0.679927 & 0.000000 \\
\hline 8 & $\mathrm{~F}$ & $-Y$ & 40 & 0.332265 & 0.445938 & 0.398204 & 0.511877 & 1.142423 & 1.256096 & 0.844142 & 1.588361 & 0.638477 & 2.666667 \\
\hline 8 & $\mathrm{~F}$ & $-Y$ & 60 & 0.217163 & 0.436852 & 0.203237 & 0.422926 & 0.746515 & 0.966204 & 0.640089 & 1.183368 & 1.035993 & 5.166667 \\
\hline 8 & $\mathrm{~F}$ & $-Z$ & 20 & 0.297931 & 0.411532 & 0.430295 & 0.543897 & 0.826249 & 0.939850 & 0.841827 & 1.237781 & 0.648540 & 2.166667 \\
\hline 8 & $\mathrm{~F}$ & $-Z$ & 40 & 0.241285 & 0.526512 & 0.649428 & 0.934655 & 1.050204 & 1.335432 & 1.175940 & 1.576716 & 1.635059 & 5.666667 \\
\hline 8 & $\mathrm{~F}$ & $-Z$ & 60 & 0.221759 & 0.638834 & 0.652446 & 1.069521 & 1.078341 & 1.495416 & 1.291280 & 1.717175 & 2.098867 & 10.000000 \\
\hline 9 & $\mathrm{~F}$ & $+x$ & 20 & 0.506366 & 0.752228 & 0.432087 & 0.677949 & 1.553731 & 1.799593 & 1.184315 & 2.305959 & 0.700359 & 1.166667 \\
\hline 9 & $\mathrm{~F}$ & $+X$ & 40 & 0.560645 & 1.023866 & 0.486920 & 0.950142 & 1.674969 & 2.138191 & 1.510787 & 2.698835 & 0.980647 & 2.500000 \\
\hline 9 & $\mathrm{~F}$ & $+X$ & 60 & 0.592069 & 1.160900 & 0.616409 & 1.185240 & 1.846361 & 2.415191 & 1.777309 & 3.007261 & 1.232863 & 3.833333 \\
\hline 9 & $\mathrm{~F}$ & $+Y$ & 20 & 0.342777 & 0.434423 & 0.344617 & 0.436262 & 1.050059 & 1.141704 & 0.779040 & 1.484481 & 0.493908 & 3.833333 \\
\hline
\end{tabular}




\begin{tabular}{|c|c|c|c|c|c|c|c|c|c|c|c|c|c|}
\hline 9 & $\mathrm{~F}$ & $+Y$ & 40 & 0.331122 & 0.517528 & 0.332664 & 0.519071 & 1.004456 & 1.190863 & 0.850193 & 1.521984 & 0.602169 & 7.000000 \\
\hline 9 & $\mathrm{~F}$ & $+Y$ & 60 & 0.333211 & 0.623180 & 0.341727 & 0.631696 & 0.966995 & 1.256964 & 0.964907 & 1.590175 & 0.742574 & 9.500000 \\
\hline 9 & $\mathrm{~F}$ & $+Z$ & 20 & 0.579576 & 1.011214 & 0.600736 & 1.032374 & 1.564107 & 1.995746 & 1.611950 & 2.575322 & 1.046162 & 4.333333 \\
\hline 9 & $\mathrm{~F}$ & $+Z$ & 40 & 0.665548 & 1.665548 & 0.697119 & 1.697119 & 1.759506 & 2.759506 & 2.362668 & 3.425054 & 1.697119 & 9.333333 \\
\hline 9 & $\mathrm{~F}$ & $+Z$ & 60 & $*$ & $*$ & $*$ & 0.580000 & $*$ & $*$ & $*$ & $*$ & 0.580000 & 10.000000 \\
\hline 9 & $\mathrm{~F}$ & $-X$ & 20 & 0.353838 & 0.467555 & 0.383834 & 0.497551 & 0.885170 & 0.998888 & 0.851389 & 1.352726 & 0.531412 & 1.000000 \\
\hline 9 & $\mathrm{~F}$ & $-x$ & 40 & 0.318612 & 0.570473 & 0.303172 & 0.555033 & 0.876847 & 1.128708 & 0.873645 & 1.447320 & 0.604765 & 2.666667 \\
\hline 9 & $\mathrm{~F}$ & $-x$ & 60 & 0.315397 & 0.744281 & 0.250874 & 0.679758 & 0.844268 & 1.273153 & 0.995155 & 1.588549 & 0.780607 & 3.500000 \\
\hline 9 & $\mathrm{~F}$ & $-Y$ & 20 & 0.556481 & 0.699756 & 0.437904 & 0.581179 & 1.751236 & 1.894511 & 1.137660 & 2.450993 & 0.578550 & 2.333333 \\
\hline 9 & $\mathrm{~F}$ & $-Y$ & 40 & 0.655022 & 1.065939 & 0.664551 & 1.075468 & 1.880668 & 2.291585 & 1.730490 & 2.946607 & 1.134195 & 4.166667 \\
\hline 9 & $\mathrm{~F}$ & $-Y$ & 60 & 0.706660 & 1.191222 & 0.675336 & 1.159898 & 2.213830 & 2.698392 & 1.866558 & 3.405052 & 1.281924 & 7.833333 \\
\hline 9 & $\mathrm{~F}$ & $-Z$ & 20 & 0.228009 & 0.453019 & 0.492481 & 0.717491 & 0.894798 & 1.119808 & 0.945500 & 1.347817 & 0.962572 & 2.666667 \\
\hline 9 & $\mathrm{~F}$ & $-Z$ & 40 & 0.169955 & 0.686955 & 0.144195 & 0.661196 & 0.401641 & 0.918641 & 0.831151 & 1.088596 & 1.352416 & 7.833333 \\
\hline 9 & $\mathrm{~F}$ & $-Z$ & 60 & 0.162325 & 0.897319 & 0.167017 & 0.902011 & 0.313959 & 1.048953 & 1.064336 & 1.211278 & 1.977147 & 10.000000 \\
\hline 10 & M & $+X$ & 20 & 0.438130 & 0.666210 & 0.397900 & 0.625980 & 1.454474 & 1.682554 & 1.064110 & 2.120684 & 0.651197 & 1.666667 \\
\hline 10 & $\mathrm{M}$ & $+X$ & 40 & 0.482706 & 0.870773 & 0.410114 & 0.798182 & 1.502215 & 1.890282 & 1.280887 & 2.372988 & 0.823361 & 1.666667 \\
\hline 10 & $M$ & $+X$ & 60 & 0.541960 & 1.066934 & 0.471660 & 0.996635 & 1.633053 & 2.158027 & 1.538595 & 2.699987 & 1.023751 & 3.000000 \\
\hline 10 & $M$ & $+Y$ & 20 & 0.362526 & 0.462957 & 0.362647 & 0.463078 & 1.177629 & 1.278060 & 0.825604 & 1.640586 & 0.510680 & 1.000000 \\
\hline 10 & $\mathrm{M}$ & $+Y$ & 40 & 0.410330 & 0.503691 & 0.393709 & 0.487070 & 1.244906 & 1.338266 & 0.897400 & 1.748597 & 0.557334 & 2.666667 \\
\hline 10 & $M$ & $+Y$ & 60 & 0.389041 & 0.569123 & 0.382746 & 0.562828 & 1.163935 & 1.344017 & 0.951869 & 1.733057 & 0.649165 & 3.333333 \\
\hline 10 & $M$ & $+Z$ & 20 & 0.516977 & 0.806950 & 0.526904 & 0.816878 & 1.389424 & 1.679398 & 1.333854 & 2.196374 & 0.840849 & 2.666667 \\
\hline 10 & $M$ & $+Z$ & 40 & 0.582496 & 1.137022 & 0.603288 & 1.157813 & 1.604681 & 2.159206 & 1.740310 & 2.741703 & 1.174600 & 5.000000 \\
\hline 10 & M & $+Z$ & 60 & 0.685013 & 1.657620 & 0.710206 & 1.682813 & 1.759355 & 2.731962 & 2.367826 & 3.416975 & 1.681791 & 7.666667 \\
\hline 10 & $\mathrm{M}$ & $-x$ & 20 & 0.487340 & 0.522447 & 0.536245 & 0.571353 & 1.379641 & 1.414749 & 1.058692 & 1.902089 & 0.605675 & 3.000000 \\
\hline 10 & $M$ & $-x$ & 40 & 0.321238 & 0.440872 & 0.346036 & 0.465670 & 0.825294 & 0.944928 & 0.786908 & 1.266166 & 0.506217 & 2.666667 \\
\hline 10 & $M$ & $-x$ & 60 & 0.297179 & 0.540589 & 0.275508 & 0.518918 & 0.819024 & 1.062434 & 0.816097 & 1.359613 & 0.606532 & 3.333333 \\
\hline 10 & $M$ & $-Y$ & 20 & 0.353579 & 0.401363 & 0.357295 & 0.405078 & 1.117061 & 1.164845 & 0.758657 & 1.518424 & 0.419862 & 2.000000 \\
\hline 10 & $\mathrm{M}$ & $-Y$ & 40 & 0.214978 & 0.399383 & 0.177652 & 0.362057 & 0.679617 & 0.864022 & 0.577035 & 1.079000 & 0.480878 & 3.333333 \\
\hline 10 & $\mathrm{M}$ & $-Y$ & 60 & 0.539624 & 0.856161 & 0.543861 & 0.860399 & 1.579838 & 1.896375 & 1.400022 & 2.435999 & 1.052436 & 3.666667 \\
\hline 10 & $M$ & $-Z$ & 20 & 0.289269 & 0.425720 & 0.642706 & 0.779158 & 1.182960 & 1.319411 & 1.068426 & 1.608680 & 0.954244 & 1.333333 \\
\hline
\end{tabular}




\begin{tabular}{|c|c|c|c|c|c|c|c|c|c|c|c|c|c|}
\hline 10 & $M$ & $-Z$ & 40 & 0.253684 & 0.594448 & 0.359383 & 0.700146 & 0.785039 & 1.125803 & 0.953831 & 1.379487 & 1.333769 & 4.000000 \\
\hline 10 & $\mathrm{M}$ & $-Z$ & 60 & 0.210092 & 0.715252 & 0.338024 & 0.843184 & 0.794652 & 1.299812 & 1.053276 & 1.509904 & 1.829352 & 6.000000 \\
\hline 11 & $M$ & $+X$ & 20 & 0.488968 & 0.692674 & 0.442862 & 0.646567 & 1.561225 & 1.764930 & 1.135535 & 2.253899 & 0.666203 & 0.666667 \\
\hline 11 & $\mathrm{M}$ & $+X$ & 40 & 0.575964 & 0.896300 & 0.526014 & 0.846350 & 1.737103 & 2.057439 & 1.422314 & 2.633403 & 0.868199 & 2.333333 \\
\hline 11 & $M$ & $+X$ & 60 & 0.580592 & 0.970264 & 0.539599 & 0.929271 & 1.752976 & 2.142648 & 1.509863 & 2.723240 & 0.960156 & 3.000000 \\
\hline 11 & $\mathrm{M}$ & $+Y$ & 20 & 0.365648 & 0.520715 & 0.367376 & 0.522443 & 1.275659 & 1.430726 & 0.888091 & 1.796374 & 0.557172 & 1.333333 \\
\hline 11 & $M$ & $+Y$ & 40 & 0.377264 & 0.705486 & 0.376259 & 0.704480 & 1.348444 & 1.676666 & 1.081744 & 2.053930 & 0.745946 & 4.000000 \\
\hline 11 & $M$ & $+Y$ & 60 & 0.384596 & 0.833597 & 0.393664 & 0.842665 & 1.195602 & 1.644603 & 1.227261 & 2.029198 & 0.894902 & 4.666667 \\
\hline 11 & $\mathrm{M}$ & $+Z$ & 20 & 0.551863 & 0.813730 & 0.560670 & 0.822537 & 1.463105 & 1.724972 & 1.374400 & 2.276835 & 0.839578 & 2.333333 \\
\hline 11 & $\mathrm{M}$ & $+Z$ & 40 & 0.644616 & 1.162700 & 0.661035 & 1.179118 & 1.649832 & 2.167916 & 1.823735 & 2.812532 & 1.195161 & 5.000000 \\
\hline 11 & $M$ & $+Z$ & 60 & 0.741792 & 1.666471 & 0.401320 & 1.325999 & 1.681567 & 2.606247 & 2.067791 & 3.348038 & 1.331001 & 8.000000 \\
\hline 11 & $M$ & $-x$ & 20 & 0.414413 & 0.452854 & 0.464646 & 0.503086 & 1.043993 & 1.082434 & 0.917500 & 1.496847 & 0.529103 & 0.666667 \\
\hline 11 & $M$ & $-x$ & 40 & 0.286694 & 0.390895 & 0.295327 & 0.399528 & 0.747416 & 0.851617 & 0.686222 & 1.138311 & 0.457917 & 2.000000 \\
\hline 11 & $\mathrm{M}$ & $-x$ & 60 & 0.284757 & 0.447956 & 0.264824 & 0.428023 & 0.754560 & 0.917759 & 0.712780 & 1.202516 & 0.555990 & 2.666667 \\
\hline 11 & M & $-Y$ & 20 & 0.326584 & 0.403868 & 0.346395 & 0.423679 & 0.984873 & 1.062157 & 0.750263 & 1.388741 & 0.430687 & 0.6666667 \\
\hline 11 & $\mathrm{M}$ & $-Y$ & 40 & 0.334533 & 0.536779 & 0.383647 & 0.585894 & 0.934745 & 1.136991 & 0.920427 & 1.471524 & 0.727282 & 3.000000 \\
\hline 11 & $M$ & $-Y$ & 60 & 0.534220 & 0.867492 & 0.574657 & 0.907929 & 1.454549 & 1.787821 & 1.442149 & 2.322042 & 1.136041 & 4.333333 \\
\hline 11 & M & $-Z$ & 20 & 0.262100 & 0.381214 & 0.643847 & 0.762961 & 1.119036 & 1.238150 & 1.025061 & 1.500250 & 0.951983 & 1.666667 \\
\hline 11 & $\mathrm{M}$ & $-Z$ & 40 & 0.201491 & 0.487032 & 0.178633 & 0.464174 & 0.464234 & 0.749775 & 0.665665 & 0.951266 & 1.076922 & 4.000000 \\
\hline 11 & $M$ & $-Z$ & 60 & 0.178320 & 0.614416 & 0.248165 & 0.684261 & 0.640113 & 1.076209 & 0.862581 & 1.254529 & 1.657535 & 7.000000 \\
\hline 12 & $M$ & $+X$ & 20 & 0.453498 & 0.629805 & 0.391472 & 0.567778 & 1.457480 & 1.633786 & 1.021277 & 2.087285 & 0.592509 & 2.000000 \\
\hline 12 & $M$ & $+X$ & 40 & 0.510120 & 0.774648 & 0.418126 & 0.682655 & 1.541647 & 1.806176 & 1.192775 & 2.316296 & 0.708780 & 3.000000 \\
\hline 12 & M & $+X$ & 60 & 0.547568 & 0.938558 & 0.449494 & 0.840484 & 1.619348 & 2.010338 & 1.388052 & 2.557906 & 0.873074 & 4.333333 \\
\hline 12 & $\mathrm{M}$ & $+Y$ & 20 & 0.442186 & 0.511571 & 0.431872 & 0.501258 & 1.401423 & 1.470809 & 0.943444 & 1.912994 & 0.555104 & 2.000000 \\
\hline 12 & $M$ & $+Y$ & 40 & 0.404844 & 0.463935 & 0.381874 & 0.440965 & 1.241932 & 1.301023 & 0.845809 & 1.705867 & 0.517661 & 3.666667 \\
\hline 12 & $M$ & $+Y$ & 60 & 0.439168 & 0.499759 & 0.397453 & 0.458044 & 1.330671 & 1.391262 & 0.897213 & 1.830431 & 0.560742 & 5.666667 \\
\hline 12 & $M$ & $+Z$ & 20 & 0.523905 & 0.803747 & 0.539106 & 0.818947 & 1.434008 & 1.713849 & 1.342852 & 2.237755 & 0.836098 & 3.000000 \\
\hline 12 & $\mathrm{M}$ & $+Z$ & 40 & 0.613679 & 1.164677 & 0.633460 & 1.184458 & 1.623414 & 2.174412 & 1.798137 & 2.788091 & 1.196210 & 5.000000 \\
\hline 12 & $\mathrm{M}$ & $+Z$ & 60 & 0.669037 & 1.632838 & 0.692777 & 1.656578 & 1.709888 & 2.673689 & 2.325615 & 3.342726 & 1.659288 & 8.333333 \\
\hline 12 & $M$ & $-x$ & 20 & 0.485237 & 0.530559 & 0.529398 & 0.574721 & 1.350336 & 1.395658 & 1.059957 & 1.880895 & 0.610086 & 2.333333 \\
\hline
\end{tabular}




\begin{tabular}{|c|c|c|c|c|c|c|c|c|c|c|c|c|c|}
\hline 12 & $M$ & $-x$ & 40 & 0.340026 & 0.467972 & 0.369293 & 0.497239 & 0.848870 & 0.976817 & 0.837265 & 1.316842 & 0.538322 & 3.333333 \\
\hline 12 & $\mathrm{M}$ & $-x$ & 60 & 0.349316 & 0.522757 & 0.371348 & 0.544789 & 0.885349 & 1.058790 & 0.894105 & 1.408106 & 0.600278 & 4.000000 \\
\hline 12 & $M$ & $-Y$ & 20 & 0.394693 & 0.479269 & 0.376013 & 0.460589 & 1.270187 & 1.354763 & 0.855282 & 1.749456 & 0.470286 & 2.333333 \\
\hline 12 & $\mathrm{M}$ & $-Y$ & 40 & 0.694600 & 0.774170 & 0.652066 & 0.731636 & 2.168120 & 2.247691 & 1.426236 & 2.942290 & 0.752470 & 3.666667 \\
\hline 12 & $M$ & $-Y$ & 60 & 0.674168 & 0.785352 & 0.510796 & 0.621981 & 2.103141 & 2.214326 & 1.296148 & 2.888493 & 0.789047 & 5.333333 \\
\hline 12 & $\mathrm{M}$ & $-Z$ & 20 & 0.356582 & 0.547291 & 0.397990 & 0.588700 & 1.107928 & 1.298638 & 0.945281 & 1.655219 & 0.849722 & 3.6666667 \\
\hline 12 & $M$ & $-Z$ & 40 & 0.246972 & 0.583981 & 0.386031 & 0.723040 & 0.800879 & 1.137888 & 0.970012 & 1.384860 & 1.195805 & 5.666667 \\
\hline 12 & $M$ & $-Z$ & 60 & 0.278833 & 0.872164 & 0.316824 & 0.910155 & 0.913414 & 1.506745 & 1.188988 & 1.785578 & 1.906925 & 8.333333 \\
\hline 13 & $\mathrm{~F}$ & $+X$ & 20 & 0.513078 & 0.665949 & 0.452399 & 0.605270 & 1.596497 & 1.749368 & 1.118348 & 2.262446 & 0.619640 & 0.500000 \\
\hline 13 & $\mathrm{~F}$ & $+X$ & 40 & 0.581334 & 0.786299 & 0.527804 & 0.732769 & 1.750266 & 1.955230 & 1.314103 & 2.536564 & 0.752556 & 0.833333 \\
\hline 13 & $\mathrm{~F}$ & $+X$ & 60 & 0.609511 & 0.931140 & 0.638655 & 0.960284 & 1.893560 & 2.215190 & 1.569794 & 2.824700 & 0.985533 & 1.666667 \\
\hline 13 & $\mathrm{~F}$ & $+Y$ & 20 & 0.352718 & 0.405519 & 0.355097 & 0.407898 & 1.083439 & 1.136240 & 0.760615 & 1.488957 & 0.444920 & 1.000000 \\
\hline 13 & $\mathrm{~F}$ & $+Y$ & 40 & 0.362945 & 0.533835 & 0.369247 & 0.540136 & 1.086236 & 1.257126 & 0.903082 & 1.620071 & 0.585530 & 1.833333 \\
\hline 13 & $\mathrm{~F}$ & $+Y$ & 60 & 0.394130 & 0.860961 & 0.404740 & 0.871571 & 1.182164 & 1.648995 & 1.265701 & 2.043125 & 0.912115 & 4.000000 \\
\hline 13 & $\mathrm{~F}$ & $+Z$ & 20 & 0.531847 & 0.743989 & 0.550968 & 0.763109 & 1.480244 & 1.692386 & 1.294957 & 2.224233 & 0.776588 & 1.000000 \\
\hline 13 & $\mathrm{~F}$ & $+Z$ & 40 & 0.577796 & 1.160172 & 0.633585 & 1.215960 & 1.632776 & 2.215151 & 1.793756 & 2.792948 & 1.219301 & 4.166667 \\
\hline 13 & $\mathrm{~F}$ & $+Z$ & 60 & 0.579284 & 1.558350 & 0.662721 & 1.641787 & 1.657318 & 2.636383 & 2.221071 & 3.215668 & 1.641759 & 5.500000 \\
\hline 13 & $\mathrm{~F}$ & $-x$ & 20 & 0.439171 & 0.478411 & 0.495950 & 0.535190 & 1.135766 & 1.175007 & 0.974361 & 1.614178 & 0.559050 & 0.166667 \\
\hline 13 & $\mathrm{~F}$ & $-x$ & 40 & 0.361341 & 0.442375 & 0.407848 & 0.488882 & 0.833883 & 0.914917 & 0.850223 & 1.276258 & 0.547137 & 0.833333 \\
\hline 13 & $\mathrm{~F}$ & $-x$ & 60 & 0.313305 & 0.453159 & 0.325355 & 0.465209 & 0.761805 & 0.901659 & 0.778515 & 1.214965 & 0.636998 & 1.500000 \\
\hline 13 & $\mathrm{~F}$ & $-Y$ & 20 & 0.518426 & 0.559771 & 0.423095 & 0.464440 & 1.725299 & 1.766643 & 0.982866 & 2.285069 & 0.470841 & 0.000000 \\
\hline 13 & $\mathrm{~F}$ & $-Y$ & 40 & 0.737199 & 0.845069 & 0.692437 & 0.800307 & 2.295956 & 2.403826 & 1.537506 & 3.141025 & 0.823933 & 1.000000 \\
\hline 13 & $\mathrm{~F}$ & $-Y$ & 60 & 0.746411 & 0.915689 & 0.703608 & 0.872886 & 2.349441 & 2.518718 & 1.619297 & 3.265129 & 0.915382 & 2.833333 \\
\hline 13 & $\mathrm{~F}$ & $-Z$ & 20 & 0.295229 & 0.414156 & 0.647044 & 0.765972 & 1.381336 & 1.500264 & 1.061200 & 1.795492 & 0.983422 & 1.500000 \\
\hline 13 & $\mathrm{~F}$ & $-Z$ & 40 & 0.358920 & 0.606578 & 0.522269 & 0.769928 & 1.406155 & 1.653814 & 1.128847 & 2.012733 & 1.359753 & 4.500000 \\
\hline 13 & $\mathrm{~F}$ & $-Z$ & 60 & 0.331969 & 0.704126 & 0.501544 & 0.873701 & 1.324178 & 1.696334 & 1.205670 & 2.028303 & 1.784827 & 7.333333 \\
\hline 14 & $\mathrm{~F}$ & $+x$ & 20 & 0.445800 & 0.667014 & 0.411918 & 0.633132 & 1.498158 & 1.719371 & 1.078932 & 2.165171 & 0.661510 & 0.000000 \\
\hline 14 & $\mathrm{~F}$ & $+X$ & 40 & 0.503382 & 0.844394 & 0.441065 & 0.782078 & 1.557092 & 1.898104 & 1.285460 & 2.401486 & 0.810488 & 1.500000 \\
\hline 14 & $\mathrm{~F}$ & $+X$ & 60 & 0.575571 & 1.156986 & 0.530160 & 1.111576 & 1.737332 & 2.318748 & 1.687146 & 2.894318 & 1.137720 & 3.000000 \\
\hline 14 & $\mathrm{~F}$ & $+Y$ & 20 & 0.387313 & 0.501864 & 0.391717 & 0.506268 & 1.185028 & 1.299579 & 0.893581 & 1.686892 & 0.555511 & 1.166667 \\
\hline
\end{tabular}




\begin{tabular}{|c|c|c|c|c|c|c|c|c|c|c|c|c|c|}
\hline 14 & $\mathrm{~F}$ & $+Y$ & 40 & 0.358235 & 0.568491 & 0.365111 & 0.575366 & 1.091935 & 1.302190 & 0.933601 & 1.660426 & 0.635944 & 4.000000 \\
\hline 14 & $\mathrm{~F}$ & $+Y$ & 60 & 0.366042 & 0.693982 & 0.373154 & 0.701094 & 1.096919 & 1.424859 & 1.067137 & 1.790902 & 0.773467 & 6.333333 \\
\hline 14 & $\mathrm{~F}$ & $+Z$ & 20 & 0.478191 & 0.728485 & 0.487716 & 0.738011 & 1.361039 & 1.611333 & 1.216202 & 2.089524 & 0.767288 & 2.000000 \\
\hline 14 & $\mathrm{~F}$ & $+Z$ & 40 & 0.565982 & 1.099891 & 0.585676 & 1.119585 & 1.524896 & 2.058805 & 1.685567 & 2.624787 & 1.139460 & 3.666667 \\
\hline 14 & $\mathrm{~F}$ & $+Z$ & 60 & 0.618241 & 1.584017 & 0.657459 & 1.623235 & 1.693778 & 2.659553 & 2.241476 & 3.277795 & 1.628015 & 8.333333 \\
\hline 14 & $\mathrm{~F}$ & $-X$ & 20 & 0.654737 & 0.653198 & 0.694262 & 0.692722 & 2.057677 & 2.056138 & 1.347459 & 2.710875 & 0.735311 & 0.333333 \\
\hline 14 & $\mathrm{~F}$ & $-x$ & 40 & 0.428684 & 0.510811 & 0.479336 & 0.561463 & 1.037096 & 1.119223 & 0.990147 & 1.547907 & 0.609903 & 1.666667 \\
\hline 14 & $\mathrm{~F}$ & $-x$ & 60 & 0.342616 & 0.485841 & 0.379499 & 0.522724 & 0.803772 & 0.946996 & 0.865340 & 1.289612 & 0.601841 & 2.666667 \\
\hline 14 & $\mathrm{~F}$ & $-Y$ & 20 & 0.362355 & 0.400819 & 0.369669 & 0.408134 & 1.141531 & 1.179996 & 0.770488 & 1.542350 & 0.427662 & 0.833333 \\
\hline 14 & $\mathrm{~F}$ & $-Y$ & 40 & 0.171065 & 0.340504 & 0.222876 & 0.392314 & 0.589617 & 0.759056 & 0.563379 & 0.930121 & 0.504796 & 3.666667 \\
\hline 14 & $\mathrm{~F}$ & $-Y$ & 60 & 0.491177 & 0.787449 & 0.472800 & 0.769072 & 1.488692 & 1.784964 & 1.260249 & 2.276140 & 1.018109 & 7.000000 \\
\hline 14 & $\mathrm{~F}$ & $-Z$ & 20 & 0.310538 & 0.435774 & 0.659486 & 0.784723 & 1.253526 & 1.378763 & 1.095261 & 1.689301 & 0.924749 & 2.666667 \\
\hline 14 & $\mathrm{~F}$ & $-Z$ & 40 & 0.250774 & 0.548866 & 0.459162 & 0.757254 & 0.939994 & 1.238086 & 1.008028 & 1.488860 & 1.295742 & 5.000000 \\
\hline 14 & $\mathrm{~F}$ & $-Z$ & 60 & 0.233717 & 0.695814 & 0.381506 & 0.843602 & 0.922745 & 1.384842 & 1.077319 & 1.618559 & 1.765501 & 9.000000 \\
\hline 15 & $M$ & $+X$ & 20 & 0.443300 & 0.563797 & 0.395188 & 0.515685 & 1.452390 & 1.572887 & 0.958985 & 2.016186 & 0.532826 & 0.666667 \\
\hline 15 & $\mathrm{M}$ & $+X$ & 40 & 0.511656 & 0.711874 & 0.429832 & 0.630050 & 1.555357 & 1.755575 & 1.141706 & 2.267231 & 0.647464 & 2.666667 \\
\hline 15 & $M$ & $+X$ & 60 & 0.554626 & 0.868081 & 0.482713 & 0.796167 & 1.661357 & 1.974812 & 1.350793 & 2.529438 & 0.816208 & 4.000000 \\
\hline 15 & M & $+Y$ & 20 & 0.389801 & 0.582452 & 0.382892 & 0.575543 & 1.419215 & 1.611866 & 0.965344 & 2.001667 & 0.600248 & 3.000000 \\
\hline 15 & $\mathrm{M}$ & $+Y$ & 40 & 0.395192 & 0.715981 & 0.390276 & 0.711065 & 1.420807 & 1.741596 & 1.106257 & 2.136788 & 0.738585 & 4.000000 \\
\hline 15 & $\mathrm{M}$ & $+Y$ & 60 & 0.402907 & 0.748238 & 0.411102 & 0.756432 & 1.227028 & 1.572358 & 1.159339 & 1.975265 & 0.797821 & 6.000000 \\
\hline 15 & $M$ & $+Z$ & 20 & 0.502876 & 0.686296 & 0.508530 & 0.691950 & 1.431203 & 1.614623 & 1.194826 & 2.117499 & 0.710776 & 5.000000 \\
\hline 15 & $M$ & $+Z$ & 40 & 0.686506 & 1.473381 & 0.677170 & 1.464046 & 2.007303 & 2.794179 & 2.150551 & 3.480684 & 1.464973 & 7.666667 \\
\hline 15 & $\mathrm{M}$ & $+Z$ & 60 & 0.629408 & 1.465678 & 0.629714 & 1.465985 & 1.675439 & 2.511709 & 2.095392 & 3.141117 & 1.465631 & 9.6666667 \\
\hline 15 & $\mathrm{M}$ & $-x$ & 20 & 0.505813 & 0.531060 & 0.557807 & 0.583053 & 1.430870 & 1.456117 & 1.088866 & 1.961930 & 0.606436 & 1.000000 \\
\hline 15 & $M$ & $-x$ & 40 & 0.298030 & 0.384231 & 0.323336 & 0.409537 & 0.761528 & 0.847729 & 0.707567 & 1.145759 & 0.453022 & 2.666667 \\
\hline 15 & $M$ & $-x$ & 60 & 0.284824 & 0.436218 & 0.270932 & 0.422326 & 0.734443 & 0.885837 & 0.707150 & 1.170661 & 0.551237 & 5.000000 \\
\hline 15 & $M$ & $-Y$ & 20 & 0.572507 & 0.578177 & 0.511912 & 0.517582 & 1.937329 & 1.942999 & 1.090090 & 2.515507 & 0.531194 & 2.000000 \\
\hline 15 & $\mathrm{M}$ & $-Y$ & 40 & 0.666489 & 0.765369 & 0.476195 & 0.575075 & 1.914795 & 2.013675 & 1.241564 & 2.680164 & 0.574938 & 3.6666667 \\
\hline 15 & $\mathrm{M}$ & $-Y$ & 60 & 0.735923 & 0.884713 & 0.704234 & 0.853024 & 2.330105 & 2.478895 & 1.588947 & 3.214818 & 0.883384 & 5.666667 \\
\hline 15 & $M$ & $-Z$ & 20 & 0.314106 & 0.413768 & 0.322104 & 0.421767 & 0.666242 & 0.765905 & 0.735873 & 1.080011 & 0.625162 & 3.333333 \\
\hline
\end{tabular}




\begin{tabular}{|c|c|c|c|c|c|c|c|c|c|c|c|c|c|}
\hline 15 & M & $-z$ & 40 & 0.247191 & 0.481596 & 0.251669 & 0.486074 & 0.671510 & 0.905916 & 0.733265 & 1.153106 & 1.104477 & 6.000000 \\
\hline 15 & M & $-Z$ & 60 & 0.202227 & 0.544405 & 0.205102 & 0.547280 & 0.439462 & 0.781640 & 0.749507 & 0.983868 & 1.022519 & 8.666667 \\
\hline
\end{tabular}


Appendix I: Data for Strain Index 9 (Raw, Transformed, and BackTransformed) 


\begin{tabular}{|c|c|c|c|c|c|c|}
\hline Subject & Gender & Direction & $\begin{array}{c}\text { Force } \\
\text { Ivl }\end{array}$ & SI 9 & $\begin{array}{c}\text { SI 9 } \\
\text { johnson } \\
\text { transform }\end{array}$ & $\begin{array}{c}\text { SI 9 back } \\
\text { transform }\end{array}$ \\
\hline 1 & $\mathrm{M}$ & $+\mathrm{X}$ & 20 & 0.674574 & -0.413767 & 0.674576 \\
\hline 1 & $\mathrm{M}$ & $+\mathrm{X}$ & 40 & 0.870475 & 0.174348 & 0.870478 \\
\hline 1 & $\mathrm{M}$ & $+\mathrm{X}$ & 60 & 1.086331 & 0.635246 & 1.086334 \\
\hline 1 & $\mathrm{M}$ & $+\mathrm{Y}$ & 20 & 0.618336 & -0.650551 & 0.618337 \\
\hline 1 & $\mathrm{M}$ & $+\mathrm{Y}$ & 40 & 0.775179 & -0.079853 & 0.775181 \\
\hline 1 & $\mathrm{M}$ & $+\mathrm{Y}$ & 60 & 0.952654 & 0.363970 & 0.952657 \\
\hline 1 & $\mathrm{M}$ & $+\mathrm{Z}$ & 20 & 0.851914 & 0.128193 & 0.851916 \\
\hline 1 & $\mathrm{M}$ & $+\mathrm{Z}$ & 40 & 1.266003 & 0.956351 & 1.266007 \\
\hline 1 & $\mathrm{M}$ & $+\mathrm{Z}$ & 60 & 1.674407 & 1.618953 & 1.674412 \\
\hline 1 & $\mathrm{M}$ & $-\mathrm{X}$ & 20 & 0.727825 & -0.226129 & 0.727827 \\
\hline 1 & $\mathrm{M}$ & $-\mathrm{X}$ & 40 & 0.519030 & -1.258776 & 0.519031 \\
\hline 1 & $\mathrm{M}$ & $-\mathrm{X}$ & 60 & 0.617519 & -0.654379 & 0.617521 \\
\hline 1 & $\mathrm{M}$ & $-\mathrm{Y}$ & 20 & 0.508880 & -1.347002 & 0.508881 \\
\hline 1 & $\mathrm{M}$ & $-\mathrm{Y}$ & 40 & 0.921408 & 0.294418 & 0.921411 \\
\hline 1 & $\mathrm{M}$ & $-\mathrm{Y}$ & 60 & 1.332661 & 1.067943 & 1.332665 \\
\hline 1 & $\mathrm{M}$ & $-\mathrm{Z}$ & 20 & 1.004524 & 0.473734 & 1.004527 \\
\hline 1 & $\mathrm{M}$ & $-\mathrm{Z}$ & 40 & 1.369257 & 1.128109 & 1.369261 \\
\hline 1 & $\mathrm{M}$ & $-\mathrm{Z}$ & 60 & 2.017920 & 2.217604 & 2.017925 \\
\hline 2 & $\mathrm{~F}$ & $+\mathrm{X}$ & 20 & 0.703149 & -0.309538 & 0.703150 \\
\hline 2 & $\mathrm{~F}$ & $+\mathrm{X}$ & 40 & 0.873712 & 0.182255 & 0.873714 \\
\hline 2 & $\mathrm{~F}$ & $+\mathrm{X}$ & 60 & 0.985831 & 0.434926 & 0.985834 \\
\hline 2 & $\mathrm{~F}$ & $+\mathrm{Y}$ & 20 & 0.494691 & -1.485063 & 0.494692 \\
\hline 2 & $\mathrm{~F}$ & $+\mathrm{Y}$ & 40 & 0.629587 & -0.599105 & 0.629588 \\
\hline 2 & $\mathrm{~F}$ & $+\mathrm{Y}$ & 60 & 0.676744 & -0.405531 & 0.676745 \\
\hline 2 & $\mathrm{~F}$ & $+\mathrm{Z}$ & 20 & 0.799058 & -0.011758 & 0.799061 \\
\hline 2 & $\mathrm{~F}$ & $+\mathrm{Z}$ & 40 & 1.365188 & 1.121452 & 1.365192 \\
\hline 2 & $\mathrm{~F}$ & $+\mathrm{Z}$ & 60 & 1.312777 & 1.034952 & 1.312781 \\
\hline 2 & $\mathrm{~F}$ & $-\mathrm{X}$ & 20 & 0.510118 & -1.335816 & 0.510119 \\
\hline 2 & $\mathrm{~F}$ & $-\mathrm{X}$ & 40 & 0.482291 & -1.623891 & 0.482291 \\
\hline 2 & $\mathrm{~F}$ & $-\mathrm{X}$ & 60 & 0.561575 & -0.954726 & 0.561576 \\
\hline 2 & $\mathrm{~F}$ & $-\mathrm{Y}$ & 20 & 0.533690 & -1.143581 & 0.533690 \\
\hline 2 & $\mathrm{~F}$ & $-\mathrm{Y}$ & 40 & 0.947094 & 0.351798 & 0.947097 \\
\hline 2 & $\mathrm{~F}$ & $-\mathrm{Y}$ & 60 & 1.183995 & 0.814263 & 1.183999 \\
\hline 2 & $\mathrm{~F}$ & $-\mathrm{Z}$ & 20 & 0.871278 & 0.176314 & 0.871281 \\
\hline 2 & $\mathrm{~F}$ & $-\mathrm{Z}$ & 40 & 1.187287 & 0.820091 & 1.187290 \\
\hline 2 & $\mathrm{~F}$ & $-\mathrm{Z}$ & 60 & 1.720450 & 1.694001 & 1.720455 \\
\hline 3 & $\mathrm{M}$ & $+\mathrm{X}$ & 20 & 0.688723 & -0.361037 & 0.688725 \\
\hline 3 & $\mathrm{M}$ & $+\mathrm{X}$ & 40 & 0.918929 & 0.288774 & 0.918931 \\
\hline & & & & & & \\
\hline
\end{tabular}




\begin{tabular}{|l|l|l|l|l|l|l|}
\hline 3 & $\mathrm{M}$ & $+\mathrm{X}$ & 60 & 1.103760 & 0.668155 & 1.103764 \\
\hline 3 & $\mathrm{M}$ & $+\mathrm{Y}$ & 20 & 0.638754 & -0.558849 & 0.638755 \\
\hline 3 & $\mathrm{M}$ & $+\mathrm{Y}$ & 40 & 0.797722 & -0.015480 & 0.797724 \\
\hline 3 & $\mathrm{M}$ & $+\mathrm{Y}$ & 60 & 0.965614 & 0.392022 & 0.965617 \\
\hline 3 & $\mathrm{M}$ & $+\mathrm{Z}$ & 20 & 0.865375 & 0.161803 & 0.865377 \\
\hline 3 & $\mathrm{M}$ & $+\mathrm{Z}$ & 40 & 1.306094 & 1.023811 & 1.306098 \\
\hline 3 & $\mathrm{M}$ & $+\mathrm{Z}$ & 60 & 1.702207 & 1.664162 & 1.702212 \\
\hline 3 & $\mathrm{M}$ & $-\mathrm{X}$ & 20 & 0.669813 & -0.432050 & 0.669814 \\
\hline 3 & $\mathrm{M}$ & $-\mathrm{X}$ & 40 & 0.594831 & -0.766375 & 0.594832 \\
\hline 3 & $\mathrm{M}$ & $-\mathrm{X}$ & 60 & 0.553200 & -1.007935 & 0.553201 \\
\hline 3 & $\mathrm{M}$ & $-\mathrm{Y}$ & 20 & 0.482026 & -1.627080 & 0.482027 \\
\hline 3 & $\mathrm{M}$ & $-\mathrm{Y}$ & 40 & 1.035846 & 0.537071 & 1.035849 \\
\hline 3 & $\mathrm{M}$ & $-\mathrm{Y}$ & 60 & 1.131386 & 0.719403 & 1.131389 \\
\hline 3 & $\mathrm{M}$ & $-\mathrm{Z}$ & 20 & 0.991394 & 0.446559 & 0.991397 \\
\hline 3 & $\mathrm{M}$ & $-\mathrm{Z}$ & 40 & 1.506794 & 1.350014 & 1.506798 \\
\hline 3 & $\mathrm{M}$ & $-\mathrm{Z}$ & 60 & 2.024192 & 2.229821 & 2.024197 \\
\hline 4 & $\mathrm{M}$ & $+\mathrm{X}$ & 20 & 0.627338 & -0.609199 & 0.627340 \\
\hline 4 & $\mathrm{M}$ & $+\mathrm{X}$ & 40 & 0.851371 & 0.126822 & 0.851373 \\
\hline 4 & $\mathrm{M}$ & $+\mathrm{X}$ & 60 & 1.076250 & 0.615992 & 1.076253 \\
\hline 4 & $\mathrm{M}$ & $+\mathrm{Y}$ & 20 & 0.581782 & -0.836391 & 0.581783 \\
\hline 4 & $\mathrm{M}$ & $+\mathrm{Y}$ & 40 & 0.729546 & -0.220515 & 0.729548 \\
\hline 4 & $\mathrm{M}$ & $+\mathrm{Y}$ & 60 & 0.895852 & 0.235297 & 0.895855 \\
\hline 4 & $\mathrm{M}$ & $+\mathrm{Z}$ & 20 & 0.871507 & 0.176874 & 0.871510 \\
\hline 4 & $\mathrm{M}$ & $+\mathrm{Z}$ & 40 & 1.243132 & 0.917329 & 1.243136 \\
\hline 4 & $\mathrm{M}$ & $+\mathrm{Z}$ & 60 & 1.696987 & 1.655650 & 1.696991 \\
\hline 4 & $\mathrm{M}$ & $-\mathrm{X}$ & 20 & 0.662641 & -0.460132 & 0.662642 \\
\hline 4 & $\mathrm{M}$ & $-\mathrm{X}$ & 40 & 0.549934 & -1.029436 & 0.549936 \\
\hline 4 & $\mathrm{M}$ & $-\mathrm{X}$ & 60 & 0.643661 & -0.537869 & 0.643663 \\
\hline 4 & $\mathrm{M}$ & $-\mathrm{Y}$ & 20 & 0.468034 & -1.812596 & 0.468035 \\
\hline 4 & $\mathrm{M}$ & $-\mathrm{Y}$ & 40 & 0.841369 & 0.101327 & 0.841371 \\
\hline 4 & $\mathrm{M}$ & $-\mathrm{Y}$ & 60 & 1.080595 & 0.624311 & 1.080598 \\
\hline 4 & $\mathrm{M}$ & $-\mathrm{Z}$ & 20 & 0.966470 & 0.393859 & 0.966473 \\
\hline 4 & $\mathrm{M}$ & $-\mathrm{Z}$ & 40 & 1.456494 & 1.269390 & 1.456499 \\
\hline 4 & $\mathrm{M}$ & $-\mathrm{Z}$ & 60 & 1.894626 & 1.989524 & 1.894631 \\
\hline 5 & $\mathrm{M}$ & $+\mathrm{X}$ & 20 & 0.623377 & -0.627210 & 0.623378 \\
\hline 5 & $\mathrm{M}$ & $+\mathrm{X}$ & 40 & 0.814005 & 0.029222 & 0.814008 \\
\hline 5 & $\mathrm{M}$ & $+\mathrm{X}$ & 60 & 0.960288 & 0.380548 & 0.960291 \\
\hline 5 & $\mathrm{M}$ & $+\mathrm{Y}$ & 20 & 0.598220 & -0.748903 & 0.598222 \\
\hline 5 & $\mathrm{M}$ & $+\mathrm{Y}$ & 40 & 0.710757 & -0.283221 & 0.710759 \\
\hline 5 & $\mathrm{M}$ & $+\mathrm{Y}$ & 60 & 0.920527 & 0.292416 & 0.920530 \\
\hline 5 & $\mathrm{M}$ & $+\mathrm{Z}$ & 20 & 0.807193 & 0.010693 & 0.807195 \\
\hline & & & & & & \\
\hline
\end{tabular}




\begin{tabular}{|l|c|c|c|c|c|c|}
\hline 5 & $\mathrm{M}$ & $+\mathrm{Z}$ & 40 & 1.240259 & 0.912397 & 1.240263 \\
\hline 5 & $\mathrm{M}$ & $+\mathrm{Z}$ & 60 & 1.509504 & 1.354349 & 1.509509 \\
\hline 5 & $\mathrm{M}$ & $-\mathrm{X}$ & 20 & 0.530315 & -1.168967 & 0.530316 \\
\hline 5 & $\mathrm{M}$ & $-\mathrm{X}$ & 40 & 0.475498 & -1.709235 & 0.475499 \\
\hline 5 & $\mathrm{M}$ & $-\mathrm{X}$ & 60 & 0.558595 & -0.973351 & 0.558596 \\
\hline 5 & $\mathrm{M}$ & $-\mathrm{Y}$ & 20 & 0.450013 & -2.120745 & 0.450014 \\
\hline 5 & $\mathrm{M}$ & $-\mathrm{Y}$ & 40 & 0.866406 & 0.164347 & 0.866408 \\
\hline 5 & $\mathrm{M}$ & $-\mathrm{Y}$ & 60 & 1.221104 & 0.879327 & 1.221108 \\
\hline 5 & $\mathrm{M}$ & $-\mathrm{Z}$ & 20 & 0.967692 & 0.396479 & 0.967695 \\
\hline 5 & $\mathrm{M}$ & $-\mathrm{Z}$ & 40 & 1.048903 & 0.562898 & 1.048906 \\
\hline 5 & $\mathrm{M}$ & $-\mathrm{Z}$ & 60 & 1.816604 & 1.854297 & 1.816609 \\
\hline 6 & $\mathrm{~F}$ & $+\mathrm{X}$ & 20 & 0.731774 & -0.213280 & 0.731776 \\
\hline 6 & $\mathrm{~F}$ & $+\mathrm{X}$ & 40 & 0.646169 & -0.527293 & 0.646171 \\
\hline 6 & $\mathrm{~F}$ & $+\mathrm{X}$ & 60 & 0.779501 & -0.067273 & 0.779503 \\
\hline 6 & $\mathrm{~F}$ & $+\mathrm{Y}$ & 20 & 0.671241 & -0.426535 & 0.671243 \\
\hline 6 & $\mathrm{~F}$ & $+\mathrm{Y}$ & 40 & 0.718734 & -0.256216 & 0.718736 \\
\hline 6 & $\mathrm{~F}$ & $+\mathrm{Y}$ & 60 & 0.842217 & 0.103507 & 0.842219 \\
\hline 6 & $\mathrm{~F}$ & $+\mathrm{Z}$ & 20 & 1.049664 & 0.564395 & 1.049668 \\
\hline 6 & $\mathrm{~F}$ & $+\mathrm{Z}$ & 40 & 1.655835 & 1.588902 & 1.655840 \\
\hline 6 & $\mathrm{~F}$ & $+\mathrm{Z}$ & 60 & 0.580000 & -0.846316 & 0.580001 \\
\hline 6 & $\mathrm{~F}$ & $-\mathrm{X}$ & 20 & 0.723728 & -0.239599 & 0.723730 \\
\hline 6 & $\mathrm{~F}$ & $-\mathrm{X}$ & 40 & 1.040503 & 0.546321 & 1.040507 \\
\hline 6 & $\mathrm{~F}$ & $-\mathrm{X}$ & 60 & 1.332930 & 1.068388 & 1.332935 \\
\hline 6 & $\mathrm{~F}$ & $-\mathrm{Y}$ & 20 & 0.583616 & -0.826275 & 0.583617 \\
\hline 6 & $\mathrm{~F}$ & $-\mathrm{Y}$ & 40 & 0.970647 & 0.402797 & 0.970650 \\
\hline 6 & $\mathrm{~F}$ & $-\mathrm{Y}$ & 60 & 1.229041 & 0.893070 & 1.229045 \\
\hline 6 & $\mathrm{~F}$ & $-\mathrm{Z}$ & 20 & 1.092538 & 0.647021 & 1.092542 \\
\hline 6 & $\mathrm{~F}$ & $-\mathrm{Z}$ & 40 & 1.623836 & 1.537352 & 1.623840 \\
\hline 6 & $\mathrm{~F}$ & $-\mathrm{Z}$ & 60 & 2.180800 & 2.563129 & 2.180805 \\
\hline 7 & $\mathrm{~F}$ & $+\mathrm{X}$ & 20 & 0.596776 & -0.756311 & 0.596778 \\
\hline 7 & $\mathrm{~F}$ & $+\mathrm{X}$ & 40 & 0.892383 & 0.227104 & 0.892386 \\
\hline 7 & $\mathrm{~F}$ & $+\mathrm{X}$ & 60 & 1.177939 & 0.803509 & 1.177943 \\
\hline 7 & $\mathrm{~F}$ & $+\mathrm{Y}$ & 20 & 0.511340 & -1.324895 & 0.511341 \\
\hline 7 & $\mathrm{~F}$ & $+\mathrm{Y}$ & 40 & 0.598158 & -0.749219 & 0.598160 \\
\hline 7 & $\mathrm{~F}$ & $+\mathrm{Y}$ & 60 & 0.788504 & -0.041438 & 0.788506 \\
\hline 7 & $\mathrm{~F}$ & $+\mathrm{Z}$ & 20 & 0.906887 & 0.261088 & 0.906890 \\
\hline 7 & $\mathrm{~F}$ & $+\mathrm{Z}$ & 40 & 1.191015 & 0.826679 & 1.191019 \\
\hline 7 & $\mathrm{~F}$ & $+\mathrm{Z}$ & 60 & 1.384610 & 1.153166 & 1.384615 \\
\hline 7 & $\mathrm{~F}$ & $-\mathrm{X}$ & 20 & 0.606464 & -0.707534 & 0.606465 \\
\hline 7 & $\mathrm{~F}$ & $-\mathrm{X}$ & 40 & 0.509307 & -1.343128 & 0.509308 \\
\hline & $\mathrm{F}$ & $-\mathrm{X}$ & 60 & 0.597529 & -0.752446 & 0.597530 \\
\hline & & & & & & \\
\hline
\end{tabular}




\begin{tabular}{|l|c|c|c|c|c|c|}
\hline 7 & $\mathrm{~F}$ & $-\mathrm{Y}$ & 20 & 0.505742 & -1.375929 & 0.505742 \\
\hline 7 & $\mathrm{~F}$ & $-\mathrm{Y}$ & 40 & 0.896713 & 0.237324 & 0.896716 \\
\hline 7 & $\mathrm{~F}$ & $-\mathrm{Y}$ & 60 & 1.131635 & 0.719860 & 1.131638 \\
\hline 7 & $\mathrm{~F}$ & $-\mathrm{Z}$ & 20 & 0.990933 & 0.445599 & 0.990937 \\
\hline 7 & $\mathrm{~F}$ & $-\mathrm{Z}$ & 40 & 1.348115 & 1.093432 & 1.348120 \\
\hline 7 & $\mathrm{~F}$ & $-\mathrm{Z}$ & 60 & 1.816276 & 1.853740 & 1.816281 \\
\hline 8 & $\mathrm{~F}$ & $+\mathrm{X}$ & 20 & 0.758688 & -0.128962 & 0.758690 \\
\hline 8 & $\mathrm{~F}$ & $+\mathrm{X}$ & 40 & 0.589655 & -0.793608 & 0.589656 \\
\hline 8 & $\mathrm{~F}$ & $+\mathrm{X}$ & 60 & 0.622370 & -0.631833 & 0.622371 \\
\hline 8 & $\mathrm{~F}$ & $+\mathrm{Y}$ & 20 & 0.667962 & -0.439233 & 0.667964 \\
\hline 8 & $\mathrm{~F}$ & $+\mathrm{Y}$ & 40 & 0.728864 & -0.222737 & 0.728866 \\
\hline 8 & $\mathrm{~F}$ & $+\mathrm{Y}$ & 60 & 1.068075 & 0.600257 & 1.068078 \\
\hline 8 & $\mathrm{~F}$ & $+\mathrm{Z}$ & 20 & 0.791307 & -0.033492 & 0.791310 \\
\hline 8 & $\mathrm{~F}$ & $+\mathrm{Z}$ & 40 & 1.166722 & 0.783482 & 1.166726 \\
\hline 8 & $\mathrm{~F}$ & $+\mathrm{Z}$ & 60 & 1.503915 & 1.345409 & 1.503920 \\
\hline 8 & $\mathrm{~F}$ & $-\mathrm{X}$ & 20 & 0.715515 & -0.267043 & 0.715517 \\
\hline 8 & $\mathrm{~F}$ & $-\mathrm{X}$ & 40 & 0.921600 & 0.294855 & 0.921603 \\
\hline 8 & $\mathrm{~F}$ & $-\mathrm{X}$ & 60 & 1.134152 & 0.724477 & 1.134156 \\
\hline 8 & $\mathrm{~F}$ & $-\mathrm{Y}$ & 20 & 0.679927 & -0.393547 & 0.679928 \\
\hline 8 & $\mathrm{~F}$ & $-\mathrm{Y}$ & 40 & 0.638477 & -0.560043 & 0.638479 \\
\hline 8 & $\mathrm{~F}$ & $-\mathrm{Y}$ & 60 & 1.035993 & 0.537364 & 1.035997 \\
\hline 8 & $\mathrm{~F}$ & $-\mathrm{Z}$ & 20 & 0.648540 & -0.517382 & 0.648542 \\
\hline 8 & $\mathrm{~F}$ & $-\mathrm{Z}$ & 40 & 1.635059 & 1.555403 & 1.635063 \\
\hline 8 & $\mathrm{~F}$ & $-\mathrm{Z}$ & 60 & 2.098867 & 2.381224 & 2.098872 \\
\hline 9 & $\mathrm{~F}$ & $+\mathrm{X}$ & 20 & 0.700359 & -0.319329 & 0.700361 \\
\hline 9 & $\mathrm{~F}$ & $+\mathrm{X}$ & 40 & 0.980647 & 0.424020 & 0.980650 \\
\hline 9 & $\mathrm{~F}$ & $+\mathrm{X}$ & 60 & 1.232863 & 0.899667 & 1.232867 \\
\hline 9 & $\mathrm{~F}$ & $+\mathrm{Y}$ & 20 & 0.493908 & -1.493273 & 0.493908 \\
\hline 9 & $\mathrm{~F}$ & $+\mathrm{Y}$ & 40 & 0.602169 & -0.728894 & 0.602170 \\
\hline 9 & $\mathrm{~F}$ & $+\mathrm{Y}$ & 60 & 0.742574 & -0.178784 & 0.742576 \\
\hline 9 & $\mathrm{~F}$ & $+\mathrm{Z}$ & 20 & 1.046162 & 0.557503 & 1.046165 \\
\hline 9 & $\mathrm{~F}$ & $+\mathrm{Z}$ & 40 & 1.697119 & 1.655866 & 1.697124 \\
\hline 9 & $\mathrm{~F}$ & $+\mathrm{Z}$ & 60 & 0.580000 & -0.846316 & 0.580001 \\
\hline 9 & $\mathrm{~F}$ & $-\mathrm{X}$ & 20 & 0.531412 & -1.160645 & 0.531413 \\
\hline 9 & $\mathrm{~F}$ & $-\mathrm{X}$ & 40 & 0.604765 & -0.715933 & 0.604766 \\
\hline 9 & $\mathrm{~F}$ & $-\mathrm{X}$ & 60 & 0.780607 & -0.064074 & 0.780609 \\
\hline 9 & $\mathrm{~F}$ & $-\mathrm{Y}$ & 20 & 0.578550 & -0.854457 & 0.578552 \\
\hline 9 & $\mathrm{~F}$ & $-\mathrm{Y}$ & 40 & 1.134195 & 0.724556 & 1.134199 \\
\hline 9 & $\mathrm{~F}$ & $-\mathrm{Y}$ & 60 & 1.281924 & 0.983276 & 1.281928 \\
\hline 9 & $\mathrm{~F}$ & $-\mathrm{Z}$ & 20 & 0.962572 & 0.385477 & 0.962575 \\
\hline 9 & $\mathrm{~F}$ & $-\mathrm{Z}$ & 40 & 1.352416 & 1.100503 & 1.352420 \\
\hline & & & & & & \\
\hline
\end{tabular}




\begin{tabular}{|c|c|c|c|c|c|c|}
\hline 9 & $\mathrm{~F}$ & $-\mathrm{Z}$ & 60 & 1.977147 & 2.139788 & 1.977152 \\
\hline 10 & $\mathrm{M}$ & $+\mathrm{X}$ & 20 & 0.651197 & -0.506380 & 0.651198 \\
\hline 10 & $\mathrm{M}$ & $+\mathrm{X}$ & 40 & 0.823361 & 0.054282 & 0.823363 \\
\hline 10 & $\mathrm{M}$ & $+\mathrm{X}$ & 60 & 1.023751 & 0.512852 & 1.023754 \\
\hline 10 & $\mathrm{M}$ & $+\mathrm{Y}$ & 20 & 0.510680 & -1.330774 & 0.510681 \\
\hline 10 & $\mathrm{M}$ & $+\mathrm{Y}$ & 40 & 0.557334 & -0.981329 & 0.557336 \\
\hline 10 & $\mathrm{M}$ & $+\mathrm{Y}$ & 60 & 0.649165 & -0.514784 & 0.649167 \\
\hline 10 & $\mathrm{M}$ & $+\mathrm{Z}$ & 20 & 0.840849 & 0.099990 & 0.840851 \\
\hline 10 & $\mathrm{M}$ & $+\mathrm{Z}$ & 40 & 1.174600 & 0.797562 & 1.174604 \\
\hline 10 & $\mathrm{M}$ & $+\mathrm{Z}$ & 60 & 1.681791 & 1.630932 & 1.681796 \\
\hline 10 & $\mathrm{M}$ & $-\mathrm{X}$ & 20 & 0.605675 & -0.711427 & 0.605676 \\
\hline 10 & $\mathrm{M}$ & $-\mathrm{X}$ & 40 & 0.506217 & -1.371496 & 0.506217 \\
\hline 10 & $\mathrm{M}$ & $-\mathrm{X}$ & 60 & 0.606532 & -0.707201 & 0.606533 \\
\hline 10 & $\mathrm{M}$ & $-\mathrm{Y}$ & 20 & 0.419862 & -3.104948 & 0.419863 \\
\hline 10 & $\mathrm{M}$ & $-\mathrm{Y}$ & 40 & 0.480878 & -1.641037 & 0.480878 \\
\hline 10 & $\mathrm{M}$ & $-\mathrm{Y}$ & 60 & 1.052436 & 0.569832 & 1.052439 \\
\hline 10 & $\mathrm{M}$ & $-\mathrm{Z}$ & 20 & 0.954244 & 0.367435 & 0.954247 \\
\hline 10 & $\mathrm{M}$ & $-\mathrm{Z}$ & 40 & 1.333769 & 1.069775 & 1.333773 \\
\hline 10 & $\mathrm{M}$ & $-\mathrm{Z}$ & 60 & 1.829352 & 1.876023 & 1.829357 \\
\hline 11 & $\mathrm{M}$ & $+\mathrm{X}$ & 20 & 0.666203 & -0.446101 & 0.666204 \\
\hline 11 & $\mathrm{M}$ & $+\mathrm{X}$ & 40 & 0.868199 & 0.168763 & 0.868202 \\
\hline 11 & $\mathrm{M}$ & $+\mathrm{X}$ & 60 & 0.960156 & 0.380261 & 0.960158 \\
\hline 11 & $\mathrm{M}$ & $+\mathrm{Y}$ & 20 & 0.557172 & -0.982364 & 0.557173 \\
\hline 11 & $\mathrm{M}$ & $+\mathrm{Y}$ & 40 & 0.745946 & -0.168198 & 0.745948 \\
\hline 11 & $\mathrm{M}$ & $+\mathrm{Y}$ & 60 & 0.894902 & 0.233058 & 0.894905 \\
\hline 11 & $\mathrm{M}$ & $+\mathrm{Z}$ & 20 & 0.839578 & 0.096715 & 0.839580 \\
\hline 11 & $\mathrm{M}$ & $+\mathrm{Z}$ & 40 & 1.195161 & 0.833988 & 1.195165 \\
\hline 11 & $\mathrm{M}$ & $+\mathrm{Z}$ & 60 & 1.331001 & 1.065197 & 1.331005 \\
\hline 11 & $\mathrm{M}$ & $-\mathrm{X}$ & 20 & 0.529103 & -1.178242 & 0.529104 \\
\hline 11 & $\mathrm{M}$ & $-\mathrm{X}$ & 40 & 0.457917 & -1.973217 & 0.457918 \\
\hline 11 & $\mathrm{M}$ & $-\mathrm{X}$ & 60 & 0.555990 & -0.989906 & 0.555991 \\
\hline 11 & $\mathrm{M}$ & $-\mathrm{Y}$ & 20 & 0.430687 & -2.625076 & 0.430688 \\
\hline 11 & $\mathrm{M}$ & $-\mathrm{Y}$ & 40 & 0.727282 & -0.227907 & 0.727284 \\
\hline 11 & $\mathrm{M}$ & $-\mathrm{Y}$ & 60 & 1.136041 & 0.727935 & 1.136044 \\
\hline 11 & $\mathrm{M}$ & $-\mathrm{Z}$ & 20 & 0.951983 & 0.362506 & 0.951986 \\
\hline 11 & $\mathrm{M}$ & $-\mathrm{Z}$ & 40 & 1.076922 & 0.617281 & 1.076925 \\
\hline 11 & $\mathrm{M}$ & $-\mathrm{Z}$ & 60 & 1.657535 & 1.591647 & 1.657539 \\
\hline 12 & $\mathrm{M}$ & $+\mathrm{X}$ & 20 & 0.592509 & -0.778510 & 0.592510 \\
\hline 12 & $\mathrm{M}$ & $+\mathrm{X}$ & 40 & 0.708780 & -0.290006 & 0.708782 \\
\hline 12 & $\mathrm{M}$ & $+\mathrm{X}$ & 60 & 0.873074 & 0.180701 & 0.873077 \\
\hline 12 & $\mathrm{M}$ & $+\mathrm{Y}$ & 20 & 0.555104 & -0.995597 & 0.555105 \\
\hline & & & & & & \\
\hline
\end{tabular}




\begin{tabular}{|c|c|c|c|c|c|c|}
\hline 12 & $\mathrm{M}$ & $+\mathrm{Y}$ & 40 & 0.517661 & -1.270238 & 0.517662 \\
\hline 12 & $\mathrm{M}$ & $+\mathrm{Y}$ & 60 & 0.560742 & -0.959899 & 0.560743 \\
\hline 12 & $\mathrm{M}$ & $+\mathrm{Z}$ & 20 & 0.836098 & 0.087713 & 0.836100 \\
\hline 12 & $\mathrm{M}$ & $+\mathrm{Z}$ & 40 & 1.196210 & 0.835834 & 1.196214 \\
\hline 12 & $\mathrm{M}$ & $+\mathrm{Z}$ & 60 & 1.659288 & 1.594482 & 1.659293 \\
\hline 12 & $\mathrm{M}$ & $-\mathrm{X}$ & 20 & 0.610086 & -0.689835 & 0.610088 \\
\hline 12 & $\mathrm{M}$ & $-\mathrm{X}$ & 40 & 0.538322 & -1.109727 & 0.538323 \\
\hline 12 & $\mathrm{M}$ & $-\mathrm{X}$ & 60 & 0.600278 & -0.738432 & 0.600279 \\
\hline 12 & $\mathrm{M}$ & $-\mathrm{Y}$ & 20 & 0.470286 & -1.780230 & 0.470287 \\
\hline 12 & $\mathrm{M}$ & $-\mathrm{Y}$ & 40 & 0.752470 & -0.147964 & 0.752472 \\
\hline 12 & $\mathrm{M}$ & $-\mathrm{Y}$ & 60 & 0.789047 & -0.039896 & 0.789049 \\
\hline 12 & $\mathrm{M}$ & $-\mathrm{Z}$ & 20 & 0.849722 & 0.122649 & 0.849724 \\
\hline 12 & $\mathrm{M}$ & $-\mathrm{Z}$ & 40 & 1.195805 & 0.835121 & 1.195808 \\
\hline 12 & $\mathrm{M}$ & $-\mathrm{Z}$ & 60 & 1.906925 & 2.011390 & 1.906930 \\
\hline 13 & $\mathrm{~F}$ & $+\mathrm{X}$ & 20 & 0.619640 & -0.644464 & 0.619642 \\
\hline 13 & $\mathrm{~F}$ & $+\mathrm{X}$ & 40 & 0.752556 & -0.147700 & 0.752558 \\
\hline 13 & $\mathrm{~F}$ & $+\mathrm{X}$ & 60 & 0.985533 & 0.434301 & 0.985536 \\
\hline 13 & $\mathrm{~F}$ & $+\mathrm{Y}$ & 20 & 0.444920 & -2.229647 & 0.444921 \\
\hline 13 & $\mathrm{~F}$ & $+\mathrm{Y}$ & 40 & 0.585530 & -0.815816 & 0.585531 \\
\hline 13 & $\mathrm{~F}$ & $+\mathrm{Y}$ & 60 & 0.912115 & 0.273167 & 0.912118 \\
\hline 13 & $\mathrm{~F}$ & $+\mathrm{Z}$ & 20 & 0.776588 & -0.075739 & 0.776590 \\
\hline 13 & $\mathrm{~F}$ & $+\mathrm{Z}$ & 40 & 1.219301 & 0.876198 & 1.219305 \\
\hline 13 & $\mathrm{~F}$ & $+\mathrm{Z}$ & 60 & 1.641759 & 1.566195 & 1.641764 \\
\hline 13 & $\mathrm{~F}$ & $-\mathrm{X}$ & 20 & 0.559050 & -0.970487 & 0.559051 \\
\hline 13 & $\mathrm{~F}$ & $-\mathrm{X}$ & 40 & 0.547137 & -1.048217 & 0.547138 \\
\hline 13 & $\mathrm{~F}$ & $-\mathrm{X}$ & 60 & 0.636998 & -0.566451 & 0.636999 \\
\hline 13 & $\mathrm{~F}$ & $-\mathrm{Y}$ & 20 & 0.470841 & -1.772416 & 0.470842 \\
\hline 13 & $\mathrm{~F}$ & $-\mathrm{Y}$ & 40 & 0.823933 & 0.055800 & 0.823935 \\
\hline 13 & $\mathrm{~F}$ & $-\mathrm{Y}$ & 60 & 0.915382 & 0.280668 & 0.915385 \\
\hline 13 & $\mathrm{~F}$ & $-\mathrm{Z}$ & 20 & 0.983422 & 0.429866 & 0.983425 \\
\hline 13 & $\mathrm{~F}$ & $-\mathrm{Z}$ & 40 & 1.359753 & 1.112547 & 1.359757 \\
\hline 13 & $\mathrm{~F}$ & $-\mathrm{Z}$ & 60 & 1.784827 & 1.800675 & 1.784832 \\
\hline 14 & $\mathrm{~F}$ & $+\mathrm{X}$ & 20 & 0.661510 & -0.464620 & 0.661512 \\
\hline 14 & $\mathrm{~F}$ & $+\mathrm{X}$ & 40 & 0.810488 & 0.019686 & 0.810490 \\
\hline 14 & $\mathrm{~F}$ & $+\mathrm{X}$ & 60 & 1.137720 & 0.731006 & 1.137724 \\
\hline 14 & $\mathrm{~F}$ & $+\mathrm{Y}$ & 20 & 0.555511 & -0.992977 & 0.555512 \\
\hline 14 & $\mathrm{~F}$ & $+\mathrm{Y}$ & 40 & 0.635944 & -0.571039 & 0.635945 \\
\hline 14 & $\mathrm{~F}$ & $+\mathrm{Y}$ & 60 & 0.773467 & -0.084866 & 0.773470 \\
\hline 14 & $\mathrm{~F}$ & $+\mathrm{Z}$ & 20 & 0.767288 & -0.103127 & 0.767290 \\
\hline 14 & $\mathrm{~F}$ & $+\mathrm{Z}$ & 40 & 1.139460 & 0.734184 & 1.139464 \\
\hline 14 & $\mathrm{~F}$ & $+\mathrm{Z}$ & 60 & 1.628015 & 1.544071 & 1.628020 \\
\hline & & & & & & \\
\hline
\end{tabular}




\begin{tabular}{|l|c|c|c|c|c|c|}
\hline 14 & $\mathrm{~F}$ & $-\mathrm{X}$ & 20 & 0.735311 & -0.201879 & 0.735313 \\
\hline 14 & $\mathrm{~F}$ & $-\mathrm{X}$ & 40 & 0.609903 & -0.690724 & 0.609904 \\
\hline 14 & $\mathrm{~F}$ & $-\mathrm{X}$ & 60 & 0.601841 & -0.730540 & 0.601843 \\
\hline 14 & $\mathrm{~F}$ & $-\mathrm{Y}$ & 20 & 0.427662 & -2.736111 & 0.427663 \\
\hline 14 & $\mathrm{~F}$ & $-\mathrm{Y}$ & 40 & 0.504796 & -1.384809 & 0.504797 \\
\hline 14 & $\mathrm{~F}$ & $-\mathrm{Y}$ & 60 & 1.018109 & 0.501453 & 1.018112 \\
\hline 14 & $\mathrm{~F}$ & $-\mathrm{Z}$ & 20 & 0.924749 & 0.301993 & 0.924752 \\
\hline 14 & $\mathrm{~F}$ & $-\mathrm{Z}$ & 40 & 1.295742 & 1.006499 & 1.295746 \\
\hline 14 & $\mathrm{~F}$ & $-\mathrm{Z}$ & 60 & 1.765501 & 1.768400 & 1.765506 \\
\hline 15 & $\mathrm{M}$ & $+\mathrm{X}$ & 20 & 0.532826 & -1.150018 & 0.532827 \\
\hline 15 & $\mathrm{M}$ & $+\mathrm{X}$ & 40 & 0.647464 & -0.521869 & 0.647466 \\
\hline 15 & $\mathrm{M}$ & $+\mathrm{X}$ & 60 & 0.816208 & 0.035163 & 0.816211 \\
\hline 15 & $\mathrm{M}$ & $+\mathrm{Y}$ & 20 & 0.600248 & -0.738581 & 0.600250 \\
\hline 15 & $\mathrm{M}$ & $+\mathrm{Y}$ & 40 & 0.738585 & -0.191417 & 0.738587 \\
\hline 15 & $\mathrm{M}$ & $+\mathrm{Y}$ & 60 & 0.797821 & -0.015204 & 0.797824 \\
\hline 15 & $\mathrm{M}$ & $+\mathrm{Z}$ & 20 & 0.710776 & -0.283157 & 0.710778 \\
\hline 15 & $\mathrm{M}$ & $+\mathrm{Z}$ & 40 & 1.464973 & 1.283008 & 1.464978 \\
\hline 15 & $\mathrm{M}$ & $+\mathrm{Z}$ & 60 & 1.465631 & 1.284064 & 1.465635 \\
\hline 15 & $\mathrm{M}$ & $-\mathrm{X}$ & 20 & 0.606436 & -0.707670 & 0.606438 \\
\hline 15 & $\mathrm{M}$ & $-\mathrm{X}$ & 40 & 0.453022 & -2.061849 & 0.453023 \\
\hline 15 & $\mathrm{M}$ & $-\mathrm{X}$ & 60 & 0.551237 & -1.020808 & 0.551238 \\
\hline 15 & $\mathrm{M}$ & $-\mathrm{Y}$ & 20 & 0.531194 & -1.162297 & 0.531194 \\
\hline 15 & $\mathrm{M}$ & $-\mathrm{Y}$ & 40 & 0.574938 & -0.875015 & 0.574940 \\
\hline 15 & $\mathrm{M}$ & $-\mathrm{Y}$ & 60 & 0.883384 & 0.205648 & 0.883387 \\
\hline 15 & $\mathrm{M}$ & $-\mathrm{Z}$ & 20 & 0.625162 & -0.619059 & 0.625163 \\
\hline 15 & $\mathrm{M}$ & $-\mathrm{Z}$ & 40 & 1.104477 & 0.669500 & 1.104481 \\
\hline 15 & $\mathrm{M}$ & $-\mathrm{Z}$ & 60 & 1.022519 & 0.510370 & 1.022523 \\
\hline & & & & & & \\
\hline 15 & & & & \\
\hline 15 & & & & \\
\hline 15 & & & & &
\end{tabular}


Appendix J: Participant Strength Data 


\section{Appendix J-1: Average maximum strength (N) by direction of exertion}

\begin{tabular}{|c|c|c|c|c|}
\hline Subject & Gender & Direction & $\begin{array}{c}\text { Avg. Max } \\
\text { Strength (N) }\end{array}$ & SD \\
\hline 1 & $M$ & $+X$ & 275.73 & 8.42 \\
\hline 1 & $\mathrm{M}$ & $+Y$ & 95.57 & 3.13 \\
\hline 1 & $M$ & $+Z$ & 92.50 & 12.10 \\
\hline 1 & $\mathrm{M}$ & $-X$ & 144.27 & 0.97 \\
\hline 1 & $M$ & $-Y$ & 258.07 & 16.87 \\
\hline 1 & $M$ & $-Z$ & 141.87 & 0.90 \\
\hline 2 & $\mathrm{~F}$ & $+X$ & 180.53 & 9.00 \\
\hline 2 & $\mathrm{~F}$ & $+Y$ & 102.30 & 8.91 \\
\hline 2 & $\mathrm{~F}$ & $+Z$ & 88.57 & 3.01 \\
\hline 2 & $\mathrm{~F}$ & $-X$ & 142.27 & 4.04 \\
\hline 2 & $\mathrm{~F}$ & $-Y$ & 228.37 & 16.37 \\
\hline 2 & $\mathrm{~F}$ & $-Z$ & 142.93 & 0.06 \\
\hline 3 & $M$ & $+X$ & 281.87 & 11.15 \\
\hline 3 & $\mathrm{M}$ & $+Y$ & 109.57 & 4.33 \\
\hline 3 & $M$ & $+Z$ & 78.40 & 6.07 \\
\hline 3 & $M$ & $-X$ & 141.50 & 3.30 \\
\hline 3 & $\mathrm{M}$ & $-Y$ & 235.37 & 5.22 \\
\hline 3 & $M$ & $-Z$ & 135.93 & 6.03 \\
\hline 4 & $\mathrm{M}$ & $+X$ & 274.80 & 9.99 \\
\hline 4 & $M$ & $+Y$ & 121.13 & 7.41 \\
\hline 4 & $M$ & $+Z$ & 96.73 & 3.79 \\
\hline 4 & $\mathrm{M}$ & $-X$ & 141.77 & 5.78 \\
\hline 4 & $M$ & $-Y$ & 227.90 & 11.17 \\
\hline 4 & $M$ & $-Z$ & 136.93 & 3.35 \\
\hline 5 & $\mathrm{M}$ & $+X$ & 288.43 & 0.06 \\
\hline 5 & $M$ & $+Y$ & 143.77 & 1.31 \\
\hline 5 & $M$ & $+Z$ & 89.63 & 2.20 \\
\hline 5 & $M$ & $-X$ & 142.93 & 1.67 \\
\hline 5 & $\mathrm{M}$ & $-Y$ & 288.30 & 0.00 \\
\hline 5 & $M$ & $-Z$ & 137.87 & 2.36 \\
\hline 6 & $\mathrm{~F}$ & $+X$ & 155.47 & 10.30 \\
\hline 6 & $\mathrm{~F}$ & $+Y$ & 61.53 & 3.26 \\
\hline 6 & $\mathrm{~F}$ & $+Z$ & 55.97 & 3.84 \\
\hline 6 & $\mathrm{~F}$ & $-X$ & 94.23 & 1.36 \\
\hline 6 & $\mathrm{~F}$ & $-Y$ & 196.33 & 11.06 \\
\hline 6 & $\mathrm{~F}$ & $-Z$ & 107.93 & 9.83 \\
\hline 7 & $\mathrm{~F}$ & $+X$ & 197.57 & 5.04 \\
\hline 7 & $\mathrm{~F}$ & $+Y$ & 67.37 & 2.11 \\
\hline
\end{tabular}




\begin{tabular}{|c|c|c|c|c|}
\hline 7 & $\mathrm{~F}$ & $+\mathrm{Z}$ & 50.53 & 1.72 \\
\hline 7 & $\mathrm{~F}$ & $-\mathrm{X}$ & 108.53 & 2.10 \\
\hline 7 & $\mathrm{~F}$ & $-\mathrm{Y}$ & 162.37 & 6.70 \\
\hline 7 & $\mathrm{~F}$ & $-\mathrm{Z}$ & 103.63 & 3.25 \\
\hline 8 & $\mathrm{~F}$ & $+\mathrm{X}$ & 243.73 & 2.44 \\
\hline 8 & $\mathrm{~F}$ & $+\mathrm{Y}$ & 130.27 & 8.10 \\
\hline 8 & $\mathrm{~F}$ & $+\mathrm{Z}$ & 76.50 & 5.88 \\
\hline 8 & $\mathrm{~F}$ & $-\mathrm{X}$ & 145.27 & 0.23 \\
\hline 8 & $\mathrm{~F}$ & $-\mathrm{Y}$ & 257.20 & 5.29 \\
\hline 8 & $\mathrm{~F}$ & $-\mathrm{Z}$ & 142.27 & 1.53 \\
\hline 9 & $\mathrm{~F}$ & $+\mathrm{X}$ & 285.50 & 1.61 \\
\hline 9 & $\mathrm{~F}$ & $+\mathrm{Y}$ & 57.37 & 1.55 \\
\hline 9 & $\mathrm{~F}$ & $+\mathrm{Z}$ & 53.73 & 1.27 \\
\hline 9 & $\mathrm{~F}$ & $-\mathrm{X}$ & 95.50 & 0.87 \\
\hline 9 & $\mathrm{~F}$ & $-\mathrm{Y}$ & 222.73 & 2.82 \\
\hline 9 & $\mathrm{~F}$ & $-\mathrm{Z}$ & 85.70 & 3.67 \\
\hline 10 & $\mathrm{M}$ & $+\mathrm{X}$ & 277.10 & 6.58 \\
\hline 10 & $\mathrm{M}$ & $+\mathrm{Y}$ & 122.50 & 1.82 \\
\hline 10 & $\mathrm{M}$ & $+\mathrm{Z}$ & 103.67 & 1.25 \\
\hline 10 & $\mathrm{M}$ & $-\mathrm{X}$ & 144.20 & 0.20 \\
\hline 10 & $\mathrm{M}$ & $-\mathrm{Y}$ & 274.73 & 18.82 \\
\hline 10 & $\mathrm{M}$ & $-\mathrm{Z}$ & 144.07 & 1.25 \\
\hline 11 & $\mathrm{M}$ & $+\mathrm{X}$ & 287.17 & 1.88 \\
\hline 11 & $\mathrm{M}$ & $+\mathrm{Y}$ & 121.23 & 7.24 \\
\hline 11 & $\mathrm{M}$ & $+\mathrm{Z}$ & 94.57 & 3.33 \\
\hline 11 & $\mathrm{M}$ & $-\mathrm{X}$ & 144.07 & 0.74 \\
\hline 11 & $\mathrm{M}$ & $-\mathrm{Y}$ & 288.33 & 0.06 \\
\hline 11 & $\mathrm{M}$ & $-\mathrm{Z}$ & 144.20 & 1.82 \\
\hline 12 & $\mathrm{M}$ & $+\mathrm{X}$ & 296.13 & 41.01 \\
\hline 12 & $\mathrm{M}$ & $+\mathrm{Y}$ & 87.90 & 6.75 \\
\hline 12 & $\mathrm{M}$ & $+\mathrm{Z}$ & 120.00 & 4.22 \\
\hline 12 & $\mathrm{M}$ & $-\mathrm{X}$ & 207.83 & 15.43 \\
\hline 12 & $\mathrm{M}$ & $-\mathrm{Y}$ & 307.33 & 6.62 \\
\hline 12 & $\mathrm{M}$ & $-\mathrm{Z}$ & 178.70 & 9.99 \\
\hline 13 & $\mathrm{~F}$ & $+\mathrm{X}$ & 187.30 & 36.78 \\
\hline 13 & $\mathrm{~F}$ & $+\mathrm{Y}$ & 72.77 & 2.31 \\
\hline 13 & $\mathrm{~F}$ & $+\mathrm{Z}$ & 75.60 & 1.49 \\
\hline 13 & $\mathrm{~F}$ & $-\mathrm{X}$ & 136.57 & 10.26 \\
\hline 13 & $\mathrm{~F}$ & $-\mathrm{Y}$ & 223.33 & 1.33 \\
\hline 13 & $\mathrm{~F}$ & $-\mathrm{Z}$ & 107.93 & 11.27 \\
\hline 14 & $\mathrm{~F}$ & $+\mathrm{X}$ & 233.67 & 19.53 \\
\hline & & & & \\
\hline
\end{tabular}




\begin{tabular}{|c|c|c|c|c|}
\hline 14 & $\mathrm{~F}$ & $+\mathrm{Y}$ & 106.27 & 6.34 \\
\hline 14 & $\mathrm{~F}$ & $+\mathrm{Z}$ & 105.97 & 2.02 \\
\hline 14 & $\mathrm{~F}$ & $-\mathrm{X}$ & 132.03 & 5.83 \\
\hline 14 & $\mathrm{~F}$ & $-\mathrm{Y}$ & 272.60 & 21.64 \\
\hline 14 & $\mathrm{~F}$ & $-\mathrm{Z}$ & 104.73 & 17.56 \\
\hline 15 & $\mathrm{M}$ & $+\mathrm{X}$ & 231.87 & 29.39 \\
\hline 15 & $\mathrm{M}$ & $+\mathrm{Y}$ & 82.17 & 3.94 \\
\hline 15 & $\mathrm{M}$ & $+\mathrm{Z}$ & 77.80 & 9.10 \\
\hline 15 & $\mathrm{M}$ & $-\mathrm{X}$ & 153.20 & 0.75 \\
\hline 15 & $\mathrm{M}$ & $-\mathrm{Y}$ & 289.83 & 45.26 \\
\hline 15 & $\mathrm{M}$ & $-\mathrm{Z}$ & 146.23 & 8.73 \\
\hline
\end{tabular}

